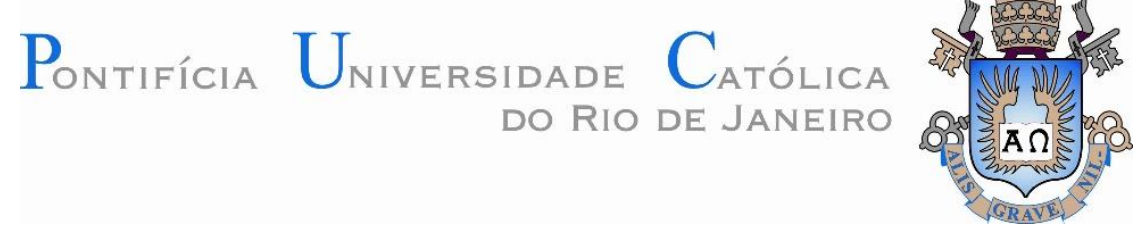

Thiago Leite Cavalcante

\title{
Desenvolvimento de sistema de monitoramento multiparamétrico da qualidade do ar em ambientes internos
}

Dissertação de Mestrado

Dissertação apresentada como requisito parcial para obtenção do grau de Mestre em Metrologia pelo Programa de Pós-Graduação em Metrologia. (Área de concentração: Metrologia para Qualidade e Inovação) da PUC-Rio.

Orientador: Prof. Daniel Ramos Louzada Coorientador: Prof. Elisabeth Costa Monteiro 
Thiago Leite Cavalcante

Desenvolvimento de sistema de monitoramento multiparamétrico da qualidade do ar em ambientes internos

Dissertação apresentada como requisito parcial para obtenção do grau de Mestre pelo Programa de PósGraduação em Metrologia (Área de concentração: Metrologia para Qualidade e Inovação) da PUC-Rio. Aprovada pela Comissão Examinadora abaixo:

Prof. Daniel Ramos Louzada

Orientador

Programa de Pós-Graduação em Metrologia - PUC-Rio

Prof. Elisabeth Costa Monteiro

Coorientador

Programa de Pós-Graduação em Metrologia - PUC-Rio

Prof. Carlos Roberto Hall Barbosa Programa de Pós-Graduação em Metrologia - PUC-Rio

Prof. Arthur Martins Barbosa Braga Departamento de Engenharia Mecânica - PUC-Rio 
Todos os direitos reservados. É proibida a reprodução total ou parcial do trabalho sem autorização da universidade, do autor e do orientador.

Thiago Leite Cavalcante

Graduado em Ciências da Computação pelo Centro Universitário Carioca (UniCarioca), em 2017, Rio de Janeiro, Brasil.

Ficha Catalográfica

Cavalcante, Thiago Leite

Desenvolvimento de sistema de monitoramento multiparamétrico da qualidade do ar em ambientes internos

/ Thiago Leite Cavalcante ; orientador: Daniel Ramos Louzada ; coorientador: Elisabeth Costa Monteiro. - 2021. 90 f. : il. color. ; $30 \mathrm{~cm}$

Dissertação (mestrado)-Pontifícia Universidade Católica do Rio de Janeiro, Centro Técnico Científico, Programa de Pós-Graduação em Metrologia, 2021. Inclui bibliografia

1. Metrologia - Teses. 2. Metrologia para Qualidade e Inovação - Teses. 3. Metrologia. 4. Qualidade do ar em ambientes internos. 5. Monitoramento multiparamétrico contínuo. 6. Grandezas atmosféricas. I. Louzada, Daniel Ramos. II. Monteiro, Elisabeth Costa. III. Pontifícia Universidade Católica do Rio de Janeiro. Centro Técnico Científico. Programa de Pós-Graduação em Metrologia. IV. Título.

CDD: 389.1 
Aos meus familiares

pelo apoio. 


\section{Agradecimentos}

A Deus Pai Todo Poderoso, ao divino mestre Jesus, e a santa Maria, mãe de Cristo.

Ao Simiromba de Deus pai Seta Branca, e a mãe Iara. Ao Ministro Avanez, Ministro Yuricy, Ministro Japuara e Ministro Aurimã, Sebastião Vasconcelos e Justina, Princesa Janaína, Príncipe Ariane, Cavaleiro de Lança Faganato Verde Anday, $1^{\circ}$ Cavaleiro da Lança Vermelha e Madalena de Cássia. A Pai João de Enoque, Pai Zé Pedro de Enoque, e Pai Joaquim das Almas. A Pai Joaquim das Cachoeiras, Pai Joaquim de Angola, Vovó Maria Conga das Cachoeiras, Vovó Luiza, Vovô Agripino, Vózinha Marilú e Mãe Tildes. Aos abnegados pretos velhos, caboclos, médicos de cura, ministros, cavaleiros, princesas doutinárias, Koatay 108 e aos demais mentores da Corrente Indiana do Espaço e das Correntes Brancas do Oriente Maior.

Aos meus pais, Bayron Tobias de Araujo Cavalcante (in memoriam) e Mariza Leite Cavalcante, pela educação e exemplos, pela dedicação e por sempre acreditarem e incentivarem. A minha irmã Tatiana Leite Cavalcante pelo apoio. A minha esposa, Mary Angela Bernasconi Suarez, pela força, determinação, paciência, fatores que tiveram grande contribuição nesse trabalho.

A todos os amigos e coordenadores do Laboratório de Sensores a Fibra Óptica (LSFO PUC-Rio), em especial (ordem alfabética), Alexandre Sant'Anna, Arthur Braga, Bruno Sena, Hugo Gomes, Paula Gouvêa e Sully Quintero.

Aos meus orientadores, Elisabeth Costa Monteiro e Daniel Ramos Louzada, ao Programa de Pós-Graduação em Metrologia (PósMQI), e ao coordenador do programa, professor Carlos Hall. Às secretárias Márcia e Paula pela ajuda e atenção.

O presente trabalho foi realizado com apoio da Coordenação de Aperfeiçoamento de Pessoal de Nível Superior - Brasil (CAPES) - Código de Financiamento 001. 


\section{Resumo}

Cavalcante, Thiago Leite; Louzada, Daniel Ramos (Orientador); Monteiro, Elisabeth Costa (Coorientadora). Desenvolvimento de sistema de monitoramento multiparamétrico da qualidade do ar em ambientes internos. Rio de Janeiro, 2021. 90 p. Dissertação de Mestrado - Programa de Pós-Graduação em Metrologia (Área de concentração: Metrologia para Qualidade e Inovação), Pontifícia Universidade Católica do Rio de Janeiro.

O tema qualidade do ar em ambientes internos é de suma importância para a sociedade devido ao seu impacto na saúde humana, e pela maior permanência de indivíduos em ambientes sem circulação de ar natural. Este trabalho descreve o desenvolvimento de um sistema portátil e de baixo custo para monitoramento de grandezas atmosféricas ligadas à qualidade do ar em ambientes internos, composto por sensores integrados a unidades locais, incluindo um sistema remoto hospedado na nuvem para armazenar os resultados das medições desses sensores. Apresentam-se as diretrizes e documentos normativos e regulatórios relacionados ao tema, além das tecnologias para sensoriamento utilizadas. Após o desenvolvimento e caracterização dos sensores, as unidades foram distribuídas em ambientes universitários com distintas dinâmicas de uso, onde o gradiente espacial das grandezas atmosféricas foi avaliado e analisado segundo os requisitos para qualidade do ar publicados na regulamentação vigente. Com o monitoramento multiparamétrico identificou-se a heterogeneidade da distribuição dos valores das grandezas, dependente da dinâmica de ocupação e das condições de ventilação, especialmente para as concentrações de $\mathrm{CO}_{2}$. Este parâmetro superou os valores recomendados pela agência reguladora em todos os ensaios realizados em sala de aula, e maiores valores mostraram-se fortemente associados à região do espaço mais próxima das vias aéreas superiores dos ocupantes. Os resultados apontam para a importância de monitoramento contínuo e em vários pontos de um plano posicionado a uma distância estratégica do piso, conforme a dinâmica de ocupação e posição média da emissão de gases pelo processo respiratório.

\section{Palavras-chave}

Metrologia; Qualidade do Ar em Ambientes Internos; Monitoramento Multiparamétrico Contínuo; Grandezas Atmosféricas. 


\section{Abstract}

Cavalcante, Thiago Leite; Louzada, Daniel Ramos (Advisor); Monteiro, Elisabeth Costa (Co-advisor). Development of a multiparametric indoor air quality monitoring system. Rio de Janeiro, 2021. 90 p. Dissertação de Mestrado - Programa de Pós-Graduação em Metrologia (Área de concentração: Metrologia para Qualidade e Inovação), Pontifícia Universidade Católica do Rio de Janeiro.

The topic of indoor air quality is of paramount importance to society due to its impact on human health and the increasing number of individuals staying in environments with no natural air circulation. This work describes the development of the system, low-cost and portable, for monitoring atmospheric quantities linked to indoor air quality, composed of sensors integrated into local units, including a remote system hosted in the cloud to store the results of measurements of these sensors. The normative and regulatory guidelines and documents related to the theme are presented, in addition to the sensing technologies used. After the development and characterization of the sensors, the units were distributed in university environments with different dynamics of use, where the spatial gradient of the atmospheric quantities was evaluated and analyzed according to the requirements for air quality published in the current regulation. With multiparametric monitoring, the heterogeneity of the distribution of the values of the quantities was identified, depending on the dynamics of occupation and ventilation conditions, especially for $\mathrm{CO}_{2}$ concentrations. This parameter exceeded the values recommended by the regulatory agency in all tests performed in the classroom, and higher values were shown to be strongly associated with the region of space closest to the occupants' upper airways. The results point to the importance of continuous monitoring and at various points in a plane positioned at a strategic distance from the floor, according to the dynamics of occupation and the average position of the emission of gases by the respiratory process.

\section{Keywords}

Metrology; Indoor Air Quality; Continuous Multiparametric Monitoring; Atmospheric Quantities. 


\section{Sumário}

1 Introdução

1.1 Objetivos: Geral e Específicos ............................................... 16

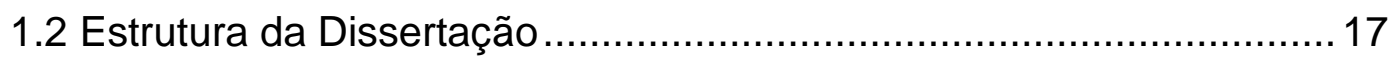

2 Confiabilidade Metrológica de grandezas atmosféricas para avaliação da qualidade do ar em ambientes internos

2.1 BIPM (International Bureau of Weights and Measures) ................... 19

2.2 OIML (Organização Internacional de Metrologia Legal) .................... 20

2.3 WHO (Wolrld Health Organization) .......................................... 20

2.4 ISO (International Organization for Standardization) ...................... 22

2.5 INMETRO (Instituto Nacional de Metrologia, Qualidade e Tecnologia)

2.5.1 RBC (Rede Brasileira de Calibração) 23

2.6 ANVISA (Agência Nacional de Vigilância Sanitária)......................... 24

2.7 CONAMA (Conselho Nacional do Meio Ambiente) .........................27

2.8 ABNT (Associação Brasileira de Normas Técnicas) ........................ 30

3 Sensores para monitoramento ambiental: princípios de medição 32

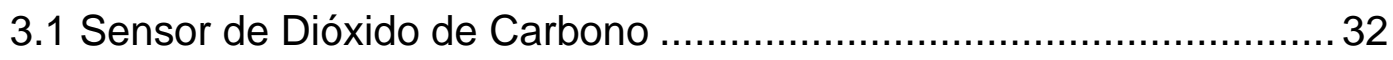

3.2 Sensor de Umidade e Temperatura ......................................... 34

3.3 Sensor de Compostos Orgânicos Voláteis ..................................... 34

3.4 Sensor de Material Particulado ...................................................... 36

3.5 Sensor de Pressão Atmosférica ........................................... 38

4 Materiais e Métodos $\quad 40$

4.1 Sistema Remoto ...................................................................... 40

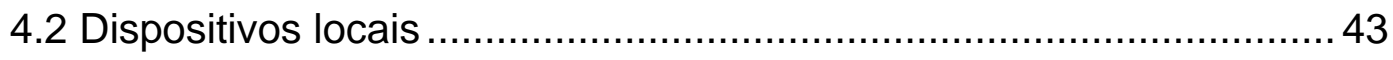


4.3 Sensores Disponíveis nos Dispositivos Locais................................. 44

4.3.1 Sensores de Dióxido de Carbono 44

4.3.2 Sensor de Umidade e Temperatura 45

4.3.3 Sensores de Compostos Orgânicos Voláteis Totais 46

4.3.4 Sensor de Material Particulado $\quad 47$

4.3.5 Sensor de Pressão Atmosférica $\quad 47$

4.4 Resumo dos sensores presentes nos dispositivos locais................... 47

4.5 Caracterização dos Sensores de Dióxido de Carbono ........................ 49

4.6 Caracterização dos Sensores de Umidade e Temperatura................. 50

4.7 Monitoramento de ambientes internos ............................................ 53

4.7.1 Monitoramento em sala de pesquisa 53

4.7.2 Monitoramento em sala de aula 54

4.7.3 Avaliação de propagações espaciais de concentrações de $\mathrm{CO}_{2}$ através de séries temporais 56

5 Resultados $\quad 58$

5.1. Caracterização de sensores de Dióxido de Carbono .........................58

5.2. Caracterização de sensores em câmara climática ............................. 60

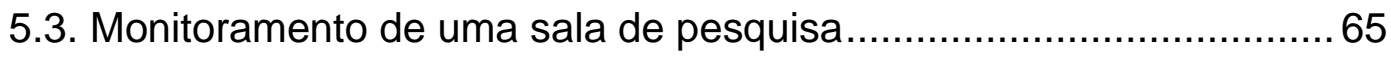

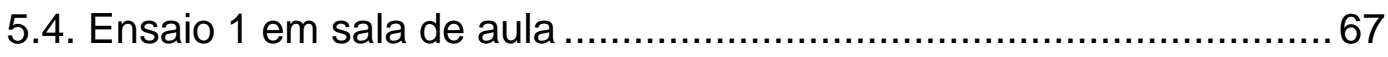

5.5. Ensaio 2 em sala de aula ...................................................... 72

6 Discussão e Conclusão 79

6.1

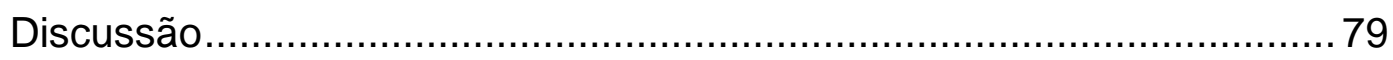

6.2

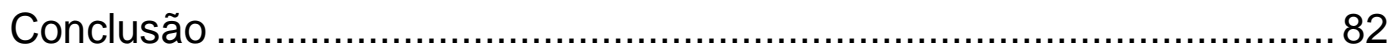

6.3

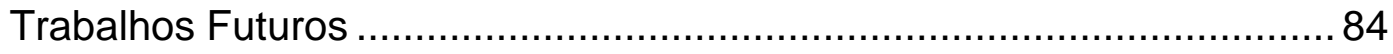

7 Referências Bibliográficas $\quad 85$ 


\section{Lista de siglas e abreviaturas}

$\begin{array}{ll}\text { PUC-Rio } & \text { Pontifícia Universidade Católica do Rio de } \\ \text { PósMQI } & \text { Janeiro. } \\ \text { CAPES } & \begin{array}{l}\text { Coograma de Pós-Graduação em Metrologia. } \\ \text { Pessoal de Nível Superior. }\end{array} \\ \text { BIPM } & \text { Bureau International des Poids et Measures } \\ \text { CIPM } & \text { Comité International des Poids et Measures } \\ \text { CGPM } & \text { Conférence Générale des Poids et Measures } \\ \text { CCQM } & \text { Comitê Consultivo para Quantidade de } \\ & \text { Substância: Metrologia em Química e } \\ \text { SI } & \text { Biologia } \\ \text { OIML } & \text { Sistema Internacional de Unidades } \\ \text { WHO } & \text { International Organization of Legal Metrology } \\ \text { ISO } & \text { World Health Organizatiom } \\ \text { INMETRO } & \text { International Organization for Standardization } \\ \text { ANVISA } & \text { Instituto Nacional de Metrologia, Qualidade e } \\ \text { CONAMA } & \text { Tecnologia. } \\ \text { ABNT } & \text { Agência Nacional de Vigilância Sanitária } \\ \text { SED } & \text { Conselho Nacional do Meio Ambiente } \\ \text { CO2 } & \text { Associação Brasileira de Normas Técnicas } \\ \text { TVOC } & \text { Síndrome do Edifício Doente } \\ \text { PM } & \text { Dióxido de Carbono. } \\ \text { IAQ } & \text { Compostos Orgênicos Voláteis Totais } \\ & \text { Material Particulado } \\ \text { Indoor Air Quality }\end{array}$




\section{Lista de figuras}

Figura 1 - Componentes presentes em um dispositivo NDIR …...............33

Figura 2 - Dispositivo de detecção por espalhamento de luz [51] ............38

Figura 3 - Dashboard disponibilizado pelo Sistema Remoto................... 42

Figura 4 - Visão geral do sistema de monitoramento.............................. 43

Figura 5 - Em (a) os sensores disponíveis são: $1-\mathrm{CO}_{2}$ (K33), 2 - VOC

(iAQ-Core), 3 - VOC (CCS811), 4 - Umidade e Temperatura (HIH6131), 6

- Material Particulado (HPMA115S0), 7 - Pressão Atmosférica (BMP180),

e o componente 5 - MCU (ESP32). Em (b) os sensores disponíveis são: 1

- $\mathrm{CO}_{2}$ (k30), 4 - Umidade e Temperatura (HIH6131) e 5 - MCU

(ESP8266)

Figura 6 - Sensores acomodados na câmara climática (a) e detalhe da disposição dos mesmos no interior da câmara (b).

Figura 7 - Planta da sala de pesquisa e posicionamento dos dispositivos locais no ensaio.

Figura 8 - Posicionamento dos sensores na sala de aula no primeiro dia de ensaio......

Figura 9 - Posicionamento dos sensores na sala de aula no segundo dia

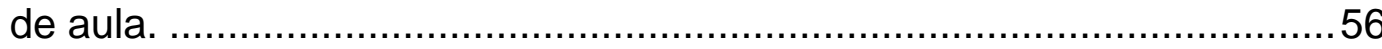

Figura 10 - Ensaio de caracterização dos sensores de CO2 ..................58

Figura 11 - Distribuição das series de dados durante o período de estabilidade do ensaio de caracterização dos sensores de $\mathrm{CO}_{2}$...... .59

Figura 12 - Condições climáticas registradas pelos sensores durante 0 ensaio em câmara climática.

Figura 13 - Séries temporais de concentrações de $\mathrm{CO}_{2}$ em (a); temperatura em (b); e umidade em (c); obtidos por quatro dispositivos locais, distribuídos em um ambiente composto por dois compartimentos.

Figura 14 - Registros de concentração de TVOC em (a); e pressão

barométrica em (b).

Figura 15 - Valores das concentrações de $\mathrm{CO}_{2}$ durante o ensaio 1 em sala de aula.

Figura 16 - Comportamento do $\mathrm{CO}_{2}$ e do $\mathrm{CO}_{2}$ estimado para o ensaio 1 em sala de aula. Em (a) é mostrado os dois registros no tempo e em (b) a correlação entre eles.

Figura 17 - Pressão Atmosférica registrada durante o ensaio 1 em sala de

aula. 72

Figura 18 - Valores das concentrações de CO2 durante o ensaio 2 em sala de aula. .73

Figura 19 - Influência de temperatura (a) e umidade (b) no sensor de TVOC modelo iAQ Core do dispositivo local 3. Figura 20 - Semelhanças entre o comportamento do $\mathrm{CO}_{2}$ e $\mathrm{CO}_{2}$ estimado no ensaio 2 em sala de aula. Em (a) é apresentado os registros dos sensores no tempo e em (b) a sua correlação. 
Figura 21 - Pressão atmosférica durante o ensaio 2 em sala de aula......78

\section{Lista de tabelas}

Tabela 1 - Características metrológicas dos sensores ............................27

Tabela 2 - Número de amostras por área construída.............................27

Tabela 3 - Padrões de qualidade do ar .............................................29

Tabela 4 - Níveis de atenção, alerta e emergência de poluentes ............29

Tabela 5 - Valores aceitáveis de poluentes.................................................. 30

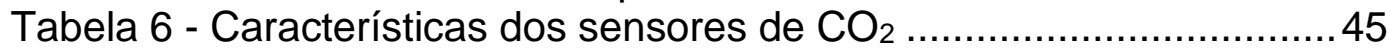

Tabela 7 - Características do sensor de umidade e temperatura..............46

Tabela 8 - Características dos sensores de TVOC ................................46

Tabela 9 - Características do sensor de PM 2,5 …...........................4 47

Tabela 10 - Características do sensor de Pressão Atmosférica................47 47

Tabela 11 - Dispositivos locais e sensores disponíveis...........................48

Tabela 12 - Especificações relevantes da câmara climática. .....................50

Tabela 13 - Condições climáticas avaliadas no ensaio............................51

Tabela 14 - Estatística descritiva das series de dados do ensaio de

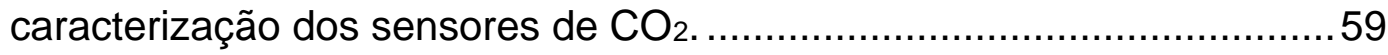

Tabela 15 - Incertezas referentes à temperatura, estimadas no ensaio da

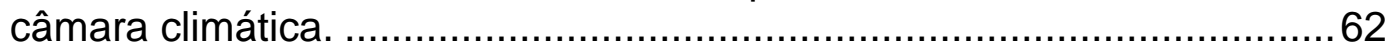

Tabela 16 - Incertezas referentes aos valores de umidade levantadas no

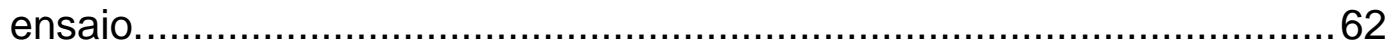

Tabela 17 - Parâmetros obtidos pela regressão linear no ensaio de temperatura.

Tabela 18 - Valores de temperatura medidos no ensaio e corrigidos pela regressão linear.

Tabela 19 - Parâmetros obtidos pela regressão linear no ensaio de umidade.

Tabela 20 - Valores de unidade medidos durante o ensaio e corrigidos

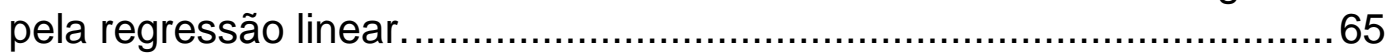

Tabela 21 - Propagação plana das concentrações de $\mathrm{CO}_{2}$ no ensaio 1 em

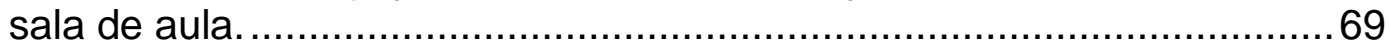

Tabela 22 - Valores máximos de concentrações de dióxido de carbono obtidos no ensaio 1 em sala de aula.

Tabela 23 - Valores de temperatura obtidos no ensaio $1 \mathrm{em}$ sala de aula.

Tabela 24 - Valores de umidade obtidos no ensaio 1 em sala de aula. ....70 Tabela 25 - Propagações das concentrações de CO2 entre as bancadas no ensaio 2 em sala de aula........................................................... 73

Tabela 26 - Valores máximos de concentrações de dióxido de carbono obtidos no ensaio 2 em sala de aula................................................ 74 Tabela 27 - Valores de temperatura obtidos no ensaio 2 em sala de aula. 
Tabela 28 - Valores de umidade obtidos no ensaio 2 em sala de aula....74

\section{Lista de Quadros}

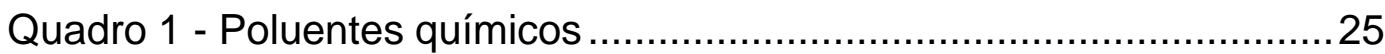




\section{1 \\ Introdução}

A partir de meados de 1950 inicia-se em grande escala o uso de condicionadores de temperatura e umidade. Hoje em dia, a utilização de ambientes climatizados é prática frequente, principalmente para a realização do controle térmico. Essa condição favorece que pessoas estejam cada vez mais submetidas a ambientes de ar recirculado, sem renovação. Esses ambientes são referenciados pela literatura científica como ambientes internos ou interiores, visto que não possuem renovação de ar. Em locais onde a renovação do ar é deficiente, os indivíduos são expostos a poluentes gerados principalmente pela emissão de gases resultantes da respiração, como o dióxido de carbono $\left(\mathrm{CO}_{2}\right)$, que podem tanto prejudicar a produtividade quanto causar problemas de saúde.

Com relação ao dióxido de carbono, a exposição a níveis elevados pode afetar os ocupantes desses ambientes, gerando sintomas como irritação nos olhos, nariz e garganta, dores de cabeça, tonturas e fadiga e em casos muito críticos levar a óbito. Além disso, a exposição contínua e por longos períodos de tempo a essas condições pode acarretar o desenvolvimento de doenças respiratórias, cardíacas, entre outras [1].

Como um dos gases nocivos ao homem, e que é gerado pela própria atividade humana, o dióxido de carbono $\left(\mathrm{CO}_{2}\right)$ é amplamente utilizado como indicador de qualidade do ar [2]. O estudo dos padrões de comportamento dos níveis de $\mathrm{CO}_{2}$ por meio de processos inteligentes permite a criação de diversas soluções de controle do mesmo nos ambientes estudados, associando essa ação a reduzidas taxas de consumo elétrico (otimização de controle ambiental). Neste sentido, existem na literatura estudos publicados [3-5] abordando algumas técnicas de predição e modelagem do comportamento das concentrações de $\mathrm{CO}_{2}$ facilitando o seu controle. Outros modelos [6,7], evidenciam correlações entre a predição dos níveis de $\mathrm{CO}_{2}$ e a estimativa do número de ocupantes em um ambiente. Foram observadas ainda pesquisas que apresentam soluções para identificar e diagnosticar avarias em 
sistemas de condicionamento térmico, utilizando redes neurais artificiais aplicadas ao monitoramento dos níveis de $\mathrm{CO}_{2}[8,9]$.

Com relação ao tema qualidade do ar, diversas pesquisas relatam estudos em ambientes de ensino [10-21], evidenciando a influência da qualidade do ar na produtividade intelectual. Entretanto, desses estudos, somente a pesquisa realizada por Haverinen-Shaughnessy et al. (2011) [15] levou em consideração cálculos de incerteza de medição.

Dentre os estudos levantados anteriormente e que abordaram o tema de qualidade do ar em ambientes de ensino, somente $2[11,16]$ foram conduzidos tanto em universidades quanto em escolas. Destes, a revisão crítica realizada por Amoatey et al. (2018) [11] relata que existem estudos inadequados de modelagem da qualidade do ar em ambientes internos, e que com os valores medidos durante as pesquisas descritas na revisão, é possível obter uma melhor estimativa dos poluentes envolvidos.

O monitoramento das concentrações de dióxido de carbono é frequentemente empregado para avaliar a qualidade do ar em ambientes universitários [10-11, 1314, 16-17], mas este não é o único parâmetro a ser analisado. Em muitos casos o monitoramento da qualidade do ar inclui medições de umidade e temperatura [11, 13-14, 16-17]. Além disso, algumas dessas pesquisas acrescentaram medições de compostos orgânicos voláteis (VOC) [10-11, 17], material particulado (PM) [11, 17], iluminância [16-17], e pressão arterial dos ocupantes de ambientes universitários em [10, 13-14], onde mesmo não sendo uma característica do ar ambiente, o parâmetro fisiológico da pressão sanguínea pode representar um indicativo de influência das características ambientais no comportamento biológico.

Tiele et al. (2018) [17] desenvolveram um sistema portátil e de baixo custo para monitoramento da qualidade do ar que emprega sensores de $\mathrm{CO}_{2}, \mathrm{CO}$, temperatura, umidade, PM, VOC, iluminância e níveis de pressão sonora. Os autores relatam que o processo de calibração para os níveis de TVOC (Compostos Voláteis Orgânicos Totais) e PM é complexo devido à síntese e variação sistemática desses parâmetros [17]. Nesse estudo [17], descreve-se um processo de calibração das concentrações de $\mathrm{CO}_{2}$, umidade e temperatura, por meio da comparação desses sensores com um sistema comercial. O estudo [17], no entanto, não informa se o 
sistema utilizado como padrão fornece resultados com rastreabilidade metrológica. Em [17] também se realizou a caracterização do sistema através de uma mistura gasosa (ar sintético), que é filtrada para conter menos que 0,1 ppm de hidrocarbonetos totais. Essa ação possibilitou a percepção de diferenças entre os valores medidos pelos três sensores de VOC avaliados, que segundo os fabricantes são calibrados com uma mistura de VOC "típica” encontrada em ambientes interiores.

Vilcekova et al. (2017) [18] investigaram a qualidade do ar em cinco salas de aula de uma escola especial para alunos com dificuldade de aprendizado, transtorno de atenção e hiperatividade. Medições de parâmetros ambientais como: temperatura, umidade, material particulado, concentrações de dióxido de carbono, níveis de pressão sonora e iluminação, além da aplicação de questionários psicométricos, foram utilizados para determinar a influência da qualidade do ar no conforto e desempenho dos ocupantes dessas salas de aula.

A revisão bibliográfica destaca a existência de diversos estudos sobre a qualidade do ar realizados por meio do monitoramento de parâmetros físicoquímicos, apresentando a concepção de alguns sistemas de monitoramento para esse fim [2-21]. Nessas pesquisas, características metrológicas foram pouco investigadas, e não se encontram descritos estudos que avaliem as grandezas relacionadas à qualidade do ar em diversos pontos de um mesmo ambiente. A caracterização da distribuição espacial dos valores dos parâmetros ambientais pode contribuir para uma análise mais apropriada do ambiente, propiciando um planejamento para melhoria da qualidade de cada espaço interno avaliado.

\section{1}

\section{Objetivos: Geral e Específicos}

A pesquisa tem como objetivo geral desenvolver, implementar e avaliar a confiabilidade metrológica de sistemas de medição de grandezas atmosféricas, para monitoramento de seu gradiente espacial e avaliação inteligente de ambientes internos da Universidade, com base nos resultados das medições de dióxido de carbono, temperatura, umidade, material particulado, compostos orgânicos voláteis e pressão atmosférica. 
Para alcançar este objetivo geral, definem-se os seguintes objetivos específicos:

- Descrever o estado da arte sobre os mensurandos físico-químicos avaliados para caracterização da qualidade do ar em ambientes internos, e identificar diretrizes e documentos normativos e regulatórios relacionados ao tema.

- Identificar a infraestrutura existente para prover rastreabilidade metrológica aos resultados de medição das diversas grandezas relacionadas à qualidade do ar em ambientes internos.

- Desenvolver sistemas de medição multiparamétrica para monitoramento e avaliação inteligente da qualidade do ar em ambientes internos, fazendo uso de sensores de dióxido de carbono, temperatura, umidade, material particulado, compostos orgânicos voláteis e pressão atmosférica.

- Realizar a caracterização metrológica e estimar a incerteza das medições do sistema de medição multiparamétrica para ambientes internos desenvolvido.

- Realizar estudos do gradiente espacial das grandezas monitoradas para avaliação da qualidade do ar, por meio de medições utilizando os sistemas de medição desenvolvidos distribuídos em múltiplas posições no volume de ambientes internos com características e finalidades distintas, como pesquisa ou ensino.

- Desenvolver ferramentas inteligentes para análise de resultados das diversas grandezas monitoradas pelos sistemas de medição multiparamétrica.

- Analisar os resultados do gradiente das grandezas monitoradas nos espaços internos, quanto ao potencial impacto à saúde, avaliados nos diferentes locais dos ambientes, em situações da rotina de ensino ou pesquisa.

\section{2 \\ Estrutura da Dissertação}

A presente dissertação está estruturada em seis capítulos, que abordam temas relacionados à qualidade do ar em ambientes internos.

O capítulo 1 introduz o tema da dissertação, apresenta os objetivos e a estrutura da dissertação. 
No capítulo 2, apresenta-se a infraestrutura para prover a confiabilidade metrológica dos resultados de medição das diversas grandezas relacionadas à qualidade do ar em ambientes internos.

O capítulo 3 aborda tecnologias de medição dos diversos sensores relacionados à qualidade do ar em ambientes internos.

O capítulo 4 descreve o desenvolvimento de sistemas para monitoramento e avaliação inteligente da qualidade do ar. Detalham-se os sensores utilizados, a solução para armazenamento de dados, a arquitetura de software empregada, e uma ferramenta para visualização dos dados gerados pelo monitoramento. Além disso, o capítulo descreve a metodologia dos ensaios de caracterização dos sensores utilizados, bem como a metodologia empregada para o monitoramento do gradiente espacial de grandezas relacionadas à qualidade do ar em ambientes universitários distintos.

O capítulo 5 relata a condução dos estudos experimentais e apresenta os resultados do comportamento espacial das grandezas monitoradas para avaliação da qualidade do ar em sala de pesquisa e ambientes de ensino. Com base nas análises busca-se avaliar a conformidade dos parâmetros monitorados com o regulamento nacional vigente.

Encerrando a dissertação, o capítulo 6 apresenta uma discussão dos resultados e a conclusão da pesquisa, indicando sugestões para futuros trabalhos. 


\section{2 \\ Confiabilidade Metrológica de grandezas atmosféricas para avaliação da qualidade do ar em ambientes internos}

O capítulo a seguir descreve as principais organizações existentes para prover confiabilidade metrológica às grandezas atmosféricas relevantes ao estudo da qualidade do ar, bem como valores aceitáveis desses parâmetros em ambientes internos.

\section{1 BIPM (International Bureau of Weights and Measures)}

O BIPM é uma organização internacional criada pela convenção do Metro e possui sua sede localizada na França. Financiada por seus Estados membros, essa organização é supervisionada pelo CIPM (Comitê Internacional de Pesos e Medidas), e fornece a base para um sistema único e coerente de medições em todo o mundo, rastreável ao Sistema Internacional de Unidades (SI) [22].

Para apoiar o CIPM, foram criados órgãos conhecidos como Comitês Consultivos que reúnem especialistas do mundo em campos específicos, prestando consultoria em questões técnicas e científicas. Esses Comitês podem formar grupos de trabalho temporários ou permanentes para estudar temas especiais, e coordenam o trabalho internacional realizado em seus respectivos campos, propondo recomendações ao CIPM em relação às unidades [22].

O Acordo de Reconhecimento Mútuo do CIPM (CIPM MRA) é um sistema onde os Institutos Nacionais de Metrologia demonstram equivalência internacional de seus padrões de medição. Esse acordo tem como resultado as capacidades de calibração e medição (CMCs) reconhecidas internacionalmente, disponibilizadas no banco de dados do CIPM MRA (KCDB) [23].

Ligado ao tema em questão, o Comitê Consultivo para Quantidade de Substância: Metrologia em Química e Biologia (CCQM) é responsável por desenvolver, aprimorar e documentar a equivalência de padrões nacionais 
(materiais de referência certificados e métodos de referência) para medições químicas e biológicas. Aconselha o CIPM em questões relacionadas a medições químicas e biológicas, incluindo conselhos sobre as atividades do programa científico do BIPM [24]. O Grupo de Trabalho de Análise de Gases, do CCQM (CCQM-GAWG), ganhou notabilidade devido ao desenvolvimento de materiais de referência e técnicas analíticas para apoiar medições de composição dos gases do efeito estufa na atmosfera, garantindo comparabilidade internacional e avanços na ciência de medição [25].

\section{2}

\section{OIML (Organização Internacional de Metrologia Legal)}

Trata-se de uma organização intergovernamental que atua no contexto mundial, tendo como objetivo harmonizar os regulamentos e controles metrológicos aplicados por serviços metrológicos nacionais ou organizações relacionadas de seus Estados Membros [26]. A OIML desenvolve Recomendações Internacionais além de outros documentos por meio de grupos de projetos vinculados a Comitês ou Subcomitês Técnicos (TCs e SCs), formados por representantes de seus Estados Membros [26]. Existem acordos de cooperação firmados entre a OIML e instituições como a ISO (International Organization for Standardization) e IEC (International Electrotechnical Commission), permitindo que fabricantes e usuários de equipamentos de medição, laboratórios de teste, entre outros, possam aplicar as publicações da OIML e dessas instituições ao mesmo tempo, sem ocasionar conflito de requisitos [26].

Apesar de existirem Comitês e Subcomitês Técnicos afins com o tema em questão, como o TC 5/SC 1 - Condições ambientais, o TC 8/SC 7 - Medição de gás, e o TC 16/SC 1 - Poluição do ar, não há ocorrência de qualquer publicação da OIML específica ao tema qualidade do ar em ambientes internos.

\section{3 \\ WHO (Wolrld Health Organization)}

A WHO é uma organização sediada em Genebra na Suíça, formada por 194 Estados Membros. Possui um número superior a 7000 funcionários trabalhando em 
150 escritórios nacionais e em seis escritórios regionais, cooperando com governos, além de outros parceiros na busca de estratégias e planos nacionais de saúde [27].

Dados da Organização informam que 9 em cada 10 pessoas respiram ar contendo altos níveis de poluentes. A WHO alerta que os efeitos combinados da poluição do ar nos ambientes externo e doméstico causam cerca de sete milhões de óbitos prematuros a cada ano, como resultado do aumento da mortalidade por acidente vascular cerebral, doenças cardíacas, doença pulmonar obstrutiva crônica, câncer de pulmão e infecções respiratórias agudas. Segundo a Organização, mais de $80 \%$ das pessoas que vivem em áreas urbanas onde a poluição do ar é monitorada são expostas a níveis de qualidade do ar que excedem os limites especificados em suas diretrizes, e que países de baixa e média renda sofrem as maiores exposições tanto em ambientes internos quanto externos [28].

Segundo a WHO, exposição à fumaça vinda de fogueiras causa 3,8 milhões de mortes prematuras a cada ano, principalmente em países de baixa e média renda. Além disso, a queima de combustíveis como esterco, madeira e carvão em fogões de baixa eficiência ou lareiras é responsável pela geração de diversos poluentes como o material particulado (PM), metano, monóxido de carbono, hidrocarbonetos poliaromáticos (PAH) e compostos orgânicos voláteis (VOC). O material particulado é um poluente que requer atenção especial. Partículas de diâmetro inferior a 2,5 micrometros (PM2,5) geralmente são mais perigosas, sendo que partículas de diâmetro inferior a 1 micrometro, podem penetrar nos tecidos e órgãos apresentando impactos sistêmicos a saúde [28].

A Organização possui diversos documentos voltados ao tema em questão, a seguir são listadas algumas publicações relevantes:

- “Air Quality Guidelines" (WHO, 2005) apresenta diretrizes voltadas à qualidade do ar, que podem orientar políticas sobre redução de efeitos na saúde causados pela poluição atmosférica. As diretrizes abordadas apresentam valores revisados para os quatro poluentes atmosféricos mais comuns: material particulado, ozônio, dióxido de nitrogênio e dióxido de enxofre.

- "WHO guidelines for indoor air quality: dampness and mould" (WHO, 2009), discute a poluição microbiana como poluente do ar em ambientes 
fechados, explicando que a presença de umidade suficiente promove a proliferação de bactérias e fungos nesses ambientes.

- "WHO guidelines for indoor air quality: selected pollutants" (WHO, 2010), destaca diretrizes voltadas ao risco à saúde pelo contato com produtos químicos normalmente presentes em ambientes internos. As substâncias enfatizadas na publicação são: benzeno, monóxido de carbono, formaldeído, naftaleno, dióxido de nitrogênio, hidrocarbonetos policíclicos aromáticos (especialmente benzo[a]pireno), rádon, tricloroetileno e tetracloretileno.

- "WHO guidelines for indoor air quality: household fuel combustion" (WHO, 2014), fornece recomendações técnicas sobre o desempenho de combustíveis e tecnologias domésticas, incentivando o uso de energia limpa.

\section{4}

\section{ISO (International Organization for Standardization)}

A ISO é uma organização internacional não governamental que possui como membros 164 organismos nacionais de normalização. Possui especialistas em diversas áreas de conhecimento que desenvolvem Normas Internacionais voluntárias, aprovadas através do consenso entre seus membros, apoiando a inovação, além de fornecer soluções relevantes ao comércio internacional [29].

O Comité Técnico TC 146 (Air quality) possui normas relevantes ao tema qualidade do ar. Um de seus Subcomités, o SC 6 (Indoor Air) reúne publicações que se aplicam a ambientes internos, como a ISO 16000:2006. Já a norma ISO 12219:2012 é voltada à qualidade do ar no interior de automóveis.

\section{5}

\section{INMETRO (Instituto Nacional de Metrologia, Qualidade e Tecnologia)}

O INMETRO é uma autarquia federal vinculada à Secretaria Especial de Produtividade, Emprego e Competitividade, do Ministério da Economia. Atua como Secretaria Executiva do Conmetro (Conselho Nacional de Metrologia, Normalização e Qualidade Industrial), que por sua vez é órgão normativo do Sinmetro (Sistema Nacional de Metrologia, Normalização e Qualidade Industrial). 
O Inmetro, o Conmetro e o Sinmetro foram criados pela lei 5.966, de 11 de dezembro de 1973 visando à integração de uma estrutura sistêmica, onde o Inmetro substituiu o INPM (Instituto Nacional de Pesos e Medidas), ampliando seu espectro de atuação junto à sociedade brasileira [30].

Através da portaria $\mathrm{n}^{\circ} 2$, de 4 de janeiro de 2017, o Inmetro unificou as Divisões de Metrologia Química e Térmica, criando a DIMQT, que faz parte da Diretoria de Metrologia Científica e Tecnologia (DIMCI). A Divisão conta com diversos laboratórios, em especial o Laboratório de Análise de Gases (LABAG) [31].

A atuação do LABAG se dá no desenvolvimento de novas metodologias analíticas para o processo de certificação de misturas gasosas a partir de padrões primários de referência (Padrões Primários de Misturas Gasosas - PPMG). Uma das atividades do Laboratório é o estudo da transferência de rastreabilidade aos padrões secundários, bem como a produção dos PPMG no Brasil [32]. O LABAG também possui convênios de cooperação técnico-científicos com Institutos Nacionais de Metrologia entre outros, além de participar de comparações interlaboratoriais nacionais e internacionais, como a CCQM K 52, que avaliou entre diversos laboratórios a capacidade de medição de dióxido de carbono diluído em ar sintético (oxigênio + nitrogênio) [32], [33].

\subsection{1 RBC (Rede Brasileira de Calibração)}

A Rede Brasileira de Calibração (RBC) foi criada para suplantar a capacidade atendimento dos laboratórios disponíveis no INMETRO, com o objetivo de disponibilizar ao país uma infraestrutura de serviços metrológicos básicos [34].

A rede é constituída por laboratórios acreditados ao INMETRO. Em relação ao tema da pesquisa a rede possui 76 laboratórios que prestam o serviço de calibração das grandezas de umidade e temperatura, e apenas um laboratório que realiza a calibração das concentrações de dióxido de carbono. A rede não possui laboratórios para calibração dos demais parâmetros estudados na pesquisa, como compostos orgânicos voláteis e material particulado. 


\section{6 ANVISA (Agência Nacional de Vigilância Sanitária)}

A ANVISA é uma autarquia sob regime especial criada pela Lei no 9.782, de 26 de janeiro de 1999. Sediada no Distrito Federal, a agência tem por finalidade promover a saúde da população realizando o controle sanitário da produção e consumo de produtos e serviços submetidos à vigilância sanitária, inclusive dos ambientes, dos processos, dos insumos e das tecnologias a eles relacionados, bem como o controle de portos, aeroportos, fronteiras e recintos alfandegados [35].

Em 2003, a agência publicou a Resolução $n^{\circ}$ 09, onde foram estabelecidos padrões referenciais de qualidade do ar em ambientes internos climatizados artificialmente (ANVISA, 2003). A resolução define valores máximos recomendáveis para contaminação biológica, química e parâmetros físicos do ar interior, identificação de fontes poluentes, métodos analíticos e recomendações para controle. Em destaque, valores voltados à contaminação química, além de parâmetros físicos do ar interior:

- 1000 ppm de dióxido de carbono - $\left(\mathrm{CO}_{2}\right)$, como indicador de renovação de ar externo, recomendado para conforto e bem-estar. Baseado na norma ASHARAE ${ }^{1}$ Standard 62 - Ventilation for Acceptable Indoor Air Quality, 2001.

- $80 \mu \mathrm{g} / \mathrm{m}^{3}$ de aerodispersóides ${ }^{2}$ totais no ar, como indicador do grau de pureza do ar e limpeza do ambiente climatizado. Baseado na Resolução $\mathrm{n}^{\circ}$ 03 de 28/06/1990 da CONAMA (Conselho Nacional do Meio Ambiente).

- A faixa recomendável de operação das Temperaturas de Bulbo Seco, nas condições internas para verão, deverá variar de $23{ }^{\circ} \mathrm{C}$ a $26^{\circ} \mathrm{C}$, com exceção de ambientes de arte que deverão operar entre $21^{\circ} \mathrm{C}$ e $23^{\circ} \mathrm{C}$. A faixa máxima de operação deverá variar de $26,5^{\circ} \mathrm{C}$ a $27^{\circ} \mathrm{C}$, com exceção das áreas de acesso que poderão operar até $28{ }^{\circ} \mathrm{C}$. A seleção da faixa depende da finalidade e do local da instalação. Para condições internas para inverno, a faixa recomendável de operação deverá variar de $20{ }^{\circ} \mathrm{C}$ a $22{ }^{\circ} \mathrm{C}$. Valores

\footnotetext{
1 ASHARAE: American Society of Heating, Refrigerating and Air Conditioning Engineers, Inc.

${ }^{2}$ Aerodispersóides: Sistema disperso, em um meio gasoso, composto de partículas sólidas e/ou mesmo
} que aerosol ou aerossol. 
baseados na NBR 6401 - Instalações Centrais de Ar Condicionado para Conforto - Parâmetros Básicos de Projeto da ABNT (Associação Brasileira de Normas Técnicas).

- A faixa recomendável de operação da Umidade Relativa, nas condições internas para verão, deverá variar de $40 \%$ a $65 \%$, com exceção de ambientes de arte que deverão operar entre $40 \%$ e $55 \%$ durante todo o ano. O valor máximo de operação deverá ser de $65 \%$, com exceção das áreas de acesso que poderão operar até $70 \%$. A seleção da faixa depende da finalidade e do local da instalação. Para condições internas para inverno, a faixa recomendável de operação deverá variar de $35 \%$ a $65 \%$. Valores baseados na NBR 6401 - Instalações Centrais de Ar Condicionado para Conforto - Parâmetros Básicos de Projeto da ABNT (Associação Brasileira de Normas Técnicas).

O Quadro 1 informa as possíveis fontes de poluentes químicos adotados pela resolução, bem como ações a serem tomadas para redução desses poluentes em ambientes internos.

Quadro 1 - Poluentes químicos

\begin{tabular}{|c|c|c|}
\hline $\begin{array}{l}\text { Agentes } \\
\text { químicos }\end{array}$ & Principais fontes & Principais medidas de correção \\
\hline CO & $\begin{array}{l}\text { Combustão (cigarros, queimadores de } \\
\text { fogões e veículos automotores). }\end{array}$ & $\begin{array}{l}\text { Manter a captação de ar exterior com baixa } \\
\text { concentração de poluentes; restringir as } \\
\text { fontes de combustão; manter a exaustão em } \\
\text { áreas em que ocorre combustão; eliminar a } \\
\text { infiltração de CO proveniente de fontes } \\
\text { externas; restringir o tabagismo em áreas } \\
\text { fechadas. }\end{array}$ \\
\hline $\mathrm{CO}_{2}$ & $\begin{array}{l}\text { Produtos de metabolismo humano e } \\
\text { combustão. }\end{array}$ & $\begin{array}{l}\text { Aumentar a renovação de ar externo; } \\
\text { restringir as fontes de combustão e o } \\
\text { tabagismo em áreas fechadas; eliminar a } \\
\text { infiltração de fontes externas. }\end{array}$ \\
\hline $\mathrm{NO}_{2}$ & Combustão. & $\begin{array}{l}\text { Restringir as fontes de combustão; manter a } \\
\text { exaustão em áreas em que ocorre combustão; } \\
\text { impedir a infiltração de } \mathrm{NO}_{2} \text { proveniente de } \\
\text { fontes externas; restringir o tabagismo em } \\
\text { áreas fechadas. }\end{array}$ \\
\hline
\end{tabular}




\begin{tabular}{|c|c|c|}
\hline $\mathrm{O}_{3}$ & $\begin{array}{l}\text { Máquinas copiadoras e impressoras a } \\
\text { laser. }\end{array}$ & $\begin{array}{l}\text { Adotar medidas específicas para reduzir a } \\
\text { contaminação dos ambientes interiores, com } \\
\text { exaustão do ambiente ou enclausuramento } \\
\text { em locais exclusivos para os equipamentos } \\
\text { que apresentem grande capacidade de } \\
\text { produção de } \mathrm{O}_{3}\end{array}$ \\
\hline Formaldeído & $\begin{array}{l}\text { Materiais de acabamento, mobiliário, } \\
\text { cola, produtos de limpeza } \\
\text { domissanitários. }\end{array}$ & $\begin{array}{l}\text { Selecionar os materiais de construção, } \\
\text { acabamento e mobiliário que possuam ou } \\
\text { emitam menos formaldeído; usar produtos } \\
\text { domissanitários que não contenham } \\
\text { formaldeído. }\end{array}$ \\
\hline $\begin{array}{c}\text { Material } \\
\text { particulado }\end{array}$ & Poeira e fibras. & $\begin{array}{l}\text { Manter filtragem de acordo com NBR- } 6402 \\
\text { da ABNT; evitar isolamento termo- acústico } \\
\text { que possa emitir fibras minerais, orgânicas } \\
\text { ou sintéticas para o ambiente climatizado; } \\
\text { reduzir as fontes internas e externas; } \\
\text { higienizar as superfícies fixas e mobiliários } \\
\text { sem o uso de vassouras, escovas ou } \\
\text { espanadores; selecionar os materiais de } \\
\text { construção e acabamento com menor } \\
\text { porosidade; adotar medidas específicas para } \\
\text { reduzir a contaminação dos ambientes } \\
\text { interiores (vide biológicos); restringir o } \\
\text { tabagismo em áreas fechadas }\end{array}$ \\
\hline $\begin{array}{c}\text { Fumo de } \\
\text { tabaco }\end{array}$ & $\begin{array}{l}\text { Queima de cigarro, charuto, cachimbo, } \\
\text { etc. }\end{array}$ & $\begin{array}{l}\text { Aumentar a quantidade de ar externo } \\
\text { admitido para renovação e/ou exaustão dos } \\
\text { poluentes; restringir o tabagismo em áreas } \\
\text { fechadas. }\end{array}$ \\
\hline $\mathrm{COV}$ & $\begin{array}{l}\text { Cera, mobiliário, produtos usados em } \\
\text { limpeza e domissanitários, solventes, } \\
\text { materiais de revestimento, tintas, colas, } \\
\text { etc. }\end{array}$ & $\begin{array}{l}\text { Selecionar os materiais de construção, } \\
\text { acabamento, mobiliário; usar produtos de } \\
\text { limpeza e domissanitários que não } \\
\text { contenham COV ou que não apresentem alta } \\
\text { taxa de volatilização e toxicidade. }\end{array}$ \\
\hline COS-V & $\begin{array}{l}\text { Queima de combustíveis e utilização de } \\
\text { pesticidas. }\end{array}$ & $\begin{array}{l}\text { Eliminar a contaminação por fontes } \\
\text { pesticidas, inseticidas e a queima de } \\
\text { combustíveis; manter a captação de ar } \\
\text { exterior afastada de poluentes. }\end{array}$ \\
\hline
\end{tabular}

${ }^{1}$ COS-V: Compostos Orgânicos Semi-Voláteis

O documento também especifica as características metrológicas que devem apresentar os sensores conforme a Tabela 1, além de definir o número mínimo de amostras dos parâmetros abordados em função da área construída (Tabela 2), 
informando ainda que os pontos amostrais devem ser distribuídos uniformemente no ambiente estudado, e coletados no horário de pico à uma altura de 1,5 m do piso.

Tabela 1 - Características metrológicas dos sensores

\begin{tabular}{clcc}
\hline & Princípio de operação & Faixa & Incerteza de Medição \\
\hline Dióxido de Carbono & $\begin{array}{l}\text { Sensor infravermelho } \\
\text { não dispersivo ou célula } \\
\text { eletroquímica }\end{array}$ & 0 a $5000 \mathrm{ppm}$ & $\begin{array}{c} \pm 0 \mathrm{ppm} \pm 2 \% \text { do } \\
\text { valor medido }\end{array}$ \\
\hline Temperatura & $\begin{array}{l}\text { Sensor de temperatura } \\
\text { do tipo termo- } \\
\text { resistência }\end{array}$ & $0{ }^{\circ} \mathrm{C} \mathrm{a} 70^{\circ} \mathrm{C}$ & $\pm 0,8^{\circ} \mathrm{C}$ do valor \\
medido
\end{tabular}

Tabela 2 - Número de amostras por área construída

\begin{tabular}{cc}
\hline Área construída $\left(\mathbf{m}^{2}\right)$ & Número mínimo de amostras \\
\hline Até 1000 & 1 \\
\hline $\mathbf{1 0 0 0}$ a 2000 & 3 \\
\hline $\mathbf{2 0 0 0}$ a 3000 & 5 \\
\hline 3000 a 5000 & 8 \\
\hline $\mathbf{5 0 0 0}$ a 10000 & 12 \\
\hline $\mathbf{1 0 0 0 0}$ a 15000 & 15 \\
\hline $\mathbf{1 5 0 0 0}$ a 20000 & 18 \\
\hline 20000 a 30000 & 21 \\
\hline Acima de 30000 & 25 \\
\hline
\end{tabular}

\section{7}

\section{CONAMA (Conselho Nacional do Meio Ambiente)}

O CONAMA é o órgão consultivo e deliberativo do Sistema Nacional do Meio Ambiente-SISNAMA instituído pela Lei 6.938/81, que dispõe sobre a Política Nacional do Meio Ambiente, regulamentada pelo Decreto 99.274/90 [36].

Em 2018, o CONAMA publicou a Resolução $n^{\circ} 491$, que estabelece padrões de qualidade do ar considerando como referência, os valores recomendados pela Organização Mundial de Saúde - OMS em 2005, bem como seus critérios de implementação (CONAMA, 2018). 
A resolução adota diversas definições acerca do tema qualidade do ar, não especificando os ambientes internos. Dentre as diversas definições, as mais relevantes são:

- Poluente atmosférico: qualquer forma de matéria em quantidade, concentração, tempo ou outras características, que tornem ou possam tornar o ar impróprio ou nocivo à saúde, inconveniente ao bem-estar público, danoso aos materiais, à fauna e flora ou prejudicial à segurança, ao uso e gozo da propriedade ou às atividades normais da comunidade.

- Padrão de qualidade do ar: um dos instrumentos de gestão da qualidade do ar, determinado como valor de concentração de um poluente específico na atmosfera, associado a um intervalo de tempo de exposição, para que o meio ambiente e a saúde da população sejam preservados em relação aos riscos de danos causados pela poluição atmosférica;

- Padrões de qualidade do ar intermediários e final, PI e PF: o primeiro termo refere-se a padrões estabelecidos como valores temporários a serem cumpridos em etapas, já o segundo menciona os valores guia definidos pela Organização Mundial de Saúde - OMS em 2005.

- Material Particulado MP10 e MP2,5: partículas de material sólido ou líquido suspensas no ar, na forma de poeira, neblina, aerossol, fuligem, entre outros, com diâmetro aerodinâmico equivalente de corte de 10 e 2,5 $\mu \mathrm{m}$;

- Índice de Qualidade do Ar - IQAR: valor utilizado para fins de comunicação e informação à população que relaciona as concentrações dos poluentes monitorados aos possíveis efeitos adversos à saúde.

- Adota-se como unidade de medida de concentração dos poluentes atmosféricos o micrograma por metro cúbico $\left(\mu \mathrm{g} / \mathrm{m}^{3}\right)$ com exceção do Monóxido de Carbono que será reportado como partes por milhão (ppm).

A Tabela 3 do anexo 1 da resolução estabelece os padrões de qualidade do ar, enquanto a Tabela 4, obtida no anexo 3 do mesmo documento, apresenta os níveis de atenção, alerta e emergência para alguns dos poluentes relevantes ao estudo. 
Tabela 3 - Padrões de qualidade do ar

\begin{tabular}{|c|c|c|c|c|c|c|}
\hline Poluente & Período de & PI-1 & PI-2 & PI-3 & PF & \\
\hline Atmosférico & Referência & $\mu \mathrm{g} / \mathrm{m}^{3}$ & $\mu \mathrm{g} / \mathrm{m}^{3}$ & $\mu \mathrm{g} / \mathrm{m}^{3}$ & $\mu \mathrm{g} / \mathrm{m}^{3}$ & ppm \\
\hline \multirow{2}{*}{ MP10 } & 24 horas & 120 & 100 & 75 & 50 & - \\
\hline & Anual $^{1}$ & 40 & 35 & 30 & 20 & - \\
\hline \multirow{2}{*}{ MP2,5 } & 24 horas & 60 & 50 & 37 & 25 & - \\
\hline & Anual $^{1}$ & 20 & 17 & 15 & 10 & - \\
\hline \multirow{2}{*}{$\mathrm{SO}_{2}$} & 24 horas & 125 & 50 & 30 & 20 & - \\
\hline & Anual $^{1}$ & 40 & 30 & 20 & - & - \\
\hline \multirow{2}{*}{$\mathrm{NO}_{2}$} & 1 hora $^{2}$ & 260 & 240 & 220 & 200 & - \\
\hline & Anual1 & 60 & 50 & 45 & 40 & - \\
\hline $\mathrm{O}_{3}$ & 8 horas $^{3}$ & 140 & 130 & 120 & 100 & - \\
\hline \multirow{2}{*}{ Fumaça } & 24 horas & 120 & 100 & 75 & 50 & - \\
\hline & Anual $^{1}$ & 40 & 35 & 30 & 20 & - \\
\hline $\mathrm{CO}$ & 8 horas $^{3}$ & - & - & - & - & 9 \\
\hline \multirow{2}{*}{ PTS } & 24 horas & - & - & - & 240 & - \\
\hline & Anual $^{4}$ & - & - & - & 80 & - \\
\hline & Anual $^{4}$ & - & - & - & 0,5 & - \\
\hline
\end{tabular}

${ }^{1}$ média aritmética anual; ${ }^{2}$ média horária; ${ }^{3}$ máxima média móvel obtida no dia; ${ }^{4}$ média geométrica anual; ${ }^{5}$ medido nas partículas totais em suspensão.

Tabela 4 - Níveis de atenção, alerta e emergência de poluentes

\begin{tabular}{ccccccc}
\hline \multicolumn{7}{c}{ Poluentes e concentrações } \\
\hline Nível & $\begin{array}{c}\mathbf{S O}_{\mathbf{2}} \\
\left(\mathbf{u g} / \mathbf{m}^{\mathbf{3}}\right)^{\mathbf{1}}\end{array}$ & $\begin{array}{c}\text { MP10 } \\
\left(\mathbf{u g} / \mathbf{m}^{\mathbf{3}}\right)^{\mathbf{1}}\end{array}$ & $\begin{array}{c}\mathbf{M P 2 , 5} \\
\left(\mathbf{u g} / \mathbf{m}^{\mathbf{3}}\right)^{\mathbf{1}}\end{array}$ & $\begin{array}{c}\mathbf{C O} \\
(\mathbf{p p m})^{\mathbf{2}}\end{array}$ & $\begin{array}{c}\mathbf{O}_{\mathbf{3}} \\
\left(\mathbf{u g} / \mathbf{m}^{\mathbf{3}}\right)^{\mathbf{2}}\end{array}$ & $\begin{array}{c}\mathbf{N O}_{\mathbf{2}} \\
\left(\mathbf{u g} / \mathbf{m}^{\mathbf{3}}\right)^{\mathbf{3}}\end{array}$ \\
\hline Atenção & 800 & 250 & 125 & 15 & 200 & 1.130 \\
\hline Alerta & 1.600 & 420 & 210 & 30 & 400 & 2.260 \\
\hline Emergência & 2.100 & 500 & 250 & 40 & 600 & 3.000 \\
\hline
\end{tabular}

${ }^{1}$ média de $24 \mathrm{~h} ;{ }^{2}$ média móvel de $8 \mathrm{~h} ;{ }^{3}$ média de $1 \mathrm{~h}$.

Finalmente, o anexo 4 da resolução apresenta o método para calcular o índice de qualidade do ar através da Equação 1, a partir dos poluentes abordados na Tabela 4. Valores aceitáveis para o índice em questão são apresentados na Tabela 5.

$$
I Q A r=I_{i n i}+\frac{I_{f i n}-I_{i n i}}{C_{f i n}+C_{i n i}}\left(C-C_{i n i}\right)
$$


Onde:

Iini $=$ valor do índice que corresponde à concentração inicial da faixa.

Ifin = valor do índice que corresponde à concentração final da faixa.

Cini = concentração inicial da faixa onde se localiza a concentração medida.

Cfin $=$ concentração final da faixa onde se localiza a concentração medida.

$\mathrm{C}=$ concentração medida do poluente.

Tabela 5 - Valores aceitáveis de poluentes

\begin{tabular}{cccccccc}
\hline & & MP10 & MP2,5 & $\mathbf{O 3}$ & $\mathbf{C O}$ & $\mathbf{N O}_{2}$ & $\mathbf{S O}_{2}$ \\
Qualidade & Índice & $(\mu \mathrm{g} / \mathbf{m 3})$ & $(\boldsymbol{\mu g} / \mathbf{m 3})$ & $(\boldsymbol{\mu g} / \mathbf{m 3})$ & $(\mathbf{p p m})$ & $\left(\boldsymbol{\mu g} / \mathbf{m}^{3}\right)$ & $\left(\boldsymbol{\mu g} / \mathbf{m}^{3}\right)$ \\
& & $\mathbf{2 4} \mathbf{h}$ & $\mathbf{2 4} \mathbf{h}$ & $\mathbf{8 h}$ & $\mathbf{8 h}$ & $\mathbf{1 h}$ & $\mathbf{2 4 h}$ \\
\hline N1 - Boa & $0-40$ & $0-50$ & $0-25$ & $0-100$ & $0-9$ & $0-200$ & $0-20$ \\
\hline
\end{tabular}

\section{8}

\section{ABNT (Associação Brasileira de Normas Técnicas)}

A ABNT é o Foro Nacional de Normalização, fundado em 1940, reconhecido pela sociedade brasileira e confirmado pelo governo federal por meio de diversos instrumentos legais. A Associação é responsável pela elaboração de Normas Brasileiras (ABNT NBR) elaboradas por seus Comitês Brasileiros (ABNT/CB), Organismos de Normalização Setorial (ABNT/ONS) e Comissões de Estudo Especiais (ABNT/CEE), contribuindo para a implementação de políticas públicas, promovendo o desenvolvimento de mercados, a defesa dos consumidores e a segurança da sociedade [37].

O Comitê Brasileiro ABNT/CB-055 (Refrigeração, Ar-Condicionado, Ventilação e Aquecimento) atua na normalização no campo da refrigeração, ar condicionado, ventilação e aquecimento, no que refere-se à terminologia, classificação; identificação; desempenho e ensaios de máquinas, equipamentos e sistemas; projeto, execução e manutenção de sistemas; conservação de alimentos perecíveis; conforto humano; qualidade do ar e conservação de energia em ambiente comercial e industrial [38].

O Comitê em questão e a Comissão de Estudo de Instalações de ar condicionado (CE-55.002.03) elaboraram a seguinte norma referente à qualidade do ar em ambientes internos: 
- ABNT NBR 16401-1:2008 Instalações de ar-condicionado - Sistemas centrais e unitários

○ Parte 1: Projetos das instalações - estabelece os parâmetros básicos e os requisitos mínimos de projeto para sistemas de ar condicionado centrais e unitários.

- Parte 2: Parâmetros de conforto térmico - especifica as combinações de variáveis ambientais e pessoais que produzam condições térmicas aceitáveis para a maioria dos ocupantes em um determinado ambiente.

- Parte 3: Qualidade do ar interior - especifica os parâmetros básicos e os requisitos mínimos para sistemas de ar condicionado, visando à obtenção de qualidade aceitável de ar interior para conforto. 


\section{3 \\ Sensores para monitoramento ambiental: princípios de medição}

O estudo proposto considera a propagação espacial de poluentes encontrados em ambientes internos. Para tal, surge a necessidade do monitoramento simultâneo em pontos distintos no ambiente avaliado, fazendo-se necessário o emprego de tecnologias de medição de baixo custo e portáteis.

$\mathrm{Na}$ literatura, as tecnologias disponíveis para medição de gás são classificadas basicamente pela variação de propriedades elétricas e de outras propriedades como a óptica, por exemplo [39]. Os diversos sensores empregados no sistema proposto nesta dissertação proporcionam o monitoramento de parâmetros ambientais, dentre os quais inclui-se a medição de gases, e seus princípios de detecção também seguem essa classificação básica. Este capítulo descreve os princípios de detecção dos sensores adotados no desenvolvimento do sistema de monitoramento.

\section{1 Sensor de Dióxido de Carbono}

Dentre os diversos princípios de detecção de gás existentes, destacam-se os métodos ópticos, por alcançarem maior sensibilidade, seletividade e estabilidade, além de apresentar maior vida útil. Os métodos ópticos para detecção de gás são baseados principalmente em espectroscopia [40]. Além disso, a resolução 9 da ANVISA (2003) recomenda o emprego desse princípio para a medição das concentrações de $\mathrm{CO}_{2}$ em ambientes internos.

A espectroscopia na região do infravermelho é uma técnica que se baseia na vibração de átomos de uma molécula. É possível obter-se um espectro infravermelho pela passagem de radiação infravermelha por uma amostra, determinando-se em seguida a quantidade de energia absorvida pela amostra [40].

Uma das aplicações da espectroscopia em questão, utilizada por sensores de $\mathrm{CO}_{2}$ e outros gases, é a medição por infravermelho não dispersivo (NDIR). A 
técnica consiste na absorção de um comprimento de onda pertencente ao espectro infravermelho, onde essa característica é utilizada para determinar a presença de gases [40].

Os dispositivos que empregam essa técnica tipicamente são compostos de 4 componentes: uma fonte de luz infravermelha (IR), uma câmara que acomoda a amostra do gás, um filtro óptico e um detector óptico [41]. A Figura 1 ilustra os a disposição dos componentes presentes em um dispositivo NDIR.

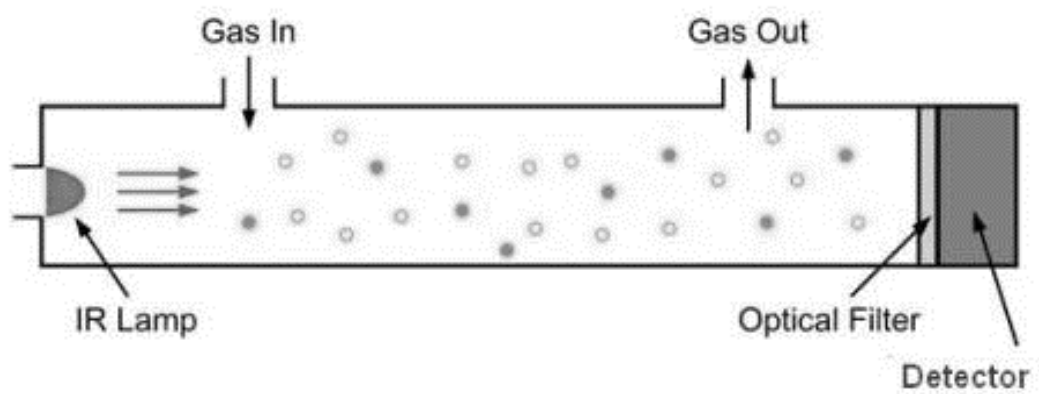

Figura 1 - Componentes presentes em um dispositivo NDIR.

Fonte: Adaptado de CO2Meter (2021).

A técnica NDIR é fundamentada na lei de absorção de luz conhecida como lei de Beer-Lambert conforme a Equação 2.

$$
I=I_{0} \cdot e^{-k C L}
$$

Onde $I_{0}$ é a intensidade inicial do feixe de radiação, $I$ é a intensidade do feixe após atravessar o gás presente na câmara, $k$ é uma constante de absorção de luz, $C$ é a concentração de gás na câmara, e $L$ é o caminho óptico da amostra, definido tipicamente pelas dimensões da câmara do sensor [41].

Existem duas principais restrições na técnica NDIR: a interferência entre faixas de absorção de gases distintos, e o limite de detecção. A sensibilidade de um sensor NDIR é definida pela magnitude do sinal do detector por unidade de intensidade de luz IR. A resolução faz alusão à menor unidade de concentração de gases que pode ser determinada, com precisão e sensibilidade especificáveis. No caso de sensores NDIR esse limite se dá em função da intensidade e estabilidade do sinal IR, e é apresentado em unidades de concentração de gás como ppb, ppm e $\mu \mathrm{g} / \mathrm{m}^{3}[40]$. 


\section{2 \\ Sensor de Umidade e Temperatura}

Umidade e temperatura estão entre as grandezas físicas mais monitoradas no campo das ciências de medição. Ao contrário da medição de temperatura, onde atinge-se uma precisão satisfatória de forma mais simples, a higrometria é uma tarefa mais complexa [42]. Dentre as diversas tecnologias disponíveis para medição das grandezas em questão, foi incorporado ao sistema proposto um dispositivo que realiza medições das duas grandezas. Esse dispositivo utiliza para medição de umidade o princípio de detecção capacitivo baseado em polímero, e um resistor térmico do tipo RTD (detector de temperatura resistiva integrado), como princípio de detecção de temperatura. Os princípios supracitados são recomendados pela resolução 9 da ANVISA (2003) para medições de umidade e temperatura em ambientes internos.

Os sensores de umidade que utilizam o princípio de detecção capacitivo baseado em polímero, são basicamente compostos por dois eletrodos simples ou interdigitados (eletrodos voltados a medições eletroquímicas em pequenas amostras), e um filme de polímero dielétrico entre eles. Essa montagem responde às variações de umidade pela alteração da permissividade dielétrica do filme polimérico, que é proporcional às mudanças da concentração no ambiente [43].

Já o sensor de temperatura incorporado ao sistema proposto possui seu princípio de detecção baseado em um RTD composto por um filme de platina. Os RTDs fornecem valores absolutos de temperatura precisos em comparação às técnicas de medição diferenciais fornecidas por termopares. Além disso, os RTDs apresentam maior imunidade a distúrbios eletromagnéticos, e o seu processo de fabricação emprega o uso de apenas um tipo de metal, sendo outra vantagem em relação aos termopares [44].

\section{3}

\section{Sensor de Compostos Orgânicos Voláteis}

Os compostos orgânicos voláteis (VOC) são compostos emitidos em forma de gases, a partir de alguns sólidos ou líquidos presentes na vida cotidiana, como mobílias, materiais de limpeza, entre outros. Os VOCs incluem uma variedade de 
elementos químicos, alguns dos quais podem ter efeitos adversos à saúde a curto e a longo prazo [45].

Na literatura são relatadas diversas tecnologias para a medição de gás, sendo que o princípio de detecção baseado no semicondutor de óxido de metal (SMO) oferece diversas vantagens como custo, consumo energético, precisão, sensibilidade, entre outras. Essas características tornam o SMO uma escolha popular para emprego em sistemas de monitoramento, exceto pela seletividade de detecção que é a principal desvantagem em seu uso [46].

A detecção nos sensores SMO baseia-se na variação de resistência elétrica de um filme de óxido de metal, devido à interação de moléculas de gás em sua superfície. Esse filme é aquecido a temperaturas de $250{ }^{\circ} \mathrm{C}$ e $500{ }^{\circ} \mathrm{C}$, com a finalidade de fornecer energia suficiente para provocar reações químicas [46].

A operação do dispositivo a altas temperaturas produzidas por um microaquecedor integrado torna necessário o aprimoramento de seus componentes internos, garantindo maior estabilidade e durabilidade, estendendo a vida útil do dispositivo. Como a temperatura fornecida influencia diretamente na detecção, é essencial a caracterização do micro-aquecedor e demais componentes. Essa caracterização não é uma tarefa trivial, e justifica por si só um estudo de pesquisa [46].

Os sensores que utilizam esse princípio atendem a diversas faixas de concentrações de gases, da ordem de ppb até milhares de ppm. Alguns sensores apresentam especificações elétricas pouco claras, além de não informarem qualquer metodologia para lidar com o problema de seletividade na detecção de gases. Geralmente na especificação dos sensores é fornecida uma tabela com a concentração de gás equivalente à sensibilidade cruzada a outros gases. $\mathrm{O}$ emprego desses dispositivos não é voltado à medição de compostos orgânicos individuais [47].

Outra limitação importante da tecnologia é que o fenômeno químico de dessorção empregado na detecção é lento, necessitando-se de alguns minutos para obtenção de medições estáveis produzidas pelo dispositivo. Além disso, a temperatura já citada e a umidade interferem nas medições e precisam ser controladas ou medidas com precisão para que suas influências sejam extraídas [47]. 
Em um estado estacionário, pesquisas realizadas relatam a seguinte relação empírica que associa as concentrações de gás à condutividade elétrica do semicondutor em questão, sendo o princípio básico de detecção do sensor [47], conforme a Equação 3:

$$
G-G_{0}=a \cdot P^{b}
$$

Onde $G$ se refere à condutividade elétrica, $G_{0}$ diz respeito à condutividade com ausência de concentração de gás, $P$ é a concentração de gás e $a$ e $b$ são constantes [47].

\section{4 \\ Sensor de Material Particulado}

Partículas atmosféricas de aerossóis variam quanto ao seu tamanho em diversas ordens de magnitude, de aglomerados recém-nucleados contendo algumas moléculas até gotículas de nuvens e partículas de poeira medindo algumas dezenas de micrometros oriundas de crostas terrestres [48]. Material particulado (PM, particulate matter) é um termo relacionado à mistura de partículas sólidas e gotículas de líquido encontradas no ar [49].

As técnicas para medição de material particulado podem ser gravimétricas, ópticas, elétricas, por meio de microbalança oscilante e por atenuação beta. Os métodos baseados em microbalança oscilante e atenuação beta são pouco encontrados em ambientes internos por existirem soluções mais práticas para essa finalidade [50].

Uma opção de baixo custo e robusta para medição de material particulado são os amostradores gravimétricos, com a desvantagem de não detectarem variações rápidas por não disponibilizarem as medições em tempo real. Para a maior compreensão das variações de PM em ambientes internos, propiciando automação de sistemas de ventilação e purificação de ar, se faz necessária a utilização de tecnologias de medição instantâneas e de baixo custo. Nesse contexto, existe uma tendência de desenvolvimento de sensores que utilizam o princípio de detecção por espalhamento de luz [50]. 
Dispositivos ópticos destinados a contagens de partículas utilizam como princípio de detecção a medição da quantidade de luz dispersa por partículas, enquanto essas atravessam um feixe de luz intensamente focado. Uma parte dessa luz dispersada é coletada por um fotodetector e em seguida é convertida em um pulso elétrico de tensão e largura proporcionais à dimensão das partículas. Essa relação é determinada a partir de uma curva de calibração obtida através de medições de partículas esféricas de tamanho e composições previamente conhecidos [48].

A Figura 2, disponível no manual de instruções do sensor de material particulado utilizado na pesquisa, exibe os principais componentes da tecnologia abordados na literatura. $\mathrm{O}$ ar amostrado é conduzido por uma janela de entrada, através de pressão negativa exercida por um pequeno exaustor na saída do dispositivo. A fonte óptica emite uma luz que atinge as partículas, sendo por fim descartada por reflexão (light trap). As partículas que atravessam o feixe de luz focalizado pela lente refletem luz para o fotodetector que captura essa reflexão na forma de pulsos. A intensidade e duração desses pulsos são processados em um microcontrolador (MCU, Microcontroller Unit) e relacionadas ao tamanho das partículas amostradas. 


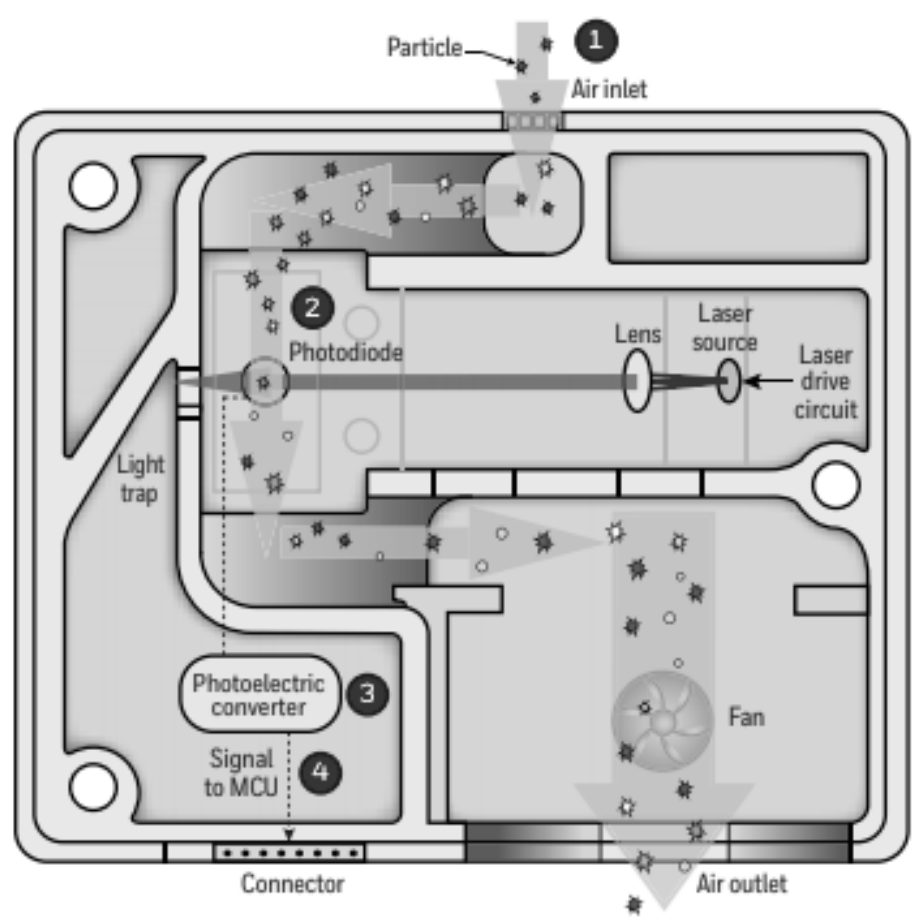

Figura 2 - Dispositivo de detecção por espalhamento de luz [51]. Fonte: Adaptado de Honeywell (2019).

Existem dispositivos de menor custo que não possuem microcontrolador integrado, e os pulsos em questão precisam ser processados externamente.

\section{5 \\ Sensor de Pressão Atmosférica}

Diferentes tipos de sensores de pressão atmosférica estão disponíveis na literatura, baseados em distintos princípios de detecção como: piezo-resistivo, capacitivo, piezo-elétrico, ótico e ressonante. Dentre esses destaca-se o princípio piezo-resistivo devido a suas dimensões reduzidas, baixo custo e processo de fabricação simplificado [52].

Sensores piezo-resistivos foram um dos primeiros dispositivos MEMS (sistemas micro-eletro-mecânicos) a serem desenvolvidos. As piezo-resistências de silicone têm uma participação importante no mercado de sensores MEMS, e são utilizadas em sensores de pressão, acelerômetros, sensores inerciais e de deformação (strain gauges) [53].

Esse princípio de detecção baseia-se no fenômeno da piezo-eletricidade, onde cargas elétricas são geradas quando materiais piezoelétricos são expostos a pressão 
ou deformação. Essa interação ocorre apenas em certos tipos de materiais que possuem estruturas cristalinas não centrossimétricas [54].

A piezo-resistividade é uma propriedade frequentemente empregada em sensores de pressão ou deformação, e esse efeito é gerado a partir de dois fatores chave: (i) substratos macios e flexíveis, e (ii) micro ou nanoestruturas especiais de materiais condutores. O baixo consumo de energia favorece o uso de sensores piezo-resistivos em sistemas portáteis e dispositivos vestíveis [54]. 


\section{4 \\ Materiais e Métodos}

Durante a pesquisa dessa dissertação foi implementado um sistema de monitoramento para avaliação de parâmetros relacionados à qualidade do ar em ambientes internos. Esse desenvolvimento pode ser dividido basicamente em 3 blocos principais, os quais atendem a diferentes funções: o sistema remoto hospedado na nuvem, os dispositivos locais e os sensores. Neste capítulo 4 são abordados, em detalhe, as diversas tecnologias e métodos empregados na concepção do sistema de monitoramento, caracterização dos sensores de Dióxido de Carbono, Umidade e Temperatura, e finalmente, aplicações práticas do monitoramento dos parâmetros de qualidade do ar em ambientes de pesquisa e uma sala de aula.

\section{1 \\ Sistema Remoto}

A base do sistema remoto é formada por uma máquina virtual (VM) hospedada em uma plataforma de armazenamento em nuvem. A infraestrutura de computação em nuvem (Cloud Computing) oferece diversos benefícios, entre eles redundância de armazenamento de dados, gestão de energia elétrica, condicionamento de equipamentos, etc. Esses fatores propiciam o desenvolvimento de aplicações que se mantêm em processamento de forma ininterrupta e de acesso simplificado, pois estão sendo executadas na nuvem. Essas características relacionam-se a um termo muito utilizado na computação em nuvem, a alta disponibilidade.

O sistema operacional ( $\mathrm{SO}$ ) utilizado na máquina virtual é o Debian, uma das distribuições Linux. Essa escolha se deu em virtude do consumo reduzido de recursos computacionais utilizado pelo sistema operacional, o que favorece o uso de máquinas virtuais de baixo custo. Outra vantagem na escolha do sistema 
operacional Debian é a variedade de aplicativos disponíveis, como bancos de dados, web servers, etc.

Os aplicativos externos adicionados ao SO foram basicamente três: um banco de dados específico para séries temporais, um sistema para geração de visualizações e painéis construídos com tecnologias web, e por fim um servidor para gestão de mensagens enviadas pelos dispositivos locais.

A atual demanda por monitoramento, com a geração de grande quantidade de informação, exige a implementação de soluções otimizadas para o armazenamento de dados. Dentre as diversas aplicações existentes em banco de dados, destaca-se na tarefa de monitoramento, uma solução conhecida como banco de dados para séries temporais, do inglês time series database (TSDB) [55]. Em geral essas aplicações apresentam compactação de dados otimizada e funções típicas para análise de séries temporais, tais como agregação de dados e cálculo de média móvel, entre outras. Normalmente os dados são armazenados em um formato, conhecido como pares de chave-valor. Neste formato o valor pode se referir a uma ou mais medições, e a chave é um identificador único do par, como a informação de data e hora em que ocorreu a medição (timestamp). O InfluxDB, que é um TSDB difundido em aplicações de monitoramento de sistemas, foi a solução computacional adotada no sistema remoto por possuir um processo simplificado de instalação, políticas de retenção de dados, entre outros recursos.

Outra questão importante nos sistemas de monitoramento é a visualização dos dados. Diversas formas de visualização estão disponíveis atualmente, garantindo ao usuário uma melhor percepção da informação analisada. Dentre formas de visualização disponíveis, se destacam as que se utilizam de tecnologias web, visto que desta forma permitem uma simplificação na sua adoção por diferentes sistemas operacionais, além de permitirem acesso por aparelhos de smartphones, smartvs e demais equipamentos que dispõem de web browser. Outra vantagem é que não há necessidade da instalação de um software adicional, o que torna o desenvolvimento mais simples.

O termo dashboard define um grupo de elementos gráficos para visualização de dados em forma de painel, e o uso de tecnologia web tem sido uma tendência na criação desses painéis. No sistema proposto nesta dissertação foi utilizada a plataforma de desenvolvimento de painéis e demais elementos gráficos Grafana. A 
plataforma simplifica a produção de interfaces gráficas de alta qualidade, produzidas com tecnologias web. Além disso, essa solução gráfica ainda facilita a integração com vários bancos de dados disponíveis, entre eles o InfluxDB.

Esse par de ferramentas (InfluxDB e o Grafana) é encontrado em diversas aplicações de monitoramento nas mais diferentes áreas de atuação, e se mostra uma solução robusta para esse fim. A Figura 3 exibe um dashboard disponibilizado pelo sistema remoto.

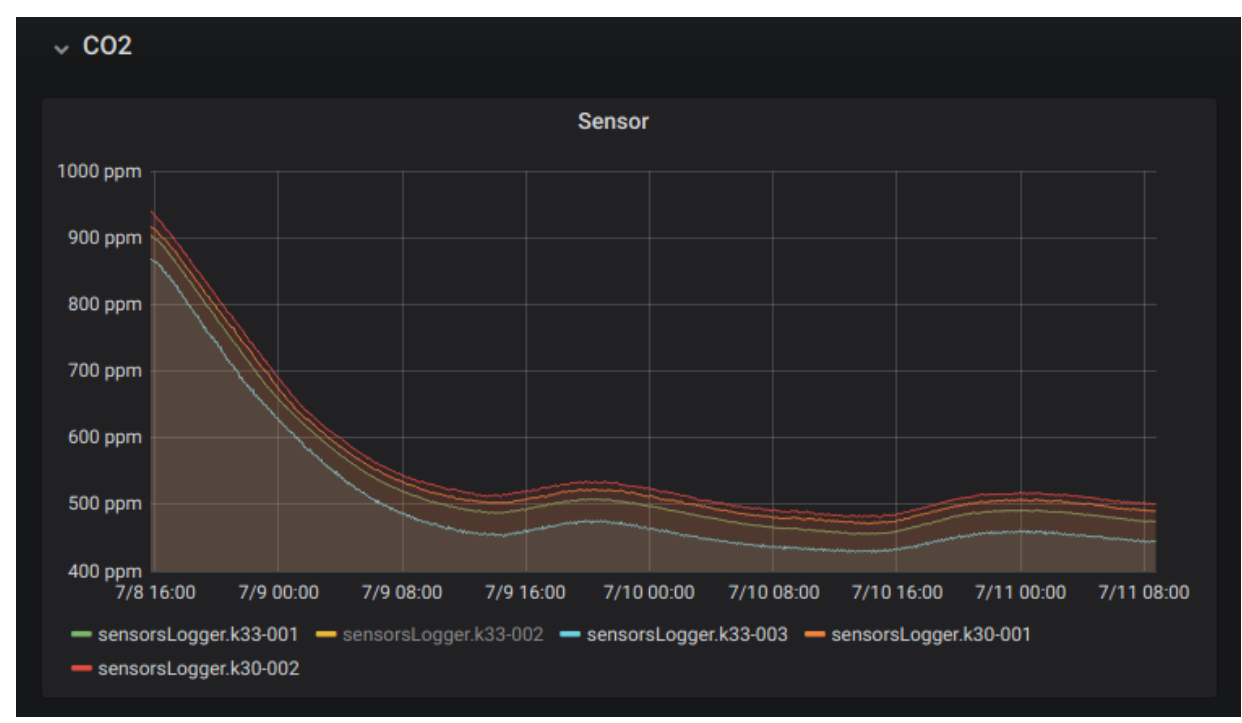

Figura 3 - Dashboard disponibilizado pelo Sistema Remoto.

Os dispositivos locais, que serão mais detalhados na Seção 4.2 Dispositivos locais, periodicamente enviam mensagens à máquina virtual, com valores de parâmetros ambientais obtidos através de seus sensores. O protocolo selecionado para gerenciar essas mensagens foi o MQTT (Message Queuing Telemetry Transport), empregado em comunicações M2M (Machine to Machine), lançado em 1999 [56]. Trata-se de um protocolo leve, voltado a dispositivos de desempenho restrito como microcontroladores, sendo frequentemente encontrado em aplicações de internet das coisas (internet of things - IoT).

Instalado na máquina virtual, um servidor MQTT, (MQTT broker), recebe as mensagens enviadas pelos dispositivos locais, que contêm os resultados das medições realizadas pelos sensores. Um script escrito em linguagem de programação Python monitora esse servidor. Quando novas mensagens dos dispositivos locais estão disponíveis, uma função executada pelo script retira essas 
mensagens do servidor e as armazena no banco de dados. A Figura 4 ilustra o procedimento descrito, e fornece uma visão geral do sistema.

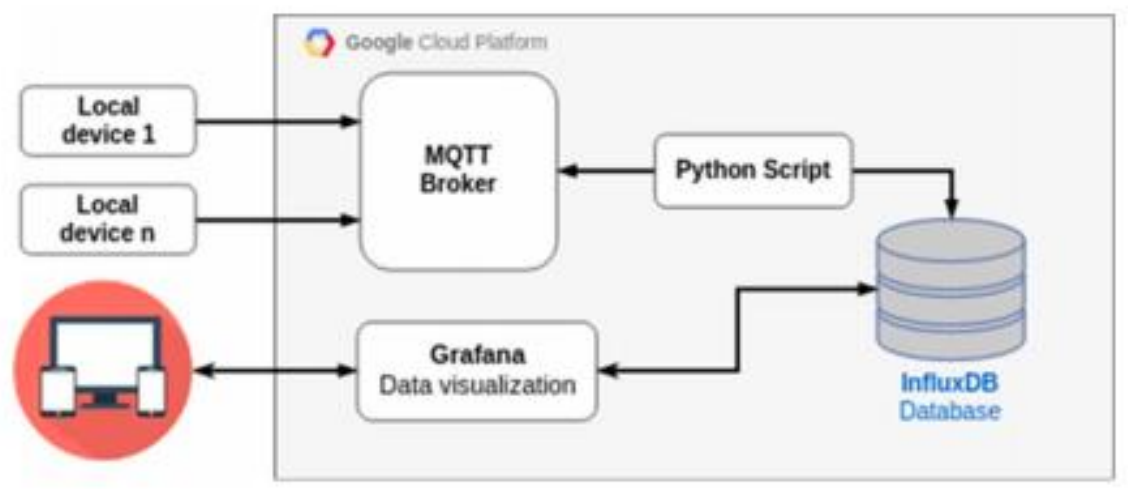

Figura 4 - Visão geral do sistema de monitoramento.

Fonte: Cavalcante, T. L., et al. (2021).

$\mathrm{Na}$ Figura 4, pode-se observar o sistema remoto hospedado na nuvem e seus diversos componentes internos, como o servidor MQTT que recebe as mensagens dos dispositivos locais, o script que armazena essas mensagens no banco de dados de séries temporais, e a plataforma responsável pela visualização de dados.

\section{2 \\ Dispositivos locais}

Os dispositivos locais são dispositivos compostos basicamente de um microcontrolador (Microcontroller Unit - MCU) com transmissor de rádio Wi-Fi integrado (padrão IEEE 802.11), capaz de realizar gerenciamento de alguns sensores, no presente caso, sensores relacionados a parâmetros ambientais. Um microcontrolador é um dispositivo versátil, pois nele são implementados protocolos voltados à comunicação com sensores, atuadores, displays, etc. Trata-se de um dispositivo voltado à execução de tarefas sequenciais, otimizado para baixo consumo de energia, o que possibilita a criação de equipamentos portáteis alimentados por baterias. Além disso, o rádio integrado simplifica o tráfego de dados, facilitando a instalação de diversos dispositivos em um mesmo ambiente. 
Alguns dispositivos locais foram equipados com o MCU modelo ESP8266 e outros com o ESP32, ambos produzidos pela Espressif Systems. Os dois modelos são compatíveis entre si. O ESP8266 é um dispositivo de menor custo, enquanto o ESP32 possui quantidade superior de memória flash e RAM (do inglês Random Access Memory), maior número de portas, suporte à programação multitarefa, etc. Para a aplicação em questão, os dois desempenham a mesma função. Mais adiante, na seção 4.4, faz-se um resumo de todos os componentes dos dispositivos locais construídos durante a pesquisa dessa dissertação, indicando quais microcontroladores foram utilizados em cada um dos dispositivos.

O firmware dos microcontroladores foi desenvolvido com a plataforma Arduino. Essa plataforma facilita o desenvolvimento de firmware através de funções que abstraem configurações comuns realizadas em MCUs. Possui bibliotecas para comunicação com sensores e outros componentes externos, além de protocolos para transmissão de dados como o MQTT.

Ao serem acionados, os microcontroladores presentes nos dispositivos locais inicializam os sensores e se conectam à rede $W i-F i$ e ao servidor MQTT na nuvem. Em seguida, a cada 20 segundos, os sensores são consultados, os resultados das medições são organizados e depois são enviados ao servidor MQTT.

Dessa forma, os dispositivos locais têm a função de gerenciar os sensores presentes, organizar os resultados das medições e enviá-los ao sistema remoto.

\section{3}

\section{Sensores Disponíveis nos Dispositivos Locais}

Cada dispositivo local gerencia sensores que possuem princípios de detecção distintos. A seguir são detalhadas as características de cada sensor disponível no sistema de monitoramento proposto, evidenciando os seus princípios de funcionamento.

\subsection{1}

\section{Sensores de Dióxido de Carbono}

Nos dispositivos locais construídos durante a pesquisa foram utilizados dois modelos diferentes de sensores de $\mathrm{CO}_{2}$, os modelos $\mathrm{K} 30$ e $\mathrm{K} 33$, ambos produzidos 
pela empresa Senseair. Estes dois modelos possuem a mesma especificação técnica, sendo que no modelo K33 existe a possibilidade de customizar algumas funções do firmware, como o tempo entre aquisições, promovendo, assim, a adoção de estratégias de baixo consumo de energia. No sistema de medição desenvolvido não foram realizadas mudanças no firmware no modelo K33, eliminando qualquer distinção entre os dois modelos disponíveis.

O princípio de operação dos sensores em questão se baseia na tecnologia de análise de radiação infravermelho não dispersivo (NDIR, do inglês nondispersive infrared). O transdutor utiliza o protocolo serial UART (Universal Asynchrounous Receiver Transmiter) para realizar a comunicação com o microcontrolador principal. A Tabela 6 informa detalhes relevantes dos dispositivos, os quais foram retirados de sua especificação técnica [57].

Tabela 6 - Características dos sensores de $\mathrm{CO}_{2}$

\begin{tabular}{lcc}
\hline Modelo & K30 e K33 & Unidade \\
\hline Faixa de medição $\left(\mathrm{CO}_{2}\right)$ & 0 a 5000 & $\mathrm{ppm}$ \\
Tempo de resposta & 25 & $\mathrm{~s}$ \\
Tensão de operação & 4,5 a 14,0 & $\mathrm{~V}$ \\
\hline
\end{tabular}

Esses sensores, quando acionados, iniciam automaticamente as medições de $\mathrm{CO}_{2}$, efetuando-as a cada 20 segundos. Após as medições, os valores dos resultados ficam armazenados na memória interna, disponíveis para transferência pelo microcontrolador principal.

\subsection{2}

\section{Sensor de Umidade e Temperatura}

Os sensores de umidade e temperatura utilizados nesta dissertação são do modelo HIH 6131 da empresa Honeywell. São configurados de tal forma que operam num mesmo transdutor. O modelo em questão destaca-se entre outros exemplares da mesma família por conter um filtro hidrofóbico em seu encapsulamento, permitindo assim seu uso em ambientes propensos à condensação [58]. O protocolo de comunicação serial utilizado é o I2C (Inter-Integrated Circuit). Outras figuras de mérito como faixa de medição e tempo de resposta são descritas na Tabela 7. 
Tabela 7 - Características do sensor de umidade e temperatura

\begin{tabular}{llcc}
\hline Modelo & & HIH6131 & Unidade \\
\hline \multirow{2}{*}{ Faixa de medição } & Umidade $(\mathrm{RH})$ & 10 a 90 & $\%$ \\
\cline { 2 - 4 } & Temperatura & 5 a 50 & ${ }^{\circ} \mathrm{C}$ \\
\hline \multirow{2}{*}{ Tempo de resposta } & Umidade & 6 a 8 & $\mathrm{~s}$ \\
\cline { 2 - 4 } & Temperatura & 5 a 30 & $\mathrm{~s}$ \\
\hline Tensão de operação & & 2,3 a 5,5 & $\mathrm{~V}$ \\
\hline
\end{tabular}

Os princípios de funcionamento dos sensores de umidade e temperatura são, respectivamente, por ação capacitiva e por ação resistiva. O sensor de umidade utiliza um polímero resistente à temperatura como princípio de detecção. No sensor de temperatura é utilizado um termo-resistor do tipo RTD (Resistance Temperature Detector), baseado em um elemento de platina [59].

\subsection{3}

\section{Sensores de Compostos Orgânicos Voláteis Totais}

$\mathrm{Na}$ presente pesquisa utilizaram-se dois sensores de compostos voláteis orgânicos totais (ou Total Volatile Organic Compounds - TVOC), a saber: modelo CCS811 e modelo iAQ-Core, produzidos pela empresa AMS AG. Ambos os modelos utilizam como princípio de operação um semicondutor de óxido de metal, e empregam o protocolo de comunicação serial I2C (Inter-Integrated Circuit). O modelo iAQ-Core é voltado ao mercado de baixo custo, enquanto o CCS811 possui melhorias como a possibilidade de inserir valores de umidade e temperatura obtidos por um sensor externo, de forma a realizar a compensação desses parâmetros no cálculo do TVOC [60]. Os dois modelos calculam estimativas das concentrações de $\mathrm{CO}_{2}$ a partir do valor do TVOC, e a Tabela 8 apresenta mais características relevantes dos sensores em questão.

Tabela 8 - Características dos sensores de TVOC

\begin{tabular}{lccc}
\hline Modelo & iAQ-Core & CCS811 & Unidade \\
\hline Faixa de medição (VOC) & 125 a 600 & 0 a 32768 & ppb \\
Primeira medição estável & 300 & 1200 & $\mathrm{~s}$ \\
Tensão de operação & $3,3 \pm 0,1$ & 1,8 a 3,6 & $\mathrm{V}$ \\
\hline
\end{tabular}




\subsection{4}

\section{Sensor de Material Particulado}

O sensor de material particulado empregado no presente estudo é do modelo HPMA115S0 da empresa Honeywell. O sensor baseia-se no princípio do espalhamento de luz para detectar a presença de partículas a partir de 2,5 mm de diâmetro. O modelo possui processamento interno, e seu protocolo de comunicação com o microcontrolador principal é o UART (Universal Asynchrounous Receiver Transmiter) [51]. Mais detalhes do sensor são descritos na Tabela 9.

Tabela 9 - Características do sensor de PM 2,5

\begin{tabular}{lcc}
\hline Modelo & HPMA115S0 & Unidade \\
\hline Faixa de medição (PM 2,5) & 0 a 1000 & $\mu \mathrm{g} / \mathrm{m}^{3}$ \\
\hline Tempo de resposta & 6 & $\mathrm{~s}$ \\
\hline Tensão de operação & $5 \pm 0,2$ & $\mathrm{~V}$
\end{tabular}

\subsection{5}

\section{Sensor de Pressão Atmosférica}

O sensor de pressão atmosférica avaliado para uso no sistema de medição é do modelo BMP180 produzido pela empresa Bosch. O modelo utiliza como sensor um piezo-resistivo para medição de pressão atmosférica e o protocolo serial de comunicação serial I2C (Inter-Integrated Circuit) [61]. Mais detalhes sobre o componente são apresentados na Tabela 10.

Tabela 10 - Características do sensor de Pressão Atmosférica

\begin{tabular}{lcc}
\hline Modelo & BMP180 & \\
\hline Faixa de medição & 30000 a 110000 & $\mathrm{~Pa}$ \\
\hline Tensão de operação & 1,8 a 13,6 & $\mathrm{V}$
\end{tabular}

\section{4}

\section{Resumo dos sensores presentes nos dispositivos locais}

No presente trabalho, foram construídos 5 dispositivos locais para avaliação de parâmetros relacionados à qualidade do ar em ambientes internos, de forma a 
possibilitar a medição simultânea em locais distintos de um mesmo ambiente. Alguns desses dispositivos não dispõem de todos os sensores descritos nesse Capítulo 4, e a Tabela 11 informa os sensores presentes em cada um dos cinco dispositivos locais.

Tabela 11 - Dispositivos locais e sensores disponíveis

\begin{tabular}{|c|c|c|c|c|c|}
\hline $\begin{array}{l}\text { Dispositivo } \\
\text { Local }\end{array}$ & 1 & 2 & 3 & 4 & 5 \\
\hline $\begin{array}{l}\text { Microcontrolad } \\
\text { or }\end{array}$ & ESP32 & ESP32 & ESP32 & ESP8266 & ESP8266 \\
\hline $\begin{array}{l}\text { Dióxido de } \\
\text { Carbono }\end{array}$ & K33 & K33 & K33 & K30 & K30 \\
\hline $\begin{array}{l}\text { Umidade e } \\
\text { Temperatura }\end{array}$ & $\mathrm{HIH} 6131$ & $\mathrm{HIH} 6131$ & $\mathrm{HIH6131}$ & HIH6131 & $\mathrm{HIH} 6131$ \\
\hline $\begin{array}{l}\text { Compostos } \\
\text { orgânicos } \\
\text { voláteis }\end{array}$ & $\begin{array}{l}\text { CCS811 e } \\
\text { iAQ-Core }\end{array}$ & $\begin{array}{l}\text { CCS811 e } \\
\text { iAQ-Core }\end{array}$ & iAQ-Core & & \\
\hline Material & HPMA115 & HPMA115 & HPMA115 & HPMA115 & HPMA115 \\
\hline Particulado & so & so & so & so & so \\
\hline $\begin{array}{l}\text { Pressão } \\
\text { Atmosférica }\end{array}$ & BMP180 & & & & \\
\hline
\end{tabular}

A seguir são apresentados alguns dos dispositivos locais construídos durante a pesquisa. A Figura 5a ilustra o dispositivo local 1, já a Figura 5 b o dispositivo local 4, ambos detalhados na Tabela 11.

(a)

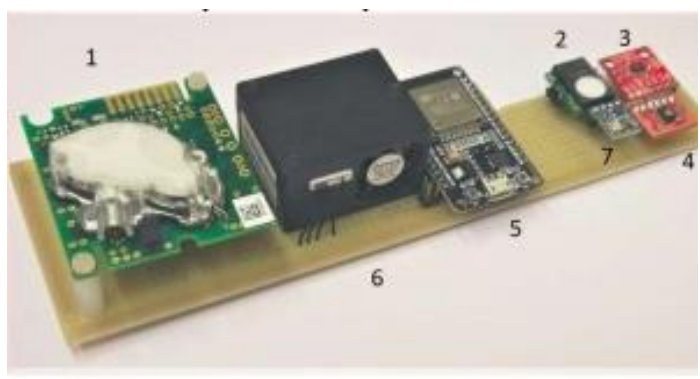

(b)

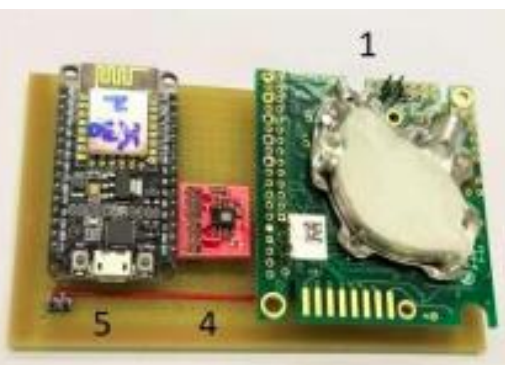

Figura 5 - Em (a) os sensores disponíveis são: 1 - $\mathrm{CO}_{2}$ (K33), 2 - VOC (iAQ-Core), 3 - VOC (CCS811), 4 - Umidade e Temperatura (HIH6131), 6 - Material Particulado (HPMA115S0), 7 - 
Pressão Atmosférica (BMP180), e o componente 5 - MCU (ESP32). Em (b) os sensores disponíveis são: 1 - $\mathrm{CO}_{2}(\mathrm{k} 30), 4$ - Umidade e Temperatura (HIH6131) e 5 - MCU (ESP8266)

Pela não disponibilidade da quantidade de sensores suficientes, os dispositivos locais foram construídos com configurações distintas de sensores. Os sensores de $\mathrm{CO}_{2}$, umidade e temperatura estão presentes em todos os dispositivos, e não há diferença entre os dois modelos de sensores de $\mathrm{CO}_{2}$, pois o firmware de ambos possui a mesma configuração. A mesma abordagem se aplica aos microcontroladores, onde os dois modelos utilizam o mesmo firmware.

\section{5}

\section{Caracterização dos Sensores de Dióxido de Carbono}

Após o desenvolvimento e montagem dos Dispositivos Locais, foi realizado o ajuste de zero dos sensores de dióxido de carbono presentes nos dispositivos. Segundo o fabricante dos sensores (Seção 4.3.1 Sensores de Dióxido de Carbono), a forma mais adequada de realizar o ajuste é expondo o componente a um gás de concentração de $\mathrm{CO}_{2}$ conhecida, tipicamente composto por $100 \%$ de nitrogênio $\left(\mathrm{N}_{2}\right)$. Para realizar o procedimento, foi introduzido um tubo com o gás $\mathrm{N}_{2} \mathrm{em}$ uma porta do sensor específica para esse fim, e aguardou-se a estabilização das indicações por cerca de 5 minutos. $\mathrm{O}$ gás $\mathrm{N}_{2}$ expulsa qualquer resquício de concentrações de $\mathrm{CO}_{2}$ no interior do sensor. Após a estabilização das indicações, foi pressionada uma chave existente no próprio sensor para fazer o ajuste de zero. O procedimento foi repetido para todos os dispositivos disponíveis.

Para caracterização dos sensores de $\mathrm{CO}_{2}$, realizou-se um ensaio no qual os dispositivos foram posicionados no interior de uma câmara hermética, na qual o nível de $\mathrm{CO}_{2}$ foi mantido quase estático. $\mathrm{O}$ estudo foi realizado em um espaço de laboratório mantido sem ocupação humana, por 40 horas. Dessa forma, a resposta dos sensores pôde ser comparada entre eles, em condições controladas. Analisouse a estatística descritiva da série de dados obtidos ao longo de um período de 70 minutos durante o qual observou-se maior estabilidade dos níveis de $\mathrm{CO}_{2}$. O valor máximo de dispersão foi avaliado segundo os limites estabelecidos pela Resolução ANVISA n ${ }^{\circ}$, de 2003. 


\section{6 \\ Caracterização dos Sensores de Umidade e Temperatura}

O ensaio de caracterização dos sensores de umidade e temperatura foi conduzido com o auxílio de uma câmara climática produzida pela Votsch, que é utilizada em testes climáticos na indústria farmacêutica, de cosméticos entre outras [62]. A Tabela 12 resume características do equipamento.

Tabela 12 - Especificações relevantes da câmara climática.

\begin{tabular}{lc}
\hline Características da câmara climática & \\
\hline Modelo & VCL 4010 \\
Volume da câmara (I) & 100 \\
Desvio de temperatura no tempo (K) & $\pm 0,3$ até $\pm 0,5$ \\
Homogeneidade de temperatura no espaço (K) & $\pm 0,5$ até $\pm 1,5$ \\
Desvio de umidade no tempo (\%) & \pm 1 até \pm 3 \\
\hline
\end{tabular}

O ensaio consistiu em acomodar as unidades de monitoramento dentro da câmara climática, conforme a Figura 6a e em maior detalhe na Figura 5b. Em seguida, o equipamento foi programado para gerar condições climáticas baseadas na combinação de valores de temperatura e umidade encontrados em ambientes internos.

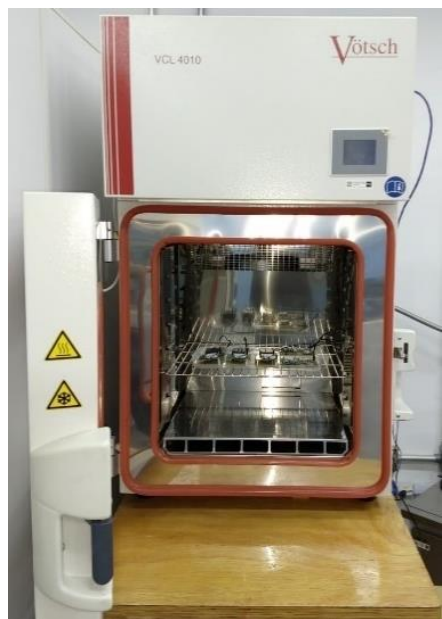

a)

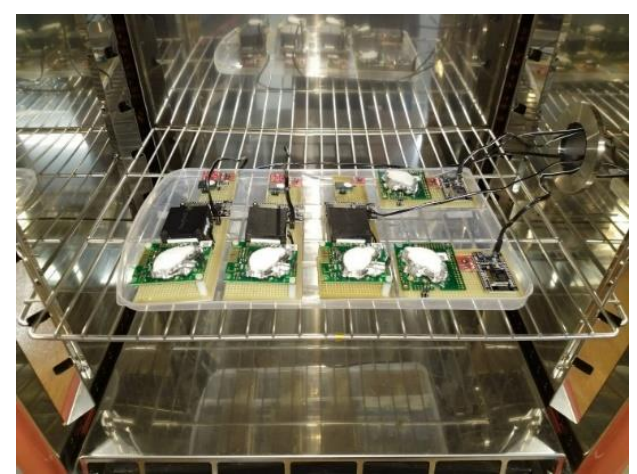

b)

Figura 6 - Sensores acomodados na câmara climática (a) e detalhe da disposição dos mesmos no interior da câmara (b). 
Para cada valor de umidade ajustado na câmara, alternaram-se diferentes valores de temperatura, resultando em 12 condições climáticas. A Tabela 13 detalha as diversas condições avaliadas no ensaio.

Tabela 13 - Condições climáticas avaliadas no ensaio.

\begin{tabular}{l|c|c|c|c|c|c|c|c|c|c|c|c}
\hline Condições avaliadas & 1 & 2 & 3 & 4 & 5 & 6 & 7 & 8 & 9 & 10 & 11 & 12 \\
\hline Umidade (\%) & \multicolumn{3}{|c|}{40} & \multicolumn{3}{|c}{50} & \multicolumn{3}{c|}{60} & \multicolumn{3}{c|}{70} \\
\hline Temperatura ( ${ }^{\circ} \mathrm{C}$ ) & 20 & 30 & 40 & 20 & 30 & 40 & 20 & 30 & 40 & 20 & 30 & 40 \\
\hline
\end{tabular}

$\mathrm{Na}$ programação do equipamento, foi previsto um período de tempo para garantir a estabilização das condições climáticas avaliadas. As três primeiras condições foram mantidas por duas horas cada uma, gerando um maior número de medições estáveis. Ao decorrer do ensaio percebeu-se que uma hora era suficiente para a estabilização da câmara, adotando-se esse novo período para a estabilização das demais condições climáticas, reduzindo-se assim o tempo necessário para a condução do ensaio.

Como explicado no capítulo 4, os dispositivos locais enviam os resultados das medições ao sistema remoto a cada 20 segundos, e esses dados foram utilizados na caracterização. Ao final do ensaio, os resultados foram inspecionados visualmente através da interface gráfica no sistema remoto, e foram separados em períodos de medições estáveis referentes a cada condição climática estudada. $\mathrm{O}$ critério empregado para essa separação foi a obtenção de conjuntos de medições estáveis superior a 30 pontos para cada condição avaliada.

Considerando as diversas fontes de incertezas associadas à realização do ensaio (câmara climática, sensores, etc.), analisou-se a contribuição de cada uma dessas fontes. Para simplificar o procedimento, a incerteza relacionada à nãouniformidade de temperatura no interior da câmara foi desconsiderada. Para essa avaliação utilizou-se o Guia para a expressão de incerteza de medição (ISO GUM) como referência dos procedimentos utilizados.

Segundo o GUM (2008, p. 10), na maioria dos casos, a melhor estimativa do valor esperado de uma grandeza que varia aleatoriamente, obtida através de $n$ observações independentes sob as mesmas condições de medição, é a média aritmética. O guia afirma ainda que o desvio-padrão experimental da média, 
apresentado pela Equação 4, pode ser usado como uma medida da incerteza, sendo a fonte de incerteza Tipo A $\left(u_{A}\right)$ considerada nesse ensaio, admitindo distribuição normal de probabilidade.

$$
u_{A}=\frac{s}{\sqrt{n}}
$$

A especificação da câmara climática, referente ao desvio de umidade e temperatura no tempo informada na tabela 13 , foi considerada como fonte de incerteza Tipo B $\left(u_{B}\right)$ do ensaio. Baseando-se no GUM (2008, p. 13), quando só é informado o intervalo de um parâmetro $a$, e não há conhecimento específico sobre os valores possíveis desse parâmetro em um intervalo informado, é prudente adotarse a distribuição uniforme ou retangular no cálculo da incerteza, conforme a Equação 5.

$$
u_{B}=\frac{a}{\sqrt{3}}
$$

Após o levantamento das incertezas Tipo A e B, obteve-se a incerteza combinada $\left(u_{c}\right)$ conforme a Equação 6.

$$
u_{c}=\sqrt{u_{A}^{2}+u_{B}^{2}}
$$

Por fim, foi calculada a incerteza expandida $(U)$ com fator de abrangência $\mathrm{k}$ $=2$ conforme a Equação 7 .

$$
U=k \cdot u_{c}
$$

Através das diversas condições climáticas avaliadas no ensaio, foi possível analisar as medições apresentadas pelos sensores no que se tange ao erro sistemático desses dispositivos em cenários distintos.

Ao final do ensaio foi calculada a média entre as medições de temperatura registradas por cada sensor, nas diferentes condições de umidade avaliadas. Em seguida, o mesmo procedimento foi aplicado nas medições de umidade, adquiridas nas diversas temperaturas propostas pelo ensaio. 
Essa conduta permitiu avaliar a influência da umidade nas medições de temperatura realizadas pelos sensores e, em seguida, a influência da temperatura nas medições de umidade realizadas pelos mesmos.

Por fim, foi calculada uma regressão linear para cada sensor ajustando suas medições aos valores programados na câmara climática. A programação da câmara foi baseada em valores de umidade e temperatura comumente encontrados em ambientes internos, pretendendo-se com isso conferir às medições ajustadas maior imunidade às variações climáticas em cenários reais.

\section{7}

\section{Monitoramento de ambientes internos}

Para se compreender o comportamento dos parâmetros ligados à qualidade do ar em ambientes internos, se faz necessário o monitoramento de ambientes distintos e variadas dinâmicas de ocupação. As seções a seguir descrevem os ensaios realizados com esse objetivo, e uma ferramenta para avaliação das propagações espaciais do dióxido de carbono.

\subsection{1 \\ Monitoramento em sala de pesquisa}

Os dispositivos locais foram distribuídos em uma sala de pesquisa (PUCRio), conforme mostrado na Figura 7, composta por dois compartimentos (salas A e B) interligados por uma porta de passagem.

As portas, principal e entre as salas, e os aparelhos de ar condicionado que operam sem renovação de ar, podem ser observados na Figura 7. O dispositivo local 5 foi posicionado no local de maior ventilação do ambiente, próximo à porta principal. 


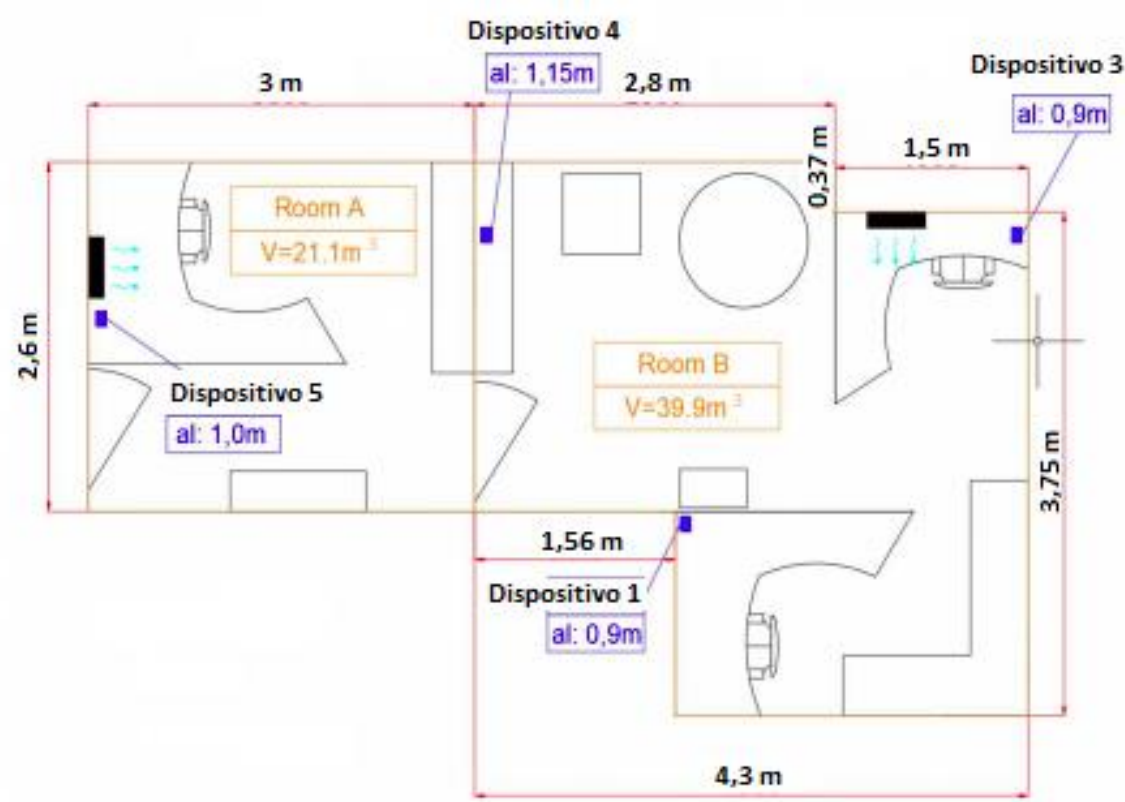

Figura 7 - Planta da sala de pesquisa e posicionamento dos dispositivos locais no ensaio.

Fonte: Adaptado de Thiago et al. (2021).

\subsection{2}

\section{Monitoramento em sala de aula}

Ensaios realizados numa sala de aula tiveram como objetivo estudar a propagação plana das concentrações de $\mathrm{CO}_{2}$, e avaliar poluentes ligados à qualidade do ar quanto ao atendimento a normas vigentes. A sala possui dimensões 7,20 $\mathrm{m}$ de comprimento por 7,30 m de largura e altura de 3,1 m, e em seu interior são dispostas 12 bancadas, organizadas em 3 colunas paralelas ao comprimento da sala (Figura 8 e Figura 9). As aulas, com 2 horas de duração, são ministradas a 20 alunos.

Os sensores foram distribuídos na sala de aula em posições estratégicas para avaliação da distribuição espacial dos poluentes em questão, por meio de comparação entre as séries temporais registradas pelos sensores. Divergências entre essas séries foram confrontadas com dinâmicas de ocupação observadas no espaço analisado.

No primeiro dia de ensaio realizado na sala de aula, os dispositivos locais foram distribuídos em 4 bancadas a uma mesma altura do piso. Para simplificar a análise as bancadas avaliadas no ensaio estão referenciadas como A, B, C e D, onde o posicionamento das mesmas na sala de aula pode ser observado na Figura 8. 


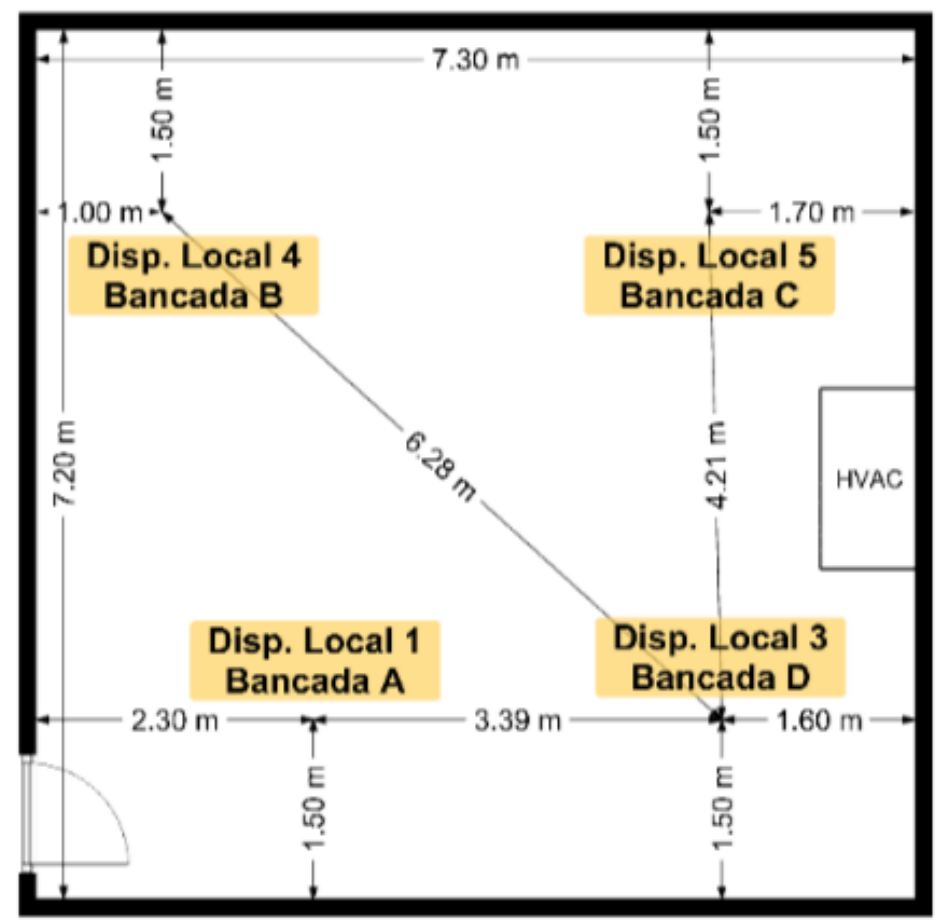

Figura 8 - Posicionamento dos sensores na sala de aula no primeiro dia de ensaio.

Assim, no primeiro ensaio foi avaliada a propagação plana das concentrações de $\mathrm{CO}_{2}$ em diversos pontos da sala de aula a uma altura de $76 \mathrm{~cm}$ do piso.

No segundo ensaio avaliou-se a propagação plana das concentrações de $\mathrm{CO}_{2}$ em duas alturas distintas em relação ao piso da sala de aula $(76 \mathrm{~cm}$ e $179 \mathrm{~cm})$. Para tal, foi instalado um par de dispositivos locais na bancada A, e outro par na bancada B, conforme a Figura 9. 


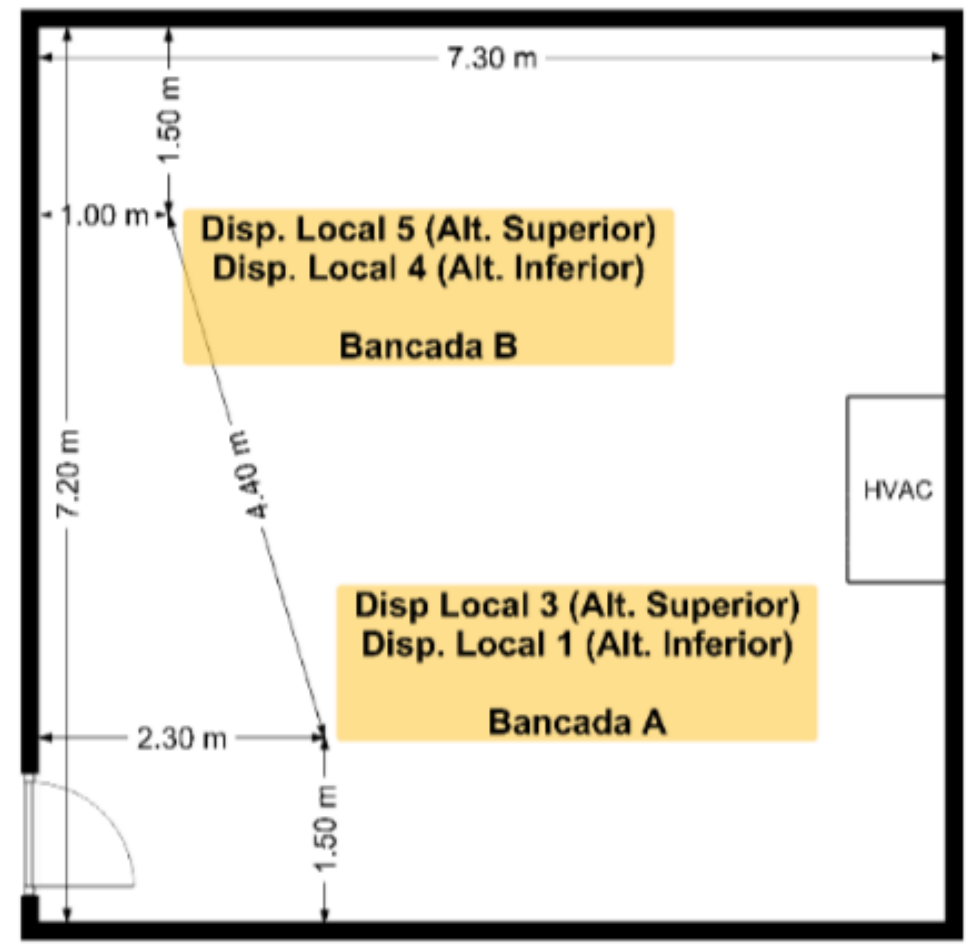

Figura 9 - Posicionamento dos sensores na sala de aula no segundo dia de aula.

\subsection{3}

\section{Avaliação de propagações espaciais de concentrações de $\mathrm{CO}_{2}$ através de séries temporais}

O comportamento de parâmetros ligados à qualidade do ar é registrado em forma de séries temporais no sistema de monitoramento proposto. Para avaliar a propagação desses parâmetros em ambientes internos, em especial as concentrações de $\mathrm{CO}_{2}$ que foram analisadas, se faz necessário o emprego de uma ferramenta específica para a comparação de séries temporais.

O Dynamic Time Wraping (DTW) é uma técnica que busca o alinhamento entre duas séries temporais que possam ter sofrido distorções não lineares, dilatadas ou comprimidas em seus eixos temporais. As distorções em questão podem ser úteis para se encontrar regiões comuns entre séries temporais, revelando similaridades entre as mesmas [63].

A técnica é amplamente utilizada em reconhecimento de voz, permitindo que formas de onda oriundas de palavras sejam reconhecidas, mesmo sendo pronunciadas em velocidades distintas. Além disso, encontram-se usos do DTW 
como medida de distância entre séries temporais em mineração de dados, reconhecimento gestual, medicina, entre outros [63].

Caso as séries sejam idênticas o valor retornado pelo algoritmo é zero. A cada divergência encontrada entre as séries esse valor retornado vai sendo incrementando. Como cada elemento de uma série é comparado com todos os elementos da outra, o DTW demanda um alto custo computacional. Utilizando-se a notação de complexidade de algoritmos (Big O), a técnica apresenta complexidade de $\mathrm{O}\left(\mathrm{N}^{2}\right)$ caso as séries tenham o mesmo número de elementos, penalizando seu uso em séries temporais longas.

Para amenizar essa questão, o FastDTW introduzido por Salvador e Chan (2007) é uma implementação do algoritmo original que atinge complexidade da ordem de $\mathrm{O}(\mathrm{N})$, sendo mais eficiente que a versão original.

Basicamente, o FastDTW reduz a resolução das séries temporais avaliadas através da média entre os pontos adjacentes de cada série. Em seguida, através de diversas iterações, o algoritmo incrementa a resolução das séries e recalcula a similaridades entre as mesmas. As iterações são interrompidas quando o algoritmo detecta uma convergência do valor de similaridade entre as séries.

Para eliminar da análise fontes de ruído, as séries temporais das concentrações de $\mathrm{CO}_{2}$ foram reagrupadas a cada 5 minutos, fazendo uso de média como função de agregação. Em função de possíveis divergências entre as curvas de calibração e construção dos sensores, todas as séries, antes de serem analisadas pelo FastDTW, foram normalizadas entre 0 e 1 , permitindo assim que o algoritmo capturasse apenas a variação do poluente em questão, evitando a introdução de algum possível viés na análise. 


\section{5 \\ Resultados}

Neste capítulo 5 são exibidos os resultados que foram obtidos nos diversos ensaios realizados na presente pesquisa, incluindo a caracterização dos dispositivos e o mapeamento espacial dos parâmetros ambientais realizados em duas modalidades de ambientes internos localizados em Campus Universitário da Pontifícia Universidade Católica do Rio de Janeiro.

\section{1.}

\section{Caracterização de sensores de Dióxido de Carbono}

No ensaio de caracterização dos sensores de dióxido de carbono, os dispositivos foram posicionados em uma câmara hermeticamente fechada, em um ambiente sem ocupação humana. Das séries de dados obtidas no ensaio, foi selecionado um período de 70 minutos correspondente à área sombreada na Figura 10, onde observou-se maior estabilidade da concentração de $\mathrm{CO}_{2}$ durante o ensaio.

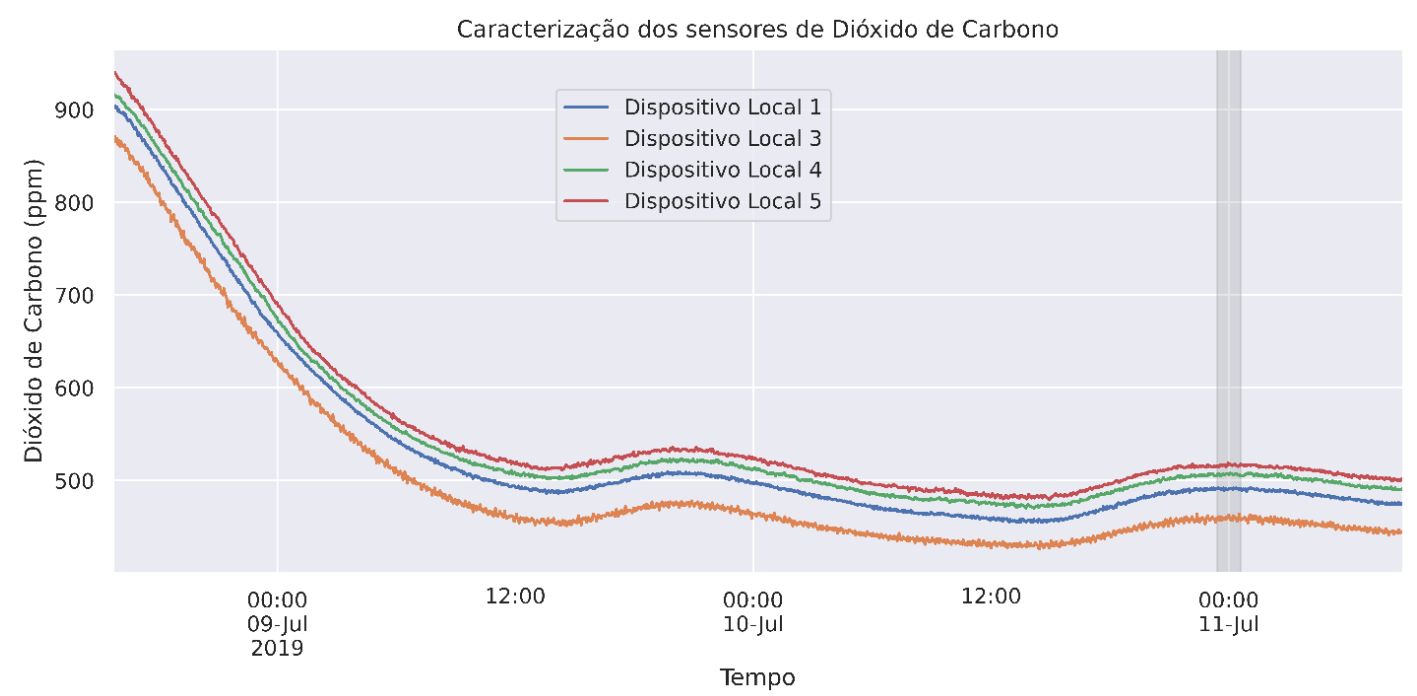

Figura 10 - Ensaio de caracterização dos sensores de CO2. 
O gráfico da Figura 11 exibe a dispersão das séries de medições durante o período selecionado, e a estatística descritiva pode ser observada na Tabela 14.

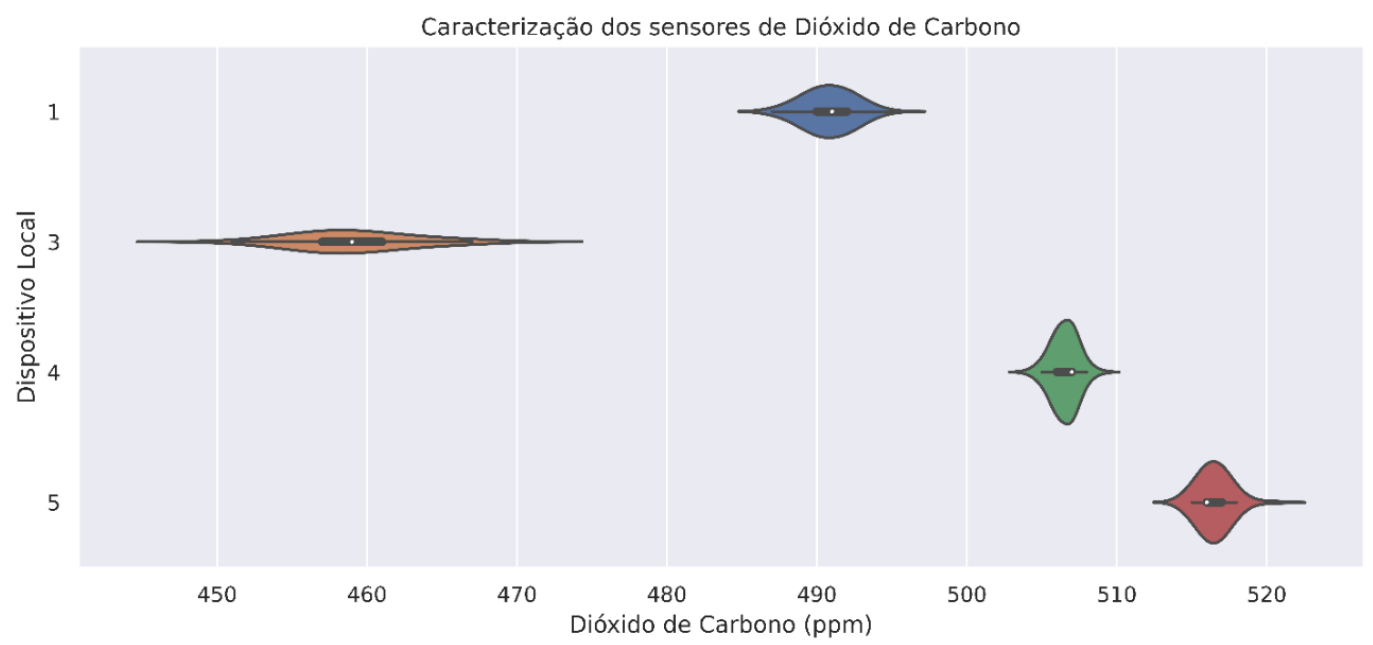

Figura 11 - Distribuição das series de dados durante o período de estabilidade do ensaio de caracterização dos sensores de $\mathrm{CO}_{2}$.

Tabela 14 - Estatística descritiva das series de dados do ensaio de caracterização dos sensores de $\mathrm{CO}_{2}$.

\begin{tabular}{lccccc}
\hline \multicolumn{7}{c}{ Dispositivo Local } \\
\hline Média & $\mathbf{1}$ & $\mathbf{3}$ & $\mathbf{4}$ & $\mathbf{5}$ & \\
\hline Erro Padrão & 490,78 & 459,15 & 506,48 & 516,48 & $\mathrm{ppm}$ \\
\hline Moda & 0,11 & 0,26 & 0,05 & 0,08 & $\mathrm{ppm}$ \\
\hline Mediana & 490 & 457 & 507 & 517 & $\mathrm{ppm}$ \\
\hline Variância & 491 & 459 & 506,6 & 516,3 & $\mathrm{ppm}$ \\
\hline Desvio Padrão & 2,49 & 14,59 & 0,63 & 1,23 & $\mathrm{ppm}^{2}$ \\
\hline Curtose & 1,58 & 3,82 & 0,79 & 1,11 & $\mathrm{ppm}$ \\
\hline Simetria & $-0,27$ & $-0,04$ & 0,19 & 2,69 & --- \\
\hline Faixa & $-0,11$ & 0,40 & $-0,25$ & 0,93 & --- \\
\hline Mínimo & 8 & 19 & 4,8 & 7,3 & $\mathrm{ppm}$ \\
\hline Máximo & 487 & 450 & 504 & 514 & $\mathrm{ppm}$ \\
\hline Amostras & 495 & 469 & 508,8 & 521,3 & $\mathrm{ppm}$ \\
\hline & 210 & 210 & 210 & 210 & --- \\
\hline
\end{tabular}

Observa-se pelo gráfico da Figura 11 que as séries de concentrações de $\mathrm{CO}_{2}$ durante o ensaio seguiram uma distribuição normal, fato corroborado pelos valores de curtose próximos a zero disponíveis na Tabela 14, exceto pelo Dispositivo Local 5 , devido à possível presença de outliers na série. As distribuições das 4 séries apresentaram simetria em torno da média, e o Dispositivo Local 3 apresentou desvio padrão superior aos demais. 
Pelos resultados informados na Tabela 14, pode se observar uma diferença entre as médias dos valores apresentados pelos sensores durante o ensaio. Seguindo a orientação do fabricante dos sensores de $\mathrm{CO}_{2}$ (Seção 4.3.1 Sensores de Dióxido de Carbono), o ajuste de zero com o gás $\mathrm{N}_{2}$ foi executado em todos os sensores disponíveis (Seção 4.5 Caracterização dos Sensores de Dióxido de Carbono). Como foi efetuado o ajuste, a diferença entre as médias foi desconsiderada, e os valores da levantados durante o ensaio (Tabela 14) foram utilizados para avaliar o atendimento dos sensores ao regulamento ambiental vigente.

\section{2.}

\section{Caracterização de sensores em câmara climática}

No ensaio em questão, realizaram-se medições em 12 condições climáticas distintas, proporcionadas pelo ajuste de valores de umidade e temperatura no interior de uma câmara climática. Os gráficos da Figura 12 ilustram as medições realizadas pelos sensores de umidade (Figura 11a) e temperatura (Figura 11b) de cada dispositivo local no interior da câmara, durante as condições climáticas avaliadas, destacando-se os 12 períodos de estabilidade.

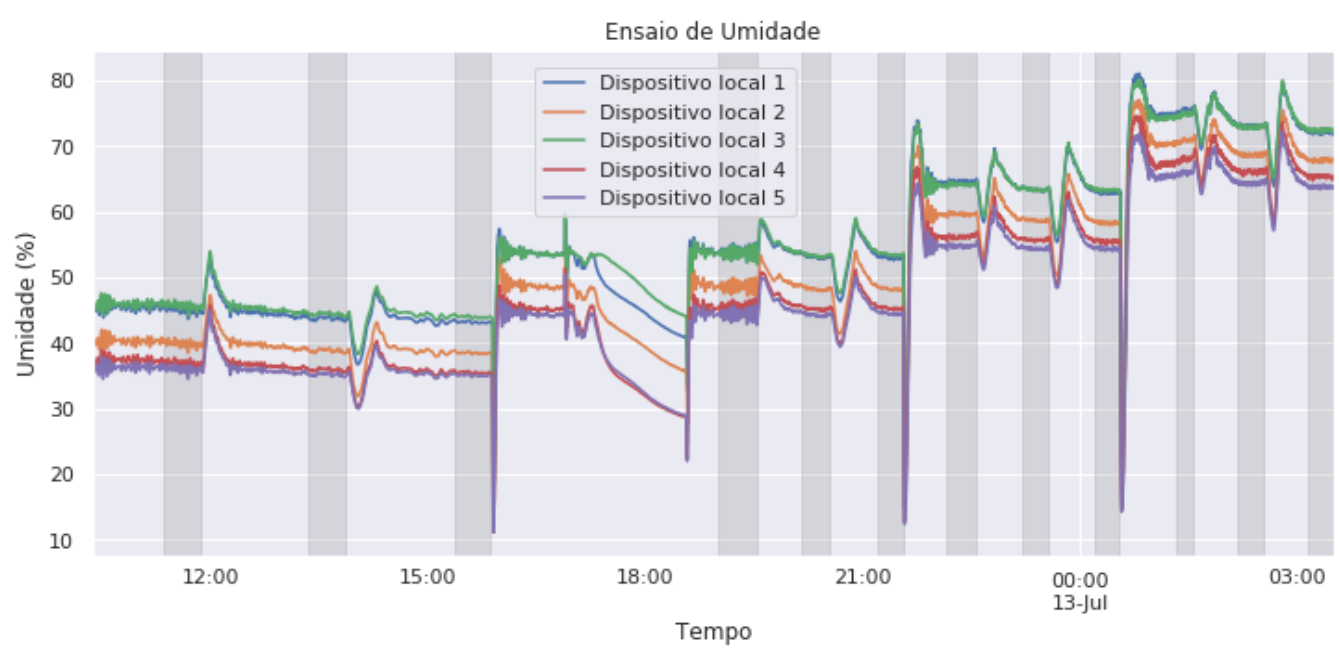




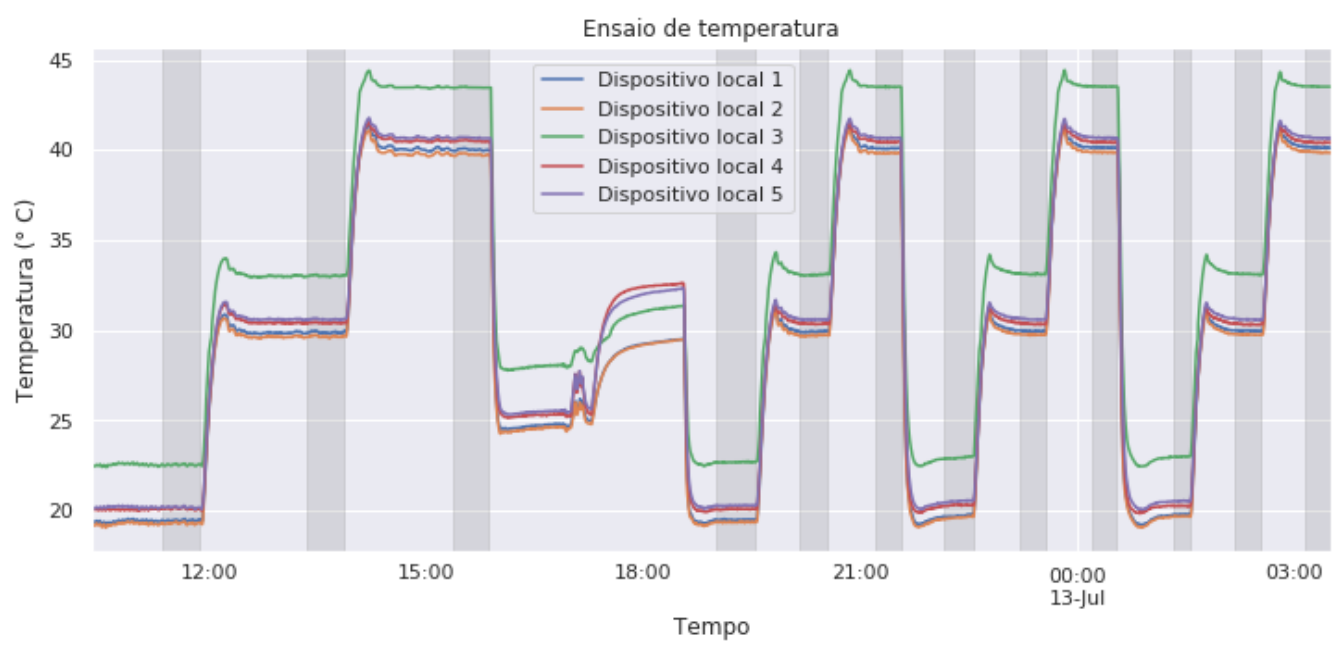

b)

Figura 12 - Condições climáticas registradas pelos sensores durante o ensaio em câmara climática.

Dos dados apresentados na Figura 12, foram separadas séries de medições estáveis referentes a cada condição climática avaliada, que aparecem em destaque na própria Figura 11. Em seguida foram estimadas as incertezas Tipos A e B, incerteza combinada e incerteza expandida para cada dispositivo avaliado no ensaio.

A Tabela 15 informa os valores das incertezas identificadas no ensaio, referentes às medições de temperatura, onde $n$ é o número de amostras, $T_{a}$ é o valor de temperatura ajustado na câmara, $T$ é a média entre valores de temperatura registrados pelos sensores, $s$ é o desvio padrão entre as medições, $u_{A}, u_{B}, u_{c}$ e $U$ são as incertezas Tipo A e B, incerteza combinada e incerteza expandida com $\mathrm{k}=$ 2. Já a Tabela 16, traz as mesmas informações, porém voltadas às medições de umidade. 
Tabela 15 - Incertezas referentes à temperatura, estimadas no ensaio da câmara climática.

\begin{tabular}{|c|c|c|c|c|c|c|c|c|c|}
\hline & Dispositil & $n$ & $T_{a}\left({ }^{\circ} \boldsymbol{C}\right)$ & $\boldsymbol{T}\left({ }^{\circ} \boldsymbol{C}\right)$ & $\boldsymbol{s}\left({ }^{\circ} \boldsymbol{C}\right)$ & $\boldsymbol{u}_{\boldsymbol{A}}\left({ }^{\circ} \boldsymbol{C}\right)$ & $\boldsymbol{u}_{B}\left({ }^{\circ} \boldsymbol{C}\right)$ & $\boldsymbol{u}_{\boldsymbol{c}}\left({ }^{\circ} \boldsymbol{C}\right)$ & $\boldsymbol{U}\left({ }^{\circ} \boldsymbol{C}\right)$ \\
\hline & 4 & 93 & 20 & 20,09 & 0,05 & 0,005 & 0,289 & 0,289 & 0,58 \\
\hline Condição 1 & 5 & 93 & 20 & 20,17 & 0,04 & 0,004 & 0,289 & 0,289 & 0,58 \\
\hline $\mathrm{T}=20^{\circ} \mathrm{C}$ & 1 & 93 & 20 & 19,44 & 0,04 & 0,004 & 0,289 & 0,289 & 0,58 \\
\hline \multirow[t]{3}{*}{$\mathrm{RH}=\mathbf{4 0} \%$} & 2 & 93 & 20 & 19,28 & 0,05 & 0,005 & 0,289 & 0,289 & 0,58 \\
\hline & 3 & 93 & 20 & 22,52 & 0,04 & 0,004 & 0,289 & 0,289 & 0,58 \\
\hline & 4 & 94 & 30 & 30,40 & 0,03 & 0,003 & 0,289 & 0,289 & 0,58 \\
\hline Condição 2 & 5 & 94 & 30 & 30,59 & 0,02 & 0,002 & 0,289 & 0,289 & 0,58 \\
\hline $\mathrm{T}=30^{\circ} \mathrm{C}$ & 1 & 94 & 30 & 29,87 & 0,04 & 0,004 & 0,289 & 0,289 & 0,58 \\
\hline \multirow[t]{3}{*}{$\mathrm{RH}=\mathbf{4 0} \%$} & 2 & 94 & 30 & 29,64 & 0,04 & 0,004 & 0,289 & 0,289 & 0,58 \\
\hline & 3 & 94 & 30 & 33,01 & 0,03 & 0,003 & 0,289 & 0,289 & 0,58 \\
\hline & 4 & 92 & 40 & 40,49 & 0,03 & 0,003 & 0,289 & 0,289 & 0,58 \\
\hline Condição 3 & 5 & 92 & 40 & 40,66 & 0,03 & 0,004 & 0,289 & 0,289 & 0,58 \\
\hline $\mathrm{T}=40^{\circ} \mathrm{C}$ & 1 & 92 & 40 & 40,00 & 0,04 & 0,005 & 0,289 & 0,289 & 0,58 \\
\hline \multirow[t]{3}{*}{$\mathrm{RH}=\mathbf{4 0} \%$} & 2 & 92 & 40 & 39,74 & 0,05 & 0,005 & 0,289 & 0,289 & 0,58 \\
\hline & 3 & 92 & 40 & 43,46 & 0,02 & 0,002 & 0,289 & 0,289 & 0,58 \\
\hline & 4 & 95 & 20 & 20,07 & 0,02 & 0,002 & 0,289 & 0,289 & 0,58 \\
\hline \multirow{4}{*}{$\begin{array}{c}\text { Condição } 4 \\
\mathrm{~T}=20^{\circ} \mathrm{C} \\
\mathrm{RH}=50 \%\end{array}$} & 5 & 95 & 20 & 20,26 & 0,02 & 0,002 & 0,289 & 0,289 & 0,58 \\
\hline & 1 & 95 & 20 & 19,46 & 0,02 & 0,002 & 0,289 & 0,289 & 0,58 \\
\hline & 2 & 94 & 20 & 19,34 & 0,02 & 0,002 & 0,289 & 0,289 & 0,58 \\
\hline & 3 & 95 & 20 & 22,67 & 0,02 & 0,002 & 0,289 & 0,289 & 0,58 \\
\hline \multirow{5}{*}{$\begin{array}{c}\text { Condição } 5 \\
\mathrm{~T}=30^{\circ} \mathrm{C} \\
\mathrm{RH}=50 \%\end{array}$} & 4 & 73 & 30 & 30,35 & 0,02 & 0,002 & 0,289 & 0,289 & 0,58 \\
\hline & 5 & 73 & 30 & 30,58 & 0,02 & 0,002 & 0,289 & 0,289 & 0,58 \\
\hline & 1 & 73 & 30 & 29,90 & 0,03 & 0,003 & 0,289 & 0,289 & 0,58 \\
\hline & 2 & 73 & 30 & 29,70 & 0,03 & 0,003 & 0,289 & 0,289 & 0,58 \\
\hline & 3 & 72 & 30 & 33,06 & 0,03 & 0,003 & 0,289 & 0,289 & 0,58 \\
\hline \multirow{5}{*}{$\begin{array}{c}\text { Condição } 6 \\
T=40^{\circ} \mathrm{C} \\
\mathrm{RH}=50 \%\end{array}$} & 4 & 66 & 40 & 40,43 & 0,02 & 0,003 & 0,289 & 0,289 & 0,58 \\
\hline & 5 & 66 & 40 & 40,65 & 0,02 & 0,003 & 0,289 & 0,289 & 0,58 \\
\hline & 1 & 66 & 40 & 40,07 & 0,02 & 0,003 & 0,289 & 0,289 & 0,58 \\
\hline & 2 & 64 & 40 & 39,81 & 0,02 & 0,003 & 0,289 & 0,289 & 0,58 \\
\hline & 3 & 65 & 40 & 43,49 & 0,01 & 0,002 & 0,289 & 0,289 & 0,58 \\
\hline \multirow{5}{*}{$\begin{array}{c}\text { Condição } 7 \\
T=20^{\circ} \mathrm{C} \\
\mathrm{RH}=60 \%\end{array}$} & 4 & 70 & 20 & 20,28 & 0,02 & 0,003 & 0,289 & 0,289 & 0,58 \\
\hline & 5 & 70 & 20 & 20,50 & 0,04 & 0,004 & 0,289 & 0,289 & 0,58 \\
\hline & 1 & 69 & 20 & 19,69 & 0,04 & 0,005 & 0,289 & 0,289 & 0,58 \\
\hline & 2 & 69 & 20 & 19,59 & 0,04 & 0,005 & 0,289 & 0,289 & 0,58 \\
\hline & 3 & 70 & 20 & 22,91 & 0,04 & 0,005 & 0,289 & 0,289 & 0,58 \\
\hline \multirow{5}{*}{$\begin{array}{c}\text { Condição } 8 \\
T=30^{\circ} \mathrm{C} \\
\mathrm{RH}=60 \%\end{array}$} & 4 & 62 & 30 & 30,34 & 0,03 & 0,003 & 0,289 & 0,289 & 0,58 \\
\hline & 5 & 61 & 30 & 30,59 & 0,02 & 0,003 & 0,289 & 0,289 & 0,58 \\
\hline & 1 & 61 & 30 & 29,94 & 0,02 & 0,002 & 0,289 & 0,289 & 0,58 \\
\hline & 2 & 60 & 30 & 29,73 & 0,01 & 0,002 & 0,289 & 0,289 & 0,58 \\
\hline & 3 & 61 & 30 & 33,10 & 0,02 & 0,002 & 0,289 & 0,289 & 0,58 \\
\hline \multirow{5}{*}{$\begin{array}{c}\text { Condição } 9 \\
\mathrm{~T}=40^{\circ} \mathrm{C} \\
\mathrm{RH}=60 \%\end{array}$} & 4 & 63 & 40 & 40,42 & 0,02 & 0,003 & 0,289 & 0,289 & 0,58 \\
\hline & 5 & 63 & 40 & 40,67 & 0,02 & 0,003 & 0,289 & 0,289 & 0,58 \\
\hline & 1 & 62 & 40 & 40,12 & 0,02 & 0,002 & 0,289 & 0,289 & 0,58 \\
\hline & 2 & 61 & 40 & 39,87 & 0,02 & 0,002 & 0,289 & 0,289 & 0,58 \\
\hline & 3 & 63 & 40 & 43,51 & 0,01 & 0,001 & 0,289 & 0,289 & 0,58 \\
\hline \multirow{5}{*}{$\begin{array}{c}\text { Condição } 10 \\
T=20^{\circ} \mathrm{C} \\
\mathrm{RH}=70 \%\end{array}$} & 4 & 40 & 20 & 20,24 & 0,02 & 0,002 & 0,289 & 0,289 & 0,58 \\
\hline & 5 & 40 & 20 & 20,52 & 0,02 & 0,002 & 0,289 & 0,289 & 0,58 \\
\hline & 1 & 39 & 20 & 19,75 & 0,02 & 0,003 & 0,289 & 0,289 & 0,58 \\
\hline & 2 & 39 & 20 & 19,66 & 0,01 & 0,002 & 0,289 & 0,289 & 0,58 \\
\hline & 3 & 40 & 20 & 22,97 & 0,01 & 0,002 & 0,289 & 0,289 & 0,58 \\
\hline \multirow{5}{*}{$\begin{array}{c}\text { Condição } 11 \\
\qquad \begin{array}{c}\mathrm{T}=30^{\circ} \mathrm{C} \\
\mathrm{RH}=70 \%\end{array}\end{array}$} & 4 & 61 & 30 & 30,32 & 0,02 & 0,003 & 0,289 & 0,289 & 0,58 \\
\hline & 5 & 61 & 30 & 30,58 & 0,02 & 0,002 & 0,289 & 0,289 & 0,58 \\
\hline & 1 & 60 & 30 & 29,96 & 0,02 & 0,002 & 0,289 & 0,289 & 0,58 \\
\hline & 2 & 60 & 30 & 29,75 & 0,01 & 0,002 & 0,289 & 0,289 & 0,58 \\
\hline & 3 & 61 & 30 & 33,10 & 0,02 & 0,002 & 0,289 & 0,289 & 0,58 \\
\hline \multirow{5}{*}{$\begin{array}{c}\text { Condição } 12 \\
T=40^{\circ} \mathrm{C} \\
\mathrm{RH}=70 \%\end{array}$} & 4 & 75 & 40 & 40,40 & 0,03 & 0,003 & 0,289 & 0,289 & 0,58 \\
\hline & 5 & 75 & 40 & 40,67 & 0,02 & 0,003 & 0,289 & 0,289 & 0,58 \\
\hline & 1 & 74 & 40 & 40,13 & 0,02 & 0,003 & 0,289 & 0,289 & 0,58 \\
\hline & 2 & 74 & 40 & 39,87 & 0,02 & 0,003 & 0,289 & 0,289 & 0,58 \\
\hline & 3 & 73 & 40 & 43,51 & 0,01 & 0,001 & 0,289 & 0,289 & 0,58 \\
\hline
\end{tabular}

Tabela 16 - Incertezas referentes aos valores de umidade levantadas no ensaio.

\begin{tabular}{lllllllll} 
Disposit & $n$ & $H_{a}(\%)$ & $H(\%)$ & $\boldsymbol{s}(\%)$ & $\boldsymbol{u}_{A}(\%)$ & $\boldsymbol{u}_{B}(\%)$ & $\boldsymbol{u}_{\boldsymbol{c}}(\%)$ & $\boldsymbol{U}(\%)$ \\
\hline
\end{tabular} 


\begin{tabular}{|c|c|c|c|c|c|c|c|c|c|}
\hline Condiçã & 4 & 93 & 40 & 36,84 & 0,49 & 0,050 & 1,732 & 1,733 & 3,47 \\
\hline 01 & 5 & 93 & 40 & 35,95 & 0,47 & 0,049 & 1,732 & 1,733 & 3,47 \\
\hline $\mathrm{T}=20^{\circ} \mathrm{C}$ & 1 & 93 & 40 & 45,07 & 0,52 & 0,053 & 1,732 & 1,733 & 3,47 \\
\hline $\mathrm{RH}=\mathbf{4 0}$ & 2 & 93 & 40 & 39,85 & 0,49 & 0,051 & 1,732 & 1,733 & 3,47 \\
\hline$\%$ & 3 & 93 & 40 & 45,65 & 0,48 & 0,050 & 1,732 & 1,733 & 3,47 \\
\hline Condiçã & 4 & 94 & 40 & 35,86 & 0,21 & 0,021 & 1,732 & 1,732 & 3,46 \\
\hline 02 & 5 & 94 & 40 & 35,14 & 0,20 & 0,020 & 1,732 & 1,732 & 3,46 \\
\hline $\mathrm{T}=30^{\circ} \mathrm{C}$ & 1 & 94 & 40 & 43,70 & 0,22 & 0,023 & 1,732 & 1,732 & 3,46 \\
\hline $\mathrm{RH}=\mathbf{4 0}$ & 2 & 94 & 40 & 38,81 & 0,23 & 0,023 & 1,732 & 1,732 & 3,46 \\
\hline$\%$ & 3 & 94 & 40 & 44,35 & 0,22 & 0,022 & 1,732 & 1,732 & 3,46 \\
\hline Condiçã & 4 & 92 & 40 & 35,47 & 0,14 & 0,015 & 1,732 & 1,732 & 3,46 \\
\hline 03 & 5 & 92 & 40 & 35,03 & 0,13 & 0,013 & 1,732 & 1,732 & 3,46 \\
\hline $\mathrm{T}=40^{\circ} \mathrm{C}$ & 1 & 92 & 40 & 43,15 & 0,14 & 0,015 & 1,732 & 1,732 & 3,46 \\
\hline $\mathrm{RH}=\mathbf{4 0}$ & 2 & 92 & 40 & 38,46 & 0,15 & 0,015 & 1,732 & 1,732 & 3,46 \\
\hline$\%$ & 3 & 92 & 40 & 43,96 & 0,15 & 0,016 & 1,732 & 1,732 & 3,46 \\
\hline Condiçã & 4 & 95 & 50 & 45,25 & 0,76 & 0,078 & 1,732 & 1,734 & 3,47 \\
\hline 04 & 5 & 95 & 50 & 44,29 & 0,73 & 0,075 & 1,732 & 1,734 & 3,47 \\
\hline $\mathrm{T}=20^{\circ} \mathrm{C}$ & 1 & 95 & 50 & 53,77 & 0,73 & 0,075 & 1,732 & 1,734 & 3,47 \\
\hline $\mathrm{RH}=50$ & 2 & 94 & 50 & 48,56 & 0,76 & 0,079 & 1,732 & 1,734 & 3,47 \\
\hline$\%$ & 3 & 95 & 50 & 53,62 & 0,73 & 0,075 & 1,732 & 1,734 & 3,47 \\
\hline Condiçã & 4 & 73 & 50 & 45,19 & 0,20 & 0,023 & 1,732 & 1,732 & 3,46 \\
\hline 05 & 5 & 73 & 50 & 44,27 & 0,20 & 0,023 & 1,732 & 1,732 & 3,46 \\
\hline $\mathrm{T}=30^{\circ} \mathrm{C}$ & 1 & 73 & 50 & 53,15 & 0,24 & 0,028 & 1,732 & 1,732 & 3,46 \\
\hline $\mathbf{R H}=\mathbf{5 0}$ & 2 & 73 & 50 & 48,23 & 0,24 & 0,028 & 1,732 & 1,732 & 3,46 \\
\hline$\%$ & 3 & 72 & 50 & 53,32 & 0,22 & 0,026 & 1,732 & 1,732 & 3,46 \\
\hline Condiçã & 4 & 66 & 50 & 45,27 & 0,17 & 0,021 & 1,732 & 1,732 & 3,46 \\
\hline 06 & 5 & 66 & 50 & 44,50 & 0,17 & 0,021 & 1,732 & 1,732 & 3,46 \\
\hline $\mathrm{T}=40^{\circ} \mathrm{C}$ & 1 & 66 & 50 & 52,97 & 0,17 & 0,021 & 1,732 & 1,732 & 3,46 \\
\hline $\mathrm{RH}=\mathbf{5 0}$ & 2 & 64 & 50 & 48,23 & 0,17 & 0,021 & 1,732 & 1,732 & 3,46 \\
\hline$\%$ & 3 & 65 & 50 & 53,47 & 0,17 & 0,021 & 1,732 & 1,732 & 3,46 \\
\hline Condiçã & 4 & 70 & 60 & 56,17 & 0,21 & 0,025 & 1,732 & 1,732 & 3,46 \\
\hline 07 & 5 & 70 & 60 & 54,74 & 0,19 & 0,022 & 1,732 & 1,732 & 3,46 \\
\hline $\mathrm{T}=20^{\circ} \mathrm{C}$ & 1 & 69 & 60 & 64,56 & 0,18 & 0,022 & 1,732 & 1,732 & 3,46 \\
\hline $\mathrm{RH}=60$ & 2 & 69 & 60 & 59,59 & 0,18 & 0,022 & 1,732 & 1,732 & 3,46 \\
\hline$\%$ & 3 & 70 & 60 & 64,11 & 0,17 & 0,021 & 1,732 & 1,732 & 3,46 \\
\hline Condiçã & 4 & 62 & 60 & 55,70 & 0,13 & 0,017 & 1,732 & 1,732 & 3,46 \\
\hline 08 & 5 & 61 & 60 & 54,35 & 0,14 & 0,018 & 1,732 & 1,732 & 3,46 \\
\hline $\mathrm{T}=30^{\circ} \mathrm{C}$ & 1 & 61 & 60 & 63,36 & 0,16 & 0,021 & 1,732 & 1,732 & 3,46 \\
\hline $\mathrm{RH}=60$ & 2 & 60 & 60 & 58,67 & 0,16 & 0,020 & 1,732 & 1,732 & 3,46 \\
\hline$\%$ & 3 & 61 & 60 & 63,36 & 0,16 & 0,021 & 1,732 & 1,732 & 3,46 \\
\hline Condiçã & 4 & 63 & 60 & 55,50 & 0,20 & 0,025 & 1,732 & 1,732 & 3,46 \\
\hline 09 & 5 & 63 & 60 & 54,35 & 0,18 & 0,022 & 1,732 & 1,732 & 3,46 \\
\hline $\mathrm{T}=40^{\circ} \mathrm{C}$ & 1 & 62 & 60 & 62,92 & 0,15 & 0,019 & 1,732 & 1,732 & 3,46 \\
\hline $\mathrm{RH}=60$ & 2 & 61 & 60 & 58,31 & 0,18 & 0,023 & 1,732 & 1,732 & 3,46 \\
\hline$\%$ & 3 & 63 & 60 & 63,29 & 0,14 & 0,018 & 1,732 & 1,732 & 3,46 \\
\hline Condiçã & 4 & 40 & 70 & 67,95 & 0,33 & 0,053 & 1,732 & 1,733 & 3,47 \\
\hline 010 & 5 & 40 & 70 & 65,87 & 0,27 & 0,043 & 1,732 & 1,733 & 3,47 \\
\hline $\mathrm{T}=20^{\circ} \mathrm{C}$ & 1 & 39 & 70 & 75,30 & 0,26 & 0,042 & 1,732 & 1,733 & 3,47 \\
\hline $\mathrm{RH}=70$ & 2 & 39 & 70 & 70,76 & 0,24 & 0,039 & 1,732 & 1,732 & 3,46 \\
\hline$\%$ & 3 & 40 & 70 & 74,79 & 0,26 & 0,041 & 1,732 & 1,733 & 3,47 \\
\hline Condiçã & 4 & 61 & 70 & 66,10 & 0,25 & 0,032 & 1,732 & 1,732 & 3,46 \\
\hline o 11 & 5 & 61 & 70 & 64,31 & 0,22 & 0,028 & 1,732 & 1,732 & 3,46 \\
\hline $\mathrm{T}=30^{\circ} \mathrm{C}$ & 1 & 60 & 70 & 73,00 & 0,19 & 0,025 & 1,732 & 1,732 & 3,46 \\
\hline $\mathbf{R H}=70$ & 2 & 60 & 70 & 68,68 & 0,20 & 0,026 & 1,732 & 1,732 & 3,46 \\
\hline$\%$ & 3 & 61 & 70 & 72,93 & 0,20 & 0,026 & 1,732 & 1,732 & 3,46 \\
\hline Condiçã & 4 & 75 & 70 & 65,37 & 0,20 & 0,023 & 1,732 & 1,732 & 3,46 \\
\hline o 12 & 5 & 75 & 70 & 63,81 & 0,18 & 0,021 & 1,732 & 1,732 & 3,46 \\
\hline $\mathrm{T}=40^{\circ} \mathrm{C}$ & 1 & 74 & 70 & 72,13 & 0,20 & 0,023 & 1,732 & 1,732 & 3,46 \\
\hline $\mathrm{RH}=70$ & 2 & 74 & 70 & 67,85 & 0,19 & 0,023 & 1,732 & 1,732 & 3,46 \\
\hline$\%$ & 3 & 73 & 70 & 72,42 & 0,18 & 0,022 & 1,732 & 1,732 & 3,46 \\
\hline
\end{tabular}

A incerteza Tipo B presente na especificação da câmara climática foi superior à incerteza Tipo A apresentada pelos sensores de umidade e temperatura dos 
dispositivos locais durante as condições climáticas avaliadas. Com isso, a contribuição da incerteza Tipo A teve pouca influência no cálculo das incertezas combinada e expandida.

Evidencia-se, na Tabela 15 e na Tabela 16, que a incerteza Tipo B, associada às especificações da câmara climática, superou a contribuição da incerteza Tipo A referente aos sensores de umidade e temperatura de cada um dos cinco dispositivos locais.

Ao final do ensaio, foi calculada uma regressão linear para os resultados das medições com os sensores de temperatura e umidade de cada dispositivo local, a fim de se corrigir os valores registrados pelos mesmos em relação aos valores ajustados na câmara climática. A Tabela 17 informa os parâmetros obtidos pela regressão linear em cada dispositivo local, onde $r^{2}$ é o coeficiente de regressão, $a$ e $b$ são os coeficientes angular e linear da curva ajustada pela regressão.

Tabela 17 - Parâmetros obtidos pela regressão linear no ensaio de temperatura.

\begin{tabular}{cccc}
\hline Dispositivo & $\boldsymbol{r}^{\mathbf{2}}$ & $\boldsymbol{a}$ & $\boldsymbol{b}$ \\
\hline $\mathbf{4}$ & 0,99999 & 0,98701 & 0,07601 \\
$\mathbf{5}$ & 0,99998 & 0,98522 & $-0,08541$ \\
$\mathbf{1}$ & 0,99998 & 0,97574 & 0,86282 \\
$\mathbf{2}$ & 0,99999 & 0,98266 & 0,84992 \\
$\mathbf{3}$ & 0,99999 & 0,96510 & $-1,95305$ \\
\hline
\end{tabular}

A Tabela 18 informa os valores de temperatura utilizados no cálculo da regressão linear $(T)$, e os valores ajustados pela mesma $\left(T_{\text {corr }}\right)$.

Tabela 18 - Valores de temperatura medidos no ensaio e corrigidos pela regressão linear.

\begin{tabular}{ccccccc}
\hline Dispositivo & $\boldsymbol{T}\left({ }^{\circ} \boldsymbol{C}\right)$ & $\boldsymbol{T}_{\text {corr }}\left({ }^{\circ} \boldsymbol{C}\right)$ & $\boldsymbol{T}\left({ }^{\circ} \boldsymbol{C}\right)$ & $\boldsymbol{T}_{\text {corr }}\left({ }^{\circ} \boldsymbol{C}\right)$ & $\boldsymbol{T}\left({ }^{\circ} \boldsymbol{C}\right)$ & $\boldsymbol{T}_{\text {corr }}\left({ }^{\circ} \boldsymbol{C}\right)$ \\
\hline $\mathbf{4}$ & 20,17 & 19,98 & 30,35 & 30,03 & 40,43 & 39,98 \\
$\mathbf{5}$ & 20,36 & 19,98 & 30,59 & 30,05 & 40,66 & 39,97 \\
$\mathbf{1}$ & 19,59 & 19,97 & 29,92 & 30,05 & 40,08 & 39,97 \\
$\mathbf{2}$ & 19,47 & 19,98 & 29,70 & 30,04 & 39,82 & 39,98 \\
$\mathbf{3}$ & 22,77 & 20,02 & 33,07 & 29,96 & 43,49 & 40,02 \\
\hline
\end{tabular}

A Tabela 19 e a Tabela 20 se referem às mesmas informações descritas anteriormente, porém voltadas às medições de umidade. 
Tabela 19 - Parâmetros obtidos pela regressão linear no ensaio de umidade.

\begin{tabular}{cccc}
\hline D. local & $\boldsymbol{r}^{\mathbf{2}}$ & $\boldsymbol{a}$ & $\boldsymbol{b}$ \\
\hline $\mathbf{4}$ & 0,99877 & 0,98109 & 5,07264 \\
$\mathbf{5}$ & 0,99911 & 1,01956 & 4,30987 \\
$\mathbf{1}$ & 0,99964 & 1,01135 & $-4,25492$ \\
$\mathbf{2}$ & 0,99935 & 0,99255 & 1,56874 \\
$\mathbf{3}$ & 0,99920 & 1,03761 & $-5,98321$ \\
\hline
\end{tabular}

Tabela 20 - Valores de unidade medidos durante o ensaio e corrigidos pela regressão linear.

\begin{tabular}{ccccccccc}
\hline D. local & $\boldsymbol{H}(\%)$ & $\boldsymbol{H}_{\text {corr }}(\%)$ & $\boldsymbol{H}(\%)$ & $\boldsymbol{H}_{\text {corr }}(\%)$ & $\boldsymbol{H}(\%)$ & $\boldsymbol{H}_{\text {corr }}(\%)$ & $\boldsymbol{H}(\%)$ & $\boldsymbol{H}_{\text {corr }}(\%)$ \\
\hline $\mathbf{4}$ & 36,06 & 40,45 & 45,24 & 49,46 & 55,79 & 59,81 & 66,47 & 70,29 \\
$\mathbf{5}$ & 35,38 & 40,38 & 44,35 & 49,53 & 54,48 & 59,86 & 64,66 & 70,24 \\
$\mathbf{1}$ & 43,97 & 40,21 & 53,30 & 49,65 & 63,61 & 60,08 & 73,48 & 70,06 \\
$\mathbf{2}$ & 39,04 & 40,31 & 48,34 & 49,55 & 58,86 & 59,99 & 69,09 & 70,15 \\
$\mathbf{3}$ & 44,65 & 40,35 & 53,47 & 49,50 & 63,59 & 60,00 & 73,38 & 70,16 \\
\hline
\end{tabular}

Os coeficientes de regressão informados na Tabela 17 e na Tabela 19 aproximaram-se de 1 confirmando que a estratégia adotada foi adequada. Esse fato pode ser observado pelas correções aplicadas aos valores apresentados na Tabela 18 e na Tabela 20.

\section{3. Monitoramento de uma sala de pesquisa}

A Figura 13 apresenta os resultados obtidos dos dispositivos locais distribuídos em diferentes pontos do espaço interno de um ambiente de pesquisa, conforme mostrado na Figura 7. São apresentados os registros de concentração de $\mathrm{CO}_{2}$ (Figura 13a), temperatura (Figura 13b) e umidade (Figura 13c), obtidos por quatro dispositivos locais. Dos cinco dispositivos locais, o dispositivo 2 não pôde ser utilizado por nestas medições por ter apresentado problemas técnicos. 


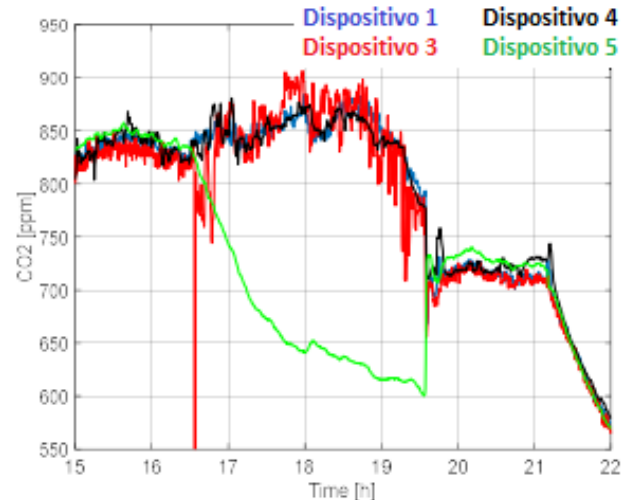

(a)

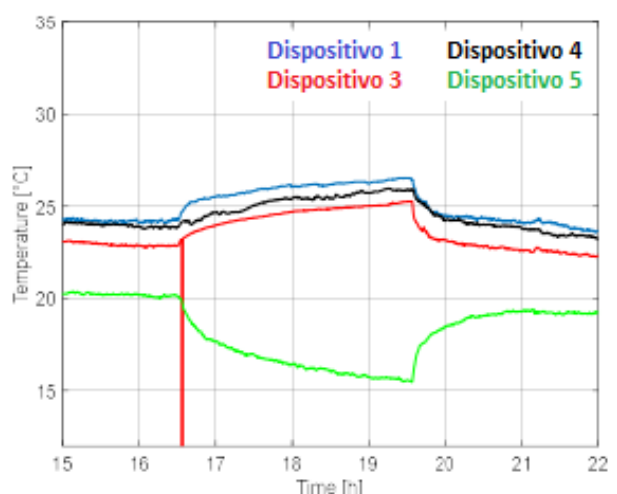

(b)

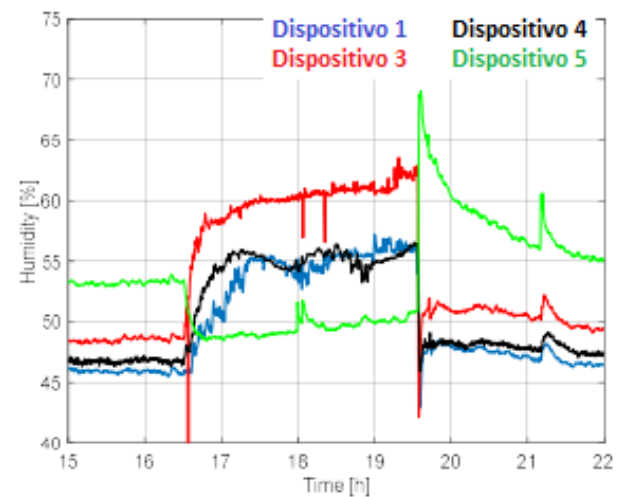

(c)

Figura 13 - Séries temporais de concentrações de $\mathrm{CO}_{2}$ em (a); temperatura em (b); e umidade em (c); obtidos por quatro dispositivos locais, distribuídos em um ambiente composto por dois compartimentos.

Ao fechar a porta entre os dois compartimentos do ambiente, em torno de 16 h 30 min (Figura 13), o dispositivo 5, único dispositivo local posicionado no compartimento sem a presença humana (Sala B) e localizado próximo ao ar condicionado e à porta de saída, apresentou redução nos valores de $\mathrm{CO}_{2}$, temperatura e umidade. Por outro lado, essas mesmas grandezas medidas pelos sensores dos outros três dispositivos locais, posicionados no ambiente na presença do pesquisador (Sala A), apresentaram aumento em seus valores. Com a reabertura do trecho entre a Sala A e a Sala B, pouco antes das $20 \mathrm{~h}$, ocorre um aumento abrupto da concentração de $\mathrm{CO}_{2}$ e umidade, com aumento mais gradual da temperatura, registrado pelo dispositivo local 5, localizado na Sala B. Os demais sensores localizados no compartimento com ocupação humana e menos ventilação (Sala A) apresentam comportamento oposto. 
A Figura 14 mostra os resultados obtidos para as medições de compostos orgânicos voláteis totais (TVOC) e da pressão barométrica registrados no mesmo intervalo de tempo apresentado na Figura 13. Esses sensores de TVOC pertencem ao dispositivo local 1, que foi posicionado mais próximo da localização humana durante os experimentos. Ambos os sensores de TVOC (Figura 14a) mostram um aumento em seus valores durante o período em que a porta entre o ambiente interno de dois compartimentos é fechada. O sensor de TVOC CCS881 apresenta uma variação menos evidente devido à compensação automática de seu valor de acordo com a temperatura e umidade (Figura 14a). O aumento da pressão barométrica, na Figura 14b, não está associado às variações da ventilação interna, mas sim a uma transição das condições meteorológicas locais que ocorreram durante as medições.

(a)

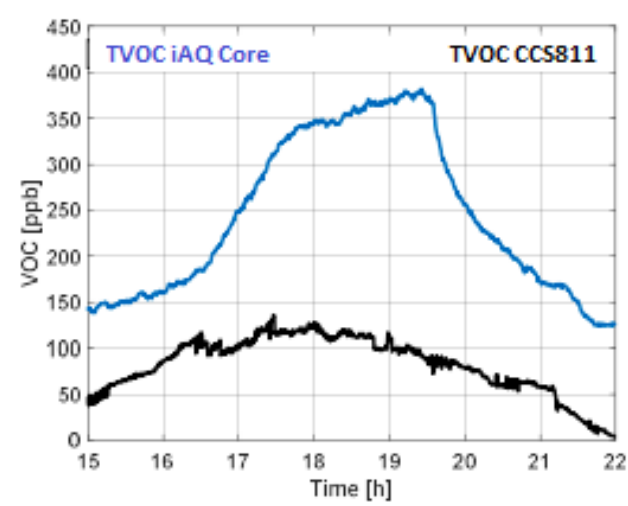

(b)

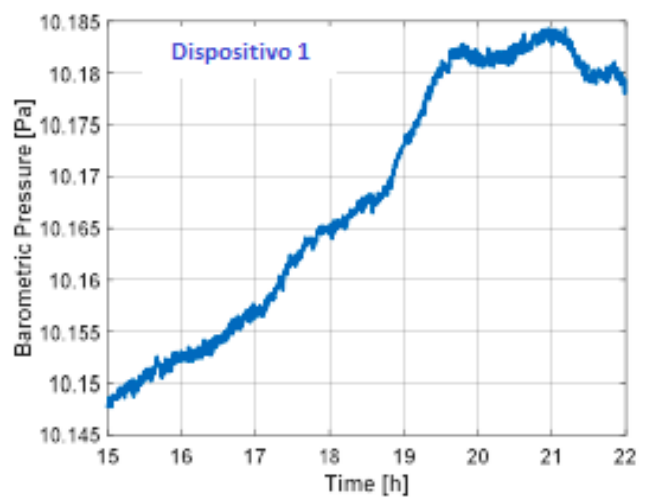

Figura 14 - Registros de concentração de TVOC em (a); e pressão barométrica em (b).

\section{4 .}

\section{Ensaio 1 em sala de aula}

No ensaio 1 realizado em ambiente de sala de aula investigaram-se diferentes dinâmicas de ocupação, a propagação das concentrações de dióxido de carbono entre 4 bancadas referenciadas como A, B, C e D na Figura 8, com os dispositivos locais posicionados na mesma altura em relação ao piso. Além das concentrações de $\mathrm{CO}_{2}$, a performance dos outros sensores disponíveis nos dispositivos locais foi avaliada durante o ensaio, e em alguns casos valores estatísticos foram levantados para discutir normas vigentes. 
Durante o decorrer da aula, observou-se que a bancada D não foi ocupada por nenhum aluno e não apresentou aglomerações em suas proximidades, sendo o ponto de monitoramento menos atingido pelas concentrações de $\mathrm{CO}_{2}$. Por esse motivo, a bancada D foi selecionada como referência de comparação com as demais, que apresentaram diferentes dinâmicas de ocupação durante a realização da aula.

Após 9 minutos do início da aula observou-se uma aglomeração de 6 alunos nas proximidades da bancada C. Ao término da aula após 105 minutos, observouse outra aglomeração, agora de 15 pessoas, ao redor da bancada B. Em nenhum momento registrou-se presença física ou aglomerações próximas à bancada $\mathrm{A}$, mas pela proximidade da entrada da sala, foi exposta à circulação de alunos durante a condução da aula. O período de monitoramento avaliado nesse ensaio foi de aproximadamente 1 hora e 45 minutos. Devido a falhas de conexão do roteador que servia acesso à internet aos dispositivos locais o monitoramento foi interrompido precocemente, impossibilitando avaliar o decaimento das concentrações de $\mathrm{CO}_{2}$ na sala de aula.

O gráfico da Figura 15 ilustra a evolução das concentrações do poluente em questão durante o período observado.

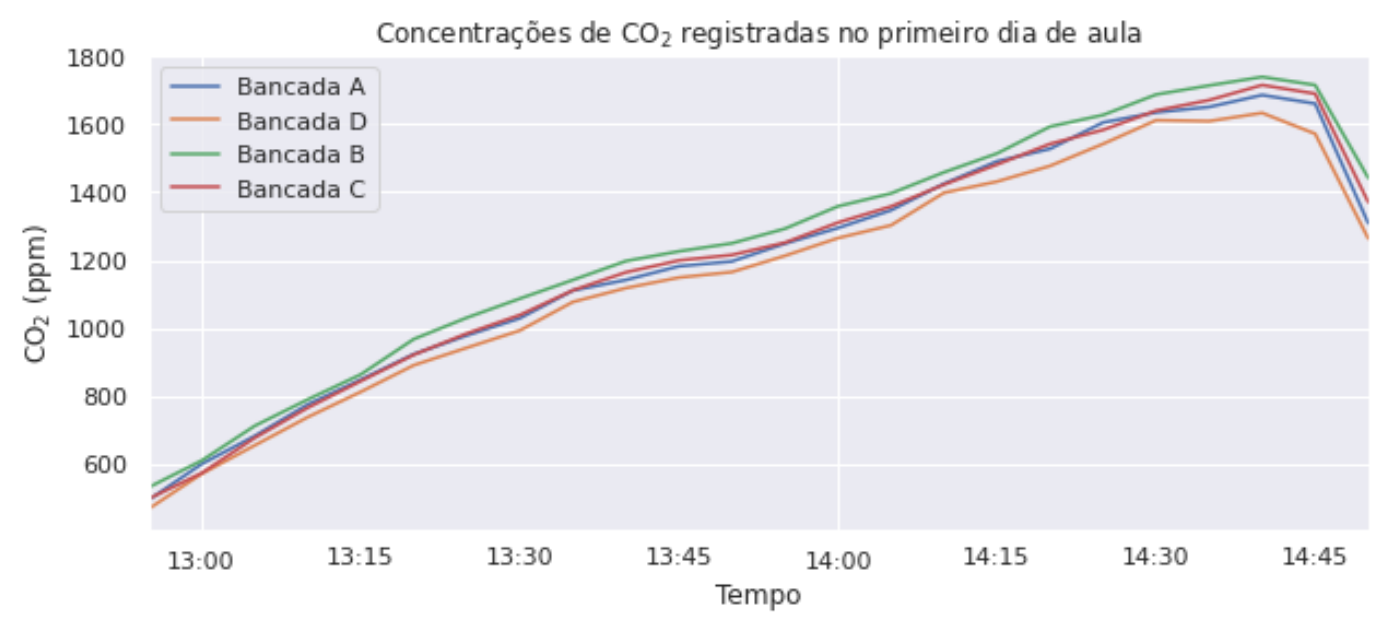

Figura 15 - Valores das concentrações de $\mathrm{CO}_{2}$ durante o ensaio 1 em sala de aula.

A bancada $\mathrm{D}$ foi comparada com as demais, pois nesta foi observada a menor ocorrência de pessoas entre as 4 avaliadas. Para verificar a concordância entre as 
séries temporais avaliadas no ensaio foi utilizado o algoritmo FastDTW, e a Tabela 21 informa o resultado das diversas comparações exploradas no ensaio.

Tabela 21 - Propagação plana das concentrações de $\mathrm{CO}_{2}$ no ensaio 1 em sala de aula.

\begin{tabular}{ll}
\hline Bancadas comparadas com a bancada D & FastDTW \\
\hline Bancada C & 0,39 \\
\hline Bancada B & 0,34 \\
\hline Bancada A & 0,17 \\
\hline
\end{tabular}

Pelos resultados apresentados na Tabela 21, referentes à propagação plana das concentrações de $\mathrm{CO}_{2}$, é possível afirmar que a maior divergência encontrada em todas as séries temporais comparadas, tomando a bancada $\mathrm{D}$ como referência, foi observada na bancada C. O efeito pode ser atribuído à aglomeração de alunos nas proximidades da bancada $\mathrm{C}$ no início do período de monitoramento.

A bancada B, mais distante da bancada D no ambiente avaliado, apresentou divergência inferior à comparação anterior. Apesar da aglomeração registrada na bancada em questão ser superior à notada na bancada $\mathrm{C}$ durante o ensaio, o evento ocorreu ao final do período estudado.

Por fim, a menor divergência encontrada entre as séries em relação a bancada D foi observada na bancada A, posicionada na saída do ambiente. Não houve registro de aglomerações nem mesmo presença fixa de alunos na bancada em questão, entendendo-se que a divergência encontrada se deu em consequência da circulação de alunos na sala.

Para avaliar se as concentrações de dióxido de carbono estão adequadas à regulação vigente, a Tabela 22 informa os valores máximos do poluente em questão registrados nas bancadas.

Tabela 22 - Valores máximos de concentrações de dióxido de carbono obtidos no ensaio 1 em sala de aula.

\begin{tabular}{lcccc}
\hline Bancada & A & D & B & C \\
\hline Orientação em relação à entrada da sala & Frente & Frente & Fundos & Fundos \\
\hline Concentração de $\mathrm{CO}_{2}$ máxima $(\mathbf{p p m})$ & 1686 & 1633 & 1739 & 1715 \\
\hline
\end{tabular}


Todos os valores indicados na Tabela 22 foram superiores ao valor máximo de 1000 ppm de $\mathrm{CO}_{2}$, recomendado pela Resolução 9 da ANVISA (2003) em ambientes internos.

Para avaliar os parâmetros de temperatura e umidade, a Tabela 23 e a Tabela 24 informam respectivamente valores da estatística descritiva das medições realizadas nas bancadas. As medições em questão foram corrigidas através da regressão linear calculada durante o ensaio na câmara climática.

Tabela 23 - Valores de temperatura obtidos no ensaio 1 em sala de aula.

\begin{tabular}{lcccc}
\hline Bancada & A & D & B & C \\
\hline Orientação em relação à entrada da sala & Frente & Frente & Fundos & Fundos \\
\hline Temperatura média $\left({ }^{\circ} \mathrm{C}\right)$ & 24,04 & 23,59 & 27,73 & 28,23 \\
\hline Temperatura mínima $\left({ }^{\circ} \mathrm{C}\right)$ & 23,52 & 23,33 & 27,23 & 27,72 \\
\hline Temperatura máxima $\left({ }^{\circ} \mathrm{C}\right)$ & 24,60 & 23,90 & 28,01 & 28,51 \\
\hline
\end{tabular}

Tabela 24 - Valores de umidade obtidos no ensaio 1 em sala de aula.

\begin{tabular}{lcccc}
\hline Bancada & A & D & B & C \\
\hline Orientação em relação à entrada da sala & Frente & Frente & Fundos & Fundos \\
\hline Umidade média (\%) & 51,42 & 52,59 & 43,01 & 42,05 \\
\hline Umidade mínima (\%) & 46,68 & 48,65 & 39,93 & 39,11 \\
\hline Umidade máxima (\%) & 53,84 & 55,20 & 45,56 & 44,97 \\
\hline
\end{tabular}

Os valores máximos de temperatura apresentados na Tabela 23, registrados nas bancadas B e C superaram o valor máximo estabelecido pela resolução 9 da ANVISA (2003), que é de $27^{\circ} \mathrm{C}$. Já a Tabela 24 apresenta valores mínimos de umidade abaixo do valor estabelecido na norma que é de $40 \%$ de umidade nas mesmas bancadas.

Sobre as medições de Compostos Orgânicos Voláteis Totais, os sensores modelo iAQ-Core dos dispositivos locais instalados nas bancadas A (dispositivo 1) e D (dispositivo 3) registraram 125 ppb de TVOC durante todo o ensaio, que é o valor mínimo da faixa de medição. A estimativa de $\mathrm{CO}_{2}$ realizada pelos sensores foi constante, registrando $450 \mathrm{ppm}$ durante o ensaio.

O sensor modelo CCS811, presente apenas no dispositivo local da bancada A (dispositivo 1), que internamente executa correção de umidade e temperatura em suas medições, registrou como valor máximo 323 ppb de TVOC durante o ensaio. 
A estimativa de $\mathrm{CO}_{2}$ que o sensor apresentou durante o ensaio teve relação direta com a medição realizada pelo sensor de $\mathrm{CO}_{2}$ disponível no mesmo dispositivo local. A estimativa e a medição das concentrações do poluente em questão durante o decorrer do ensaio podem ser observadas pelo gráfico da Figura 15a, e o gráfico de dispersão da Figura 15b confirma a relação existente entre esses valores.

(a)

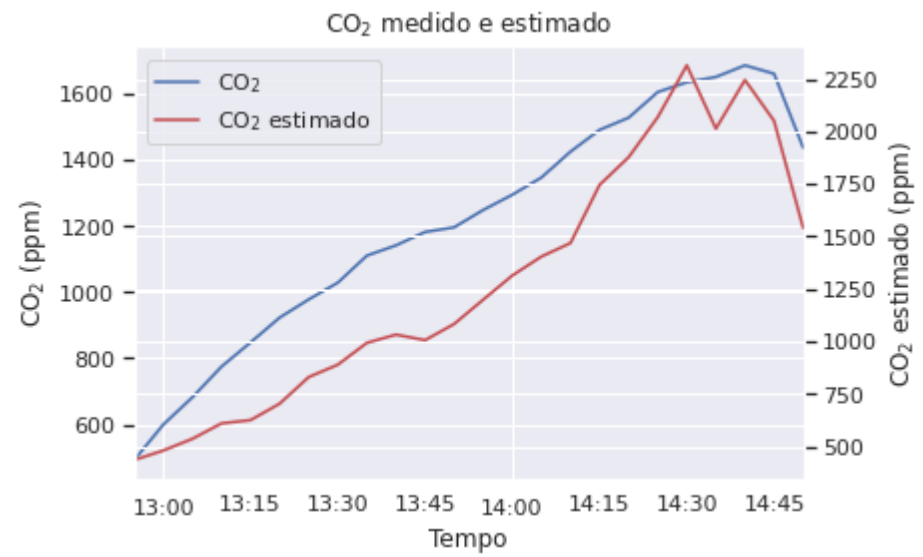

(b)

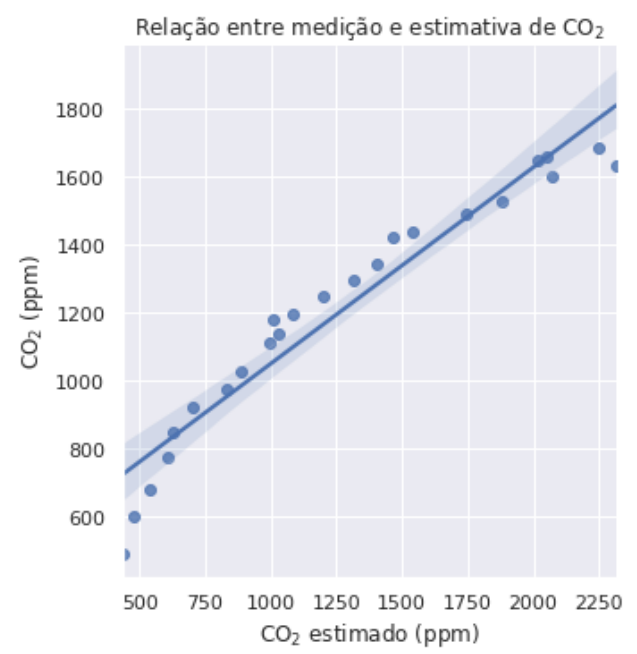

Figura 16 - Comportamento do $\mathrm{CO}_{2}$ e do $\mathrm{CO}_{2}$ estimado para o ensaio $1 \mathrm{em}$ sala de aula. Em (a) é mostrado os dois registros no tempo e em (b) a correlação entre eles.

Os valores de pressão atmosférica registrados durante o ensaio podem ser observados pelo gráfico da Figura 17. Importante destacar que apenas o dispositivo local 1 , instalado na bancada $\mathrm{A}$, possui esse sensor. 


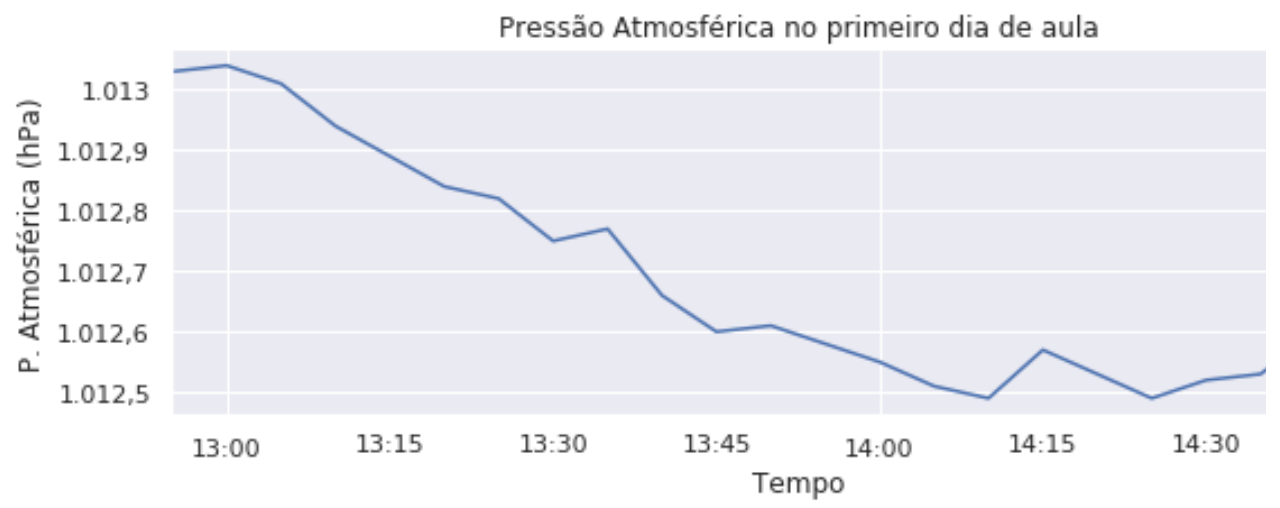

Figura 17 - Pressão Atmosférica registrada durante o ensaio 1 em sala de aula.

Os sensores de Material Particulado não registraram qualquer valor durante o ensaio, e suas medições foram desconsideradas devido à detecção de uma falha no firmware do micro controlador dos dispositivos locais, fato constatado após testes posteriores.

\section{5.}

\section{Ensaio $2 \mathrm{em}$ sala de aula}

Enquanto no ensaio $1 \mathrm{em}$ sala de aula os dispositivos locais foram posicionados na mesma altura em quatro bancadas, nas medições do ensaio 2 , as propagações das concentrações de dióxido de carbono foram estudadas em duas alturas distintas (propagações superior e inferior no Capítulo 4), por dois pares de dispositivos locais instalados em duas bancadas referenciadas como A e B na Figura 9. Além das propagações planas avaliadas entre as bancadas, também foi estudado o efeito local entre os pares de sensores instalados em cada bancada.

Novamente o desempenho dos demais sensores de cada dispositivo local foi avaliada, e valores estatísticos de algumas medições foram levantados para confrontar os mesmos com as normas vigentes.

Durante o decorrer da aula os alunos se concentraram no final da sala nas proximidades da bancada B. Não houve presença fixa na bancada A, observandose apenas a circulação de alunos ao seu redor pela proximidade da porta. Passados 105 minutos, todos os alunos e o professor se concentraram de pé nas proximidades da bancada B. 
O período total de monitoramento nesse ensaio foi de aproximadamente 3 horas, sendo possível avaliar a ascensão e queda das concentrações de $\mathrm{CO}_{2}$.

O gráfico da Figura 18 ilustra o comportamento das concentrações de $\mathrm{CO}_{2}$ durante o período de realização da aula.

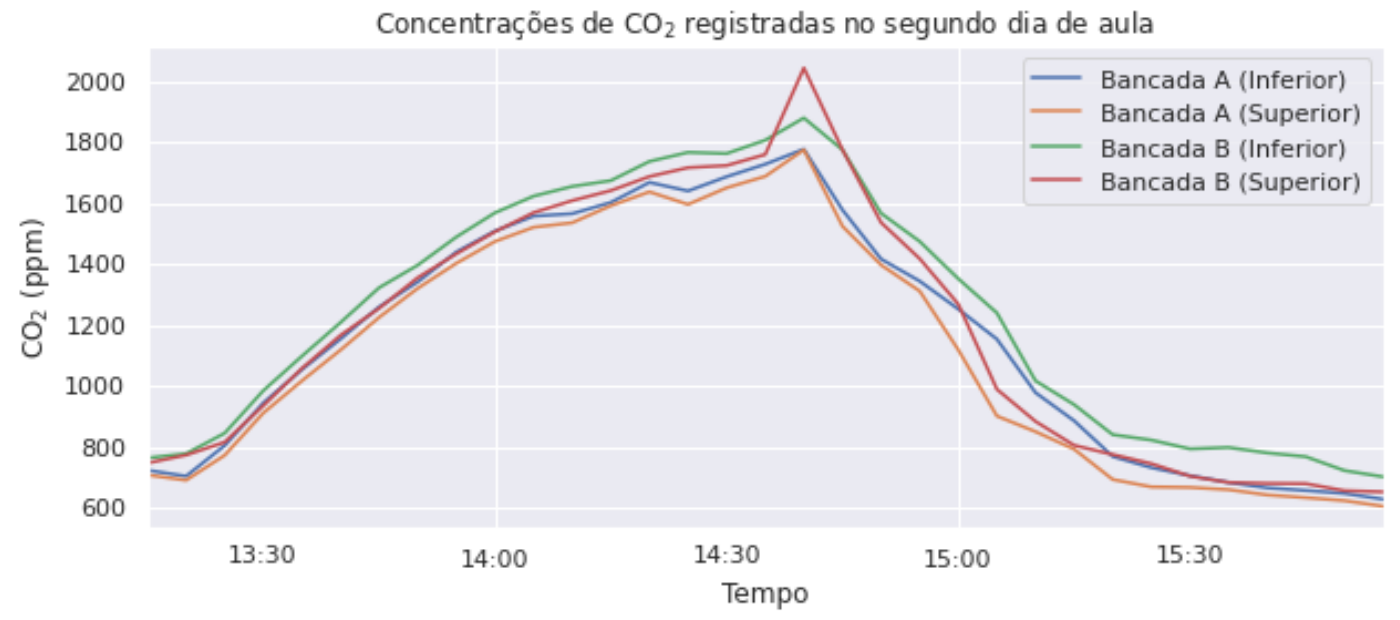

Figura 18 - Valores das concentrações de CO2 durante o ensaio 2 em sala de aula.

A similaridade entre as 4 séries temporais disponíveis foi analisada pelo algoritmo FastDTW. A Tabela 25 informa a avaliação feita pelo algoritmo, referente às propagações planas além de comparações locais das concentrações de $\mathrm{CO}_{2}$ entre pares de dispositivos locais na mesma bancada.

Tabela 25 - Propagações das concentrações de CO2 entre as bancadas no ensaio 2 em sala de aula.

\begin{tabular}{lll}
\hline Tipo de Avaliação & Propagação ou bancada avaliada & FastDTW \\
\hline \multirow{2}{*}{ Propagação plana } & Entre bancadas - Superior & 0,95 \\
\cline { 2 - 3 } & Entre bancadas - Inferior & 0,70 \\
\hline \multirow{2}{*}{ Comparação local } & Bancada A & 0,59 \\
\cline { 2 - 3 } & Bancada B & 1,03 \\
\hline
\end{tabular}

Em relação às propagações planas das concentrações de $\mathrm{CO}_{2}$, cujos valores são apresentados na Tabela 25, observa-se uma maior similaridade entre as séries temporais geradas pelos sensores instalados nas alturas inferiores entre as bancadas, em contraste aos sensores instalados nas alturas superiores. Esse fato sugere que a propagação plana inferior das concentrações do poluente apresentou-se mais homogênea em comparação à superior. 
As séries temporais registradas pelos sensores de $\mathrm{CO}_{2}$ da bancada $\mathrm{B}$ (Tabela 25) apresentaram maior divergência que as séries registradas na bancada A. Esse efeito pode ser atribuído a presença fixa de alunos apenas na bancada B durante o decorrer do ensaio.

Para avaliar se as concentrações de dióxido de carbono estão adequadas à regulação vigente, a Tabela 26 informa os valores máximos do poluente em questão registrados nas bancadas.

Tabela 26 - Valores máximos de concentrações de dióxido de carbono obtidos no ensaio 2 em sala de aula.

\begin{tabular}{lcccc}
\hline Bancada & \multicolumn{2}{c}{ A } & \multicolumn{2}{c}{ B } \\
\hline Altura em relação ao piso & Inferior & Superior & Inferior & Superior \\
\hline Concentração de $\mathrm{CO}_{2}$ máxima (ppm) & 1776 & 1774 & 1878 & 2042 \\
\hline
\end{tabular}

Os valores apresentados na Tabela 26 superaram o limite estabelecido na resolução 9 da ANVISA (2003), que estabelece como valor máximo 1000 ppm de $\mathrm{CO}_{2}$ em ambientes internos.

Em relação aos parâmetros de temperatura e umidade, a Tabela 27 e a Tabela 28 informam, respectivamente, os valores da estatística descritiva das medições registradas nas bancadas. As medições em questão foram corrigidas através da regressão linear que foi executada durante o ensaio de caracterização na câmara climática.

Tabela 27 - Valores de temperatura obtidos no ensaio 2 em sala de aula.

\begin{tabular}{lcccc}
\hline Bancada & \multicolumn{2}{c}{ A } & \multicolumn{2}{c}{ B } \\
\hline Altura em relação ao piso & Inferior & Superior & Inferior & Superior \\
\hline Temperatura média $\left({ }^{\circ} \mathrm{C}\right)$ & 23,98 & 23,42 & 28,02 & 28,93 \\
\hline Temperatura mínima $\left({ }^{\circ} \mathrm{C}\right)$ & 22,97 & 22,00 & 26,91 & 28,51 \\
\hline Temperatura máxima $\left({ }^{\circ} \mathrm{C}\right)$ & 25,63 & 25,20 & 29,06 & 29,57 \\
\hline
\end{tabular}

Tabela 28 - Valores de umidade obtidos no ensaio 2 em sala de aula.

\begin{tabular}{lcccc}
\hline Bancada & \multicolumn{2}{c}{ A } & \multicolumn{2}{c}{ B } \\
\hline Altura em relação ao piso & Inferior & Superior & Inferior & Superior \\
\hline Umidade média (\%) & 60,22 & 62,88 & 48,96 & 48,06 \\
\hline Umidade mínima (\%) & 52,25 & 54,98 & 42,21 & 41,02 \\
\hline Umidade máxima (\%) & 70,09 & 72,92 & 57,65 & 57,17 \\
\hline
\end{tabular}


Os valores apresentados na Tabela 27 indicam que a temperatura máxima registrada pelos sensores presentes na bancada $\mathrm{B}$, posicionada próximo ao fundo da sala de aula, ultrapassou o limite admitido pela resolução 9 da ANVISA (2003) que é de $27^{\circ}$ C. Já na bancada A, posicionada no início da sala, foram registradas temperaturas abaixo do valor mínimo especificado na resolução, que é de $23^{\circ} \mathrm{C}$, em ambos os sensores.

Conforme a Tabela 28, os valores de umidade registrados por ambos sensores presentes na bancada B, posicionada ao fundo da sala de aula, estiveram em conformidade com a resolução 9 da ANVISA (2003), que admite valores na faixa de $40 \%$ a $65 \%$ do parâmetro em questão. Na bancada A, posicionada ao início da sala, foi superado o valor máximo de umidade estabelecido pela norma nas duas alturas avaliadas.

Sobre as medições de Compostos Orgânicos Voláteis Totais dos dois sensores modelo iAQ-Core presentes nos dispositivos locais instalados na bancada A, o sensor posicionado na altura inferior (dispositivo local 1), registrou durante todo o decorrer da aula o valor de $125 \mathrm{ppb}$ de TVOC e estimativa de $\mathrm{CO}_{2}$ de $450 \mathrm{ppm}$, que são valores mínimos da faixa de medição. Já o sensor posicionado na altura superior, dispositivo local 3, apresentou oscilações em suas medições associadas às variações de temperatura e umidade causadas pelo ciclo de operação do aparelho de ar-condicionado presente na sala, tendo registrado o valor máximo de $156 \mathrm{ppb}$ de TVOC. Os gráficos da Figura 18 ilustram a relação entre o poluente em questão e os parâmetros físicos temperatura (Figura 18a) e umidade (Figura 18b), sendo que o sensor modelo iAQ-Core (presente no dispositivo local 3) não possui opção para corrigir esses parâmetros em suas medições. 


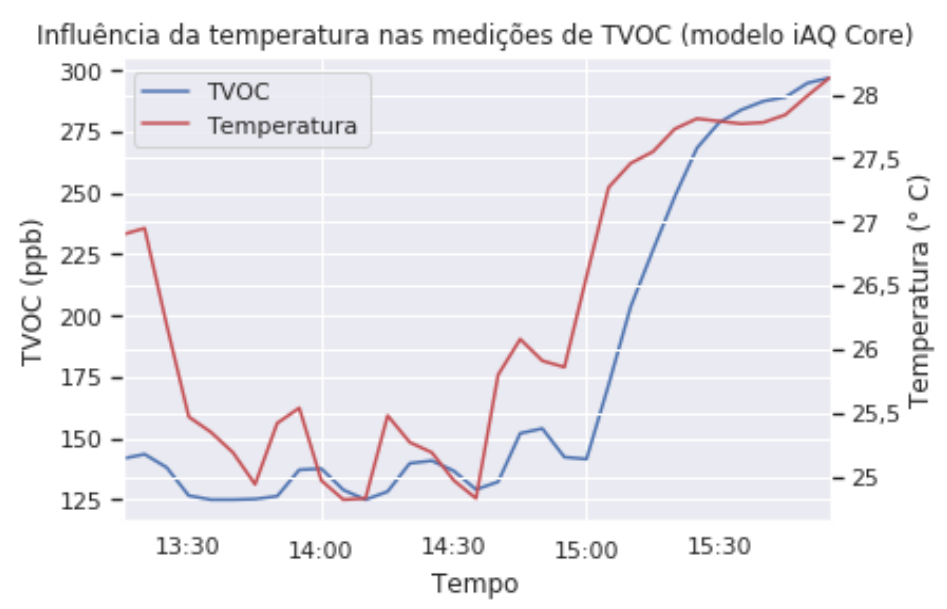

a)

Influência da umidade nas medições de TVOC (modelo iAQ Core)

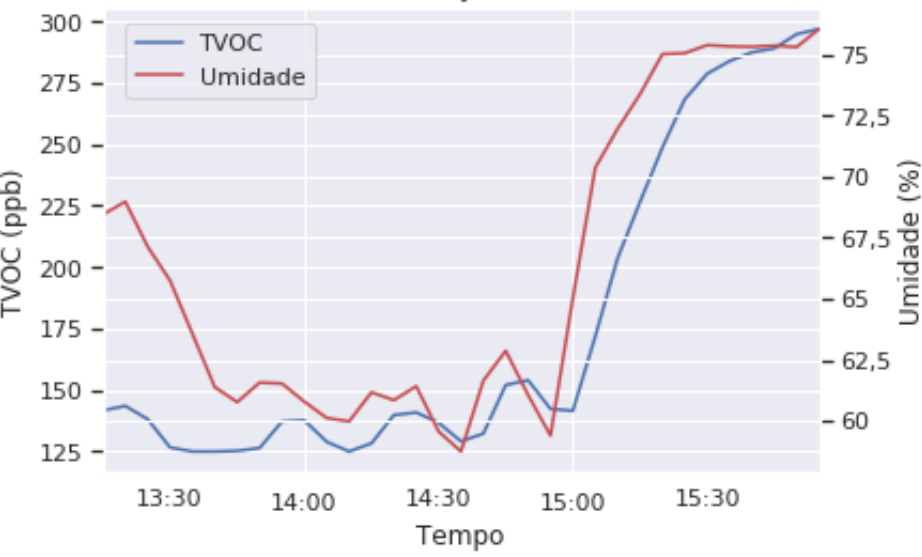

b) Figura 19 - Influência de temperatura (a) e umidade (b) no sensor de TVOC modelo iAQ Core do
dispositivo local 3.

O sensor modelo CCS811, disponível apenas no dispositivo local presente na bancada A posicionado na altura inferior (dispositivo 1), registrou como valor máximo 143 ppb de TVOC, sendo que esse sensor faz internamente a correção dos parâmetros de umidade e temperatura em suas medições. A estimativa de $\mathrm{CO}_{2}$ que o sensor registrou ao longo do ensaio relacionou-se diretamente com as medições executadas pelo sensor de $\mathrm{CO}_{2}$ presente no mesmo dispositivo local. O gráfico da Figura 19a exibe as estimativas e as medições de $\mathrm{CO}_{2}$ ao decorrer do ensaio, e gráfico de dispersão da Figura 19b ilustra a relação entre esses valores. 
(a)

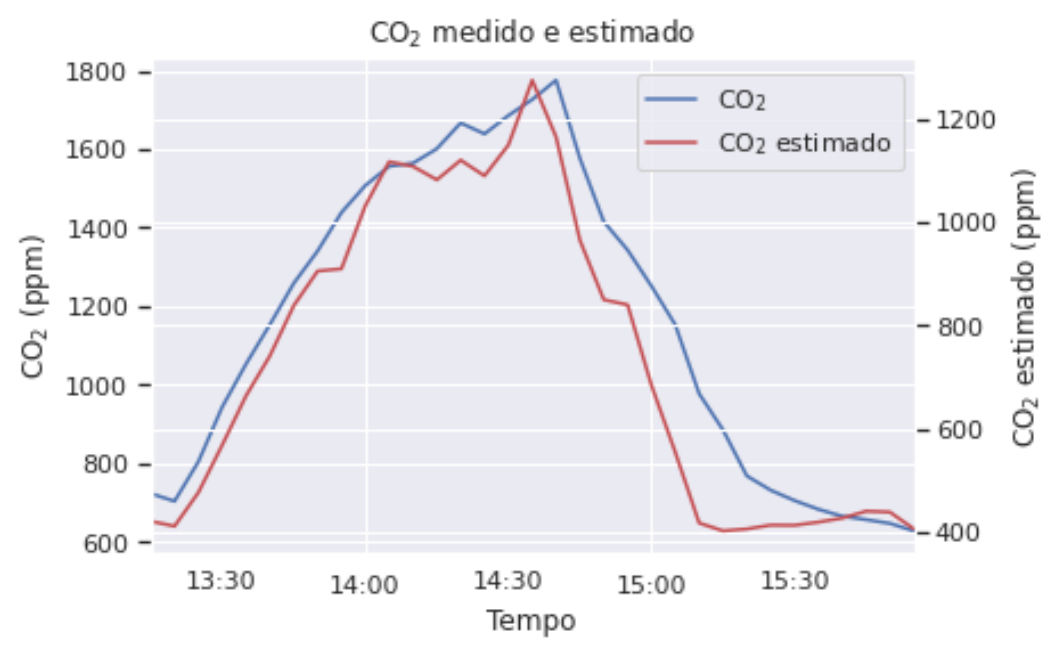

(b)

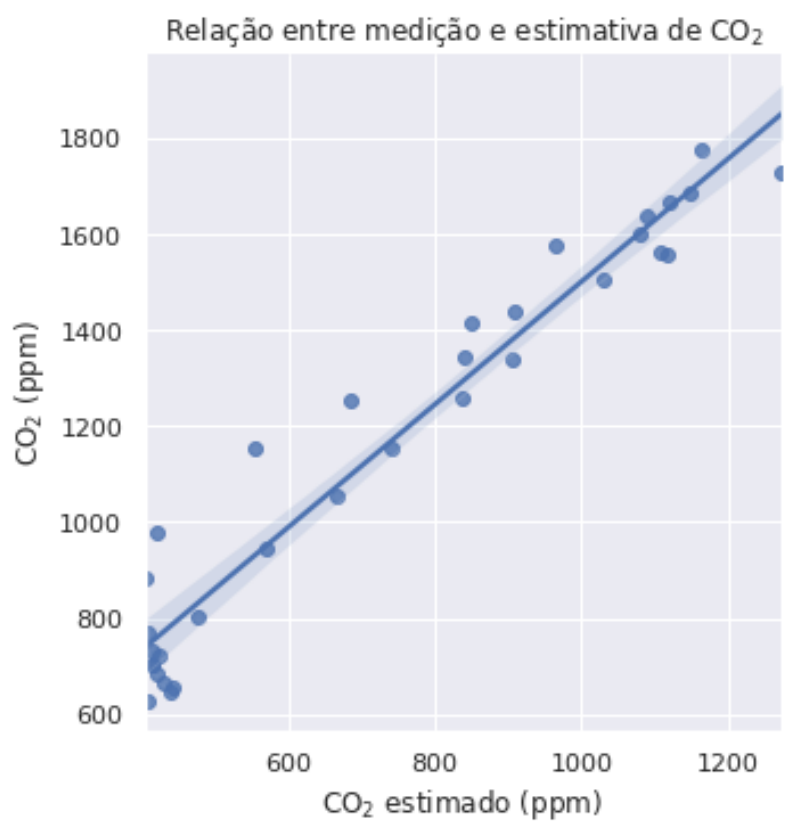

Figura 20 - Semelhanças entre o comportamento do $\mathrm{CO}_{2}$ e $\mathrm{CO}_{2}$ estimado no ensaio 2 em sala de aula. Em (a) é apresentado os registros dos sensores no tempo e em (b) a sua correlação.

Os valores de pressão atmosférica registrados durante o ensaio podem ser observados pelo gráfico da Figura 21, destacando-se que essas medições foram realizadas pelo sensor do dispositivo local presente na bancada A (dispositivo 1), posicionado na altura inferior. 


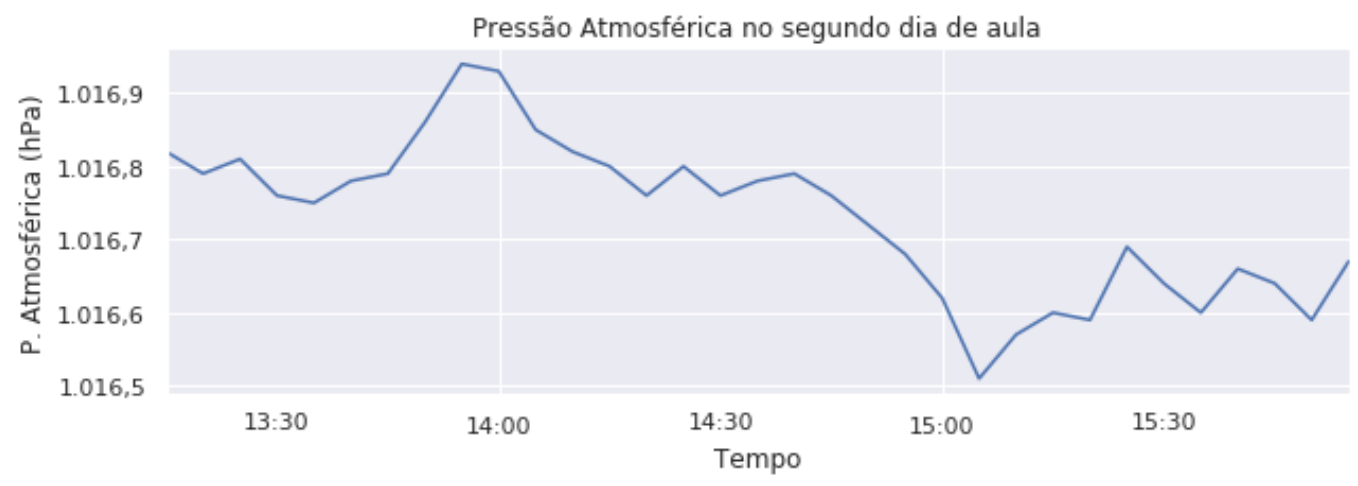

Figura 21 - Pressão atmosférica durante o ensaio 2 em sala de aula.

Assim, como no ensaio 1 realizado em sala de aula, os sensores de Material Particulado não registraram qualquer valor durante o ensaio, e suas medições foram desconsideradas devido à detecção uma falha no firmware do microcontrolador dos dispositivos locais, fato constatado após testes posteriores. 


\section{6 \\ Discussão e Conclusão}

Este capítulo apresenta a discussão dos resultados obtidos com a caracterização dos sensores utilizados nos sistemas de medição desenvolvidos e com os ensaios realizados com estes sistemas distribuídos no espaço interno de ambientes da universidade (PUC-Rio), como sala de pesquisa e sala de aula. Ao final é apresentada a conclusão da pesquisa e sugestões de trabalhos futuros.

\section{1 \\ Discussão}

A caracterização dos sensores de dióxido de carbono dos sistemas de medição multiparamétrica desenvolvidos indicou que os valores medidos ao longo de 70 minutos de medição em condição ambiental estável variaram 19 ppm no pior caso, para um nível de $\mathrm{CO}_{2}$ no ambiente de cerca de 500 ppm. Segundo a orientação técnica fornecida pela Resolução ANVISA nº 9, de 2003, a incerteza de medição do dispositivo deve ter como valor máximo de dispersão: \pm 50 ppm $+2 \%$ do valor medido. Assim, considerando o valor medido de 500 ppm, a faixa máxima de variação do valor medido da grandeza no ensaio controlado deve ser de até \pm [(50 $\mathrm{ppm}) \pm(2 \%$ de $500 \mathrm{ppm})]= \pm 60 \mathrm{ppm}$. Observa-se que a faixa máxima de variação calculada a partir da recomendação técnica da Resolução ANVISA ( \pm 60 ppm) é aproximadamente 3 vezes superior à faixa de variação obtida no estudo controlado (19 ppm), caracterizando a adequação dos dispositivos sensores de $\mathrm{CO}_{2}$ aos limites técnicos estabelecidos no regulamento.

Assim como o ensaio de caracterização dos sensores de dióxido de carbono realizado nesta pesquisa, o sistema desenvolvido por Tiele et al. (2018) [17] passou por um processo de caracterização dos sensores de $\mathrm{CO}_{2}$ em uma câmara plástica selada. Apesar de apresentar uma metodologia mais controlada, devido à insuflação na câmara de um gás formado por uma mistura sintética utilizada para fazer o ajuste de zero em equipamentos analisadores de gases, o ensaio conduzido por por Tiele 
et al. (2018) [17] não avaliou parâmetros metrológicos que comprovassem o atendimento dos sensores de $\mathrm{CO}_{2}$ a regulamento ambiental vigente.

No presente trabalho, os ensaios realizados em ambiente interior de sala de pesquisa indicaram níveis de dióxido de carbono crescente a uma taxa dependente das condições de ventilação e área de distribuição. A ocupação do espaço de pesquisa por um único pesquisador não ultrapassou os limites aceitáveis de 1000 ppm para a concentração de $\mathrm{CO}_{2}$ em ambientes internos, conforme resolução $n^{\circ} 9$ de 2003 da ANVISA (ANVISA, 2003).

Por sua vez, nas medições realizadas em sala de aula, em todas as bancadas foram registradas concentrações de dióxido de carbono que ultrapassaram o limite admitido pela resolução ANVISA (ANVISA, 2003). Na análise da propagação plana, as maiores discrepâncias indicadas pelo FastDTW em todas as séries temporais comparadas foi entre as bancadas posicionadas no fundo da sala em relação às localizadas da frente, nas quais não ocorreu ocupação. A avaliação das discrepâncias entre dispositivos posicionados no mesmo local, mas a diferentes distâncias do piso, realizada no Ensaio 2 em sala de aula, indicou maior discrepância entre aqueles dispostos nas bancadas do fundo, nas quais houve aglomeração em comparação aos posicionados na bancada da frente, já que os sensores mais afastados do piso também estavam mais próximos às fontes de $\mathrm{CO}_{2}$, provenientes das vias aéreas superiores dos ocupantes. A localização espacial da emissão humana do gás pelo sistema respiratório também pode ter determinado a maior homogeneidade observada entre as séries temporais geradas pelos sensores instalados nas alturas inferiores das bancadas, em contraste aos sensores instalados nas alturas superiores.

Os resultados obtidos no presente estudo confirmam a recomendação da Resolução da ANVISA, que solicita posicionamento do sensor ao centro do ambiente ou em uma zona ocupada, localizado a uma altura fixa de 1,5 $\mathrm{m}$ do piso. Essa distância pode ser considerada intermediária entre uma posição em pé ou sentada dos ocupantes do ambiente, podendo, porém, estar inadequada caso o ambiente tenha ocupação predominantemente infantil. Embora a Resolução recomende mais de um ponto amostral somente para ambientes internos com área superior a $1000 \mathrm{~m}^{2}$ (ANVISA, 2003), os ensaios 1 e 2, realizados em espaço com 
área de $53 \mathrm{~m}^{2}$, apontam para a necessidade do monitoramento em múltiplos pontos de um ambiente interno.

No presente trabalho, os dois ensaios realizados em sala de aula resultaram em valores de temperatura mais elevadas nas bancadas com maior ocupação dos alunos, posicionadas no fundo da sala, em comparação com as bancadas da frente da sala, onde, em geral, só o docente transitava. Nessas bancadas de maior ocupação os valores de temperatura ultrapassaram o limite admitido pela resolução $n^{\circ} 9$ da ANVISA (ANVISA, 2003). Da mesma forma, os valores de umidade registrados nos sensores das bancadas do fundo da sala apresentaram-se um pouco abaixo do valor mínimo recomendado pela resolução da ANVISA (ANVISA, 2003).

Devido a sua capacidade de compensação interna dos parâmetros de umidade e temperatura, os sensores CCS811 registraram menor variação das concentrações de Compostos Orgânicos Voláteis Totais (TVOC) do que os sensores iAQ-Core. O sensor de TVOC CCS811 foi capaz de realizar uma boa estimativa do dióxido de carbono, quando comparada à medição real pelo sensor de $\mathrm{CO}_{2}$ no mesmo dispositivo local.

Na literatura, Vilcekova et al. (2017) [18] investigaram, além da qualidade do ar, o comportamento do ruído acústico e iluminação em salas de aula de uma escola para crianças com transtorno de aprendizado, e através de questionários verificaram o impacto de cada parâmetro avaliado no conforto e desempenho de alunos e funcionários. Apesar do estudo [18] detectar concentrações de $\mathrm{CO}_{2}$ inadequadas, destacam os resultados para material particulado como mais preocupantes e, portanto, consideram este parâmetro como o principal poluente avaliado no monitoramento. Evidenciaram, em alunos e funcionários, sintomas de Síndrome do Edifício Doente (SED) como cansaço, dor de cabeça, dificuldade de concentração, irritação nos olhos e nariz, e dor de garganta [18]. A SED é uma síndrome reconhecida pela Organização Mundial da Saúde desde a década de 1980, e se caracteriza por doenças causadas ou estimuladas pela poluição do ar em espaços fechados [64]. A descrição da metodologia do monitoramento proposto no estudo de Vilcekova et al. (2017) [18], no entanto, não menciona o posicionamento dos sensores em um local que privilegiasse a dinâmica de ocupação do espaço, não considera a altura dos ocupantes (adultos e crianças), nem relata se esses permaneceram maior parte do tempo de pé ou sentados. O monitoramento 
simultâneo em múltiplos pontos realizados nos ensaios que compõem essa dissertação possibilitaria uma avaliação mais adequada das concentrações de $\mathrm{CO}_{2}$ no espaço avaliado, caracterizando de forma confiável a importância deste poluente em relação aos demais parâmetros monitorados.

\section{2 Conclusão}

No presente trabalho foram desenvolvidos sistemas de medição multiparamétrica, compostos por grupos de sensores para monitoramento de grandezas relacionadas à qualidade do ar, com foco em ambientes internos. Também foi desenvolvido um sistema hospedado na nuvem para acesso remoto aos resultados das medições realizadas por esses dispositivos, sendo armazenados em um banco de dados e exibidos em forma de dashboards. Após o desenvolvimento, esses dispositivos foram utilizados para monitoramento e avaliação inteligente da qualidade do ar em ambientes internos da Universidade, fazendo uso de sensores de dióxido de carbono, temperatura, umidade, material particulado, compostos orgânicos voláteis e pressão atmosférica.

O monitoramento do espaço interno de uma sala de pesquisa, utilizando os dispositivos locais distribuídos em diferentes pontos do ambiente, caracterizou uma variação dos níveis de dióxido de carbono, temperatura e umidade ao longo do espaço, apontando para a necessidade de monitoramento em múltiplos locais do ambiente para que se obtenha uma análise adequada da qualidade do ar interior.

Considerando que a existência de gradiente espacial nas concentrações de dióxido de carbono foi detectada por meio de poucos pontos de medição, utilizouse o algoritmo fastDTW para avaliar o comportamento das propagações desse poluente. No ensaio 1 das medições realizadas em ambiente de sala de aula analisou-se a distribuição espacial de parâmetros ligados à qualidade do ar ao longo de um mesmo plano. Os resultados mostraram maior gradiente das concentrações de $\mathrm{CO}_{2}$ entre bancadas ocupadas pelos estudantes com relação às desocupadas. Por sua vez, no ensaio 2 investigou-se a distribuição espacial dos parâmetros ligados à qualidade do ar em dois planos, localizados a alturas distintas do piso. Com o algoritmo fastDTW, identificou-se maior gradiente das concentrações de $\mathrm{CO}_{2}$ entre 
os valores registrados no plano superior em relação ao inferior. Esse efeito está relacionado ao posicionamento dos alunos de pé para realização de práticas experimentais durante a aula, ocasionando maiores concentrações do dióxido de carbono próximo às vias aéreas superiores, localizadas na altura do plano superior de medição. Estes resultados corroboram com a recomendação da Resolução ANVISA $n^{\circ}$ 9, de 2003, que indica o monitoramento com sensor posicionado 1,5 $m$ do piso. No entanto, a análise da propagação plana realizada no presente trabalho aponta para a necessidade de mais pontos amostrais, mesmo em ambientes com área muito inferior a $1000 \mathrm{~m}^{2}$, que é a dimensão para a qual a Resolução solicita a utilização de mais pontos de medição.

Em ambos os ensaios realizados em sala de aula, em todos os pontos de medição as concentrações de $\mathrm{CO}_{2}$ superaram os valores recomendados pela Resolução ANVISA n ${ }^{\circ}$ 9, de 2003, com os níveis mais elevados alcançados nos locais de maior aglomeração dos estudantes, e na altura da via aérea superior. Da mesma forma, as bancadas ocupadas pelos alunos apresentaram valores de temperatura mais elevados e de umidade mais baixos do que as bancadas que permaneceram desocupadas. Os valores de temperatura superaram os limites estabelecidos pelo regulamento da ANVISA apenas nas bancadas ocupadas pelos alunos.

O sensor de Compostos Orgânicos Voláteis modelo CCS811, que internamente faz a compensação dos valores de umidade e temperatura, além de disponibilizar uma estimativa das concentrações de $\mathrm{CO}_{2}$ a partir de suas medições, foi empregado em todos os experimentos realizados em sala de pesquisa e nos ensaios em sala de aula. A estimativa da concentração do dióxido de carbono apresentou uma correlação linear com os valores detectados pelo sensor de $\mathrm{CO}_{2}$ disponível no mesmo sistema de medição, com a vantagem de se tratar de um componente eletrônico de menor custo, dimensões e consumo energético reduzidos. Esses resultados apontam para a possibilidade de uso desse dispositivo em aplicações de monitoramento de baixo custo, e em equipamentos alimentados por baterias como smartphones.

Por meio do monitoramento espacial utilizando as unidades de medição desenvolvidas evidenciou-se a ocorrência de níveis elevados e heterogeneidade da distribuição de concentrações de $\mathrm{CO}_{2}$ e de temperatura em ambiente acadêmico, 
apontando para a necessidade do acompanhamento quotidiano dessas grandezas em espaços indoor para garantia de conforto e bem-estar de discentes e docentes.

\section{3}

\section{Trabalhos Futuros}

Realização de ensaios para avaliação da eficácia de possíveis medidas de correção dos valores associados aos parâmetros físicos e de composição química do ar dos ambientes interiores.

Ampliação do número de pontos de medição para maior resolução do mapeamento em diferentes planos do espaço interno, incluindo um sistema de medição posicionado no ambiente externo ao local de medição.

Ajuste do firmware do sensor de material particulado, e utilização das medições para discutir a adequação de ambientes internos conforme a Resolução ${ }^{\circ}$ 491 de 2018 do Conselho Nacional do Meio Ambiente (CONAMA), que estabelece padrões de qualidade do ar baseados em valores recomendados pela Organização Mundial de Saúde.

Conforme explicado no Capítulo 2 (Confiabilidade Metrológica), em relação aos sensores disponíveis nos dispositivos para monitoramento, a Rede Brasileira de Calibração possui laboratórios que prestam serviços de calibração para as grandezas, umidade, temperatura e concentrações de dióxido de carbono. Futuramente se planeja o uso desses laboratórios para calibrar os dispositivos desenvolvidos, conferindo maior confiabilidade metrológica a suas medições e rastreabilidade.

Deseja-se ainda, a integração dos sistemas de medição com aturadores de troca de ar em ambientes interiores, permitindo que a qualidade do ar seja mantida adequada , mesmo sem a necessidade da intervenção humana direta. 


\section{7}

\section{Referências Bibliográficas}

1 PROTECTION, E.-E. Introduction to Indoor Air Quality | Indoor Air Quality (IAQ) | US EPA. Disponível em: <https://www.epa.gov/indoor-airquality-iaq/introduction-indoor-air-quality>. Acesso em: 7 maio. 2019.

2 PERSILY, A. K. Evaluating building IAQ and ventilation with indoor carbon dioxide. ASHRAE Transactions, 1997.

3 MACARULLA, M. et al. Modelling indoor air carbon dioxide concentration using grey-box models. Building and Environment, v. 117, p. 146-153, 15 maio 2017.

4 PANTAZARAS, A. et al. Predicting the CO2 levels in buildings using deterministic and identified models. Energy and Buildings, v. 127, p. 774 785, 1 set. 2016.

5 WANG, Z.; WANG, L. Indoor air quality control for energy-efficient buildings using $\mathrm{CO}_{2}$ predictive model. IEEE 10th International Conference on Industrial Informatics. Anais...IEEE, jul. 2012.

SZCZUREK, A.; MACIEJEWSKA, M.; PIETRUCHA, T. Occupancy determination based on time series of CO 2 concentration, temperature and relative humidity. Energy and Buildings, v. 147, p. 142-154, 15 jul. 2017.

7 HABIB, U.; ZUCKER, G. Automatic occupancy prediction using unsupervised learning in buildings data. IEEE International Symposium on Industrial Electronics. Anais...IEEE, jun. 2017.

8 WANG, S.; CHEN, Y. Fault-tolerant control for outdoor ventilation air flow rate in buildings based on neural network. Building and Environment, v. 37, n. 7, p. 691-704, jul. 2002.

9 ALLEN, W. H.; RUBAAI, A.; CHAWLA, R. Fuzzy Neural Network-Based Health Monitoring for HVAC System Variable-Air-Volume Unit. IEEE Transactions on Industry Applications, v. 52, n. 3, p. 2513-2524, 1 maio 2016. 
10 AZUMA, K. et al. Effects of low-level inhalation exposure to carbon dioxide in indoor environments: A short review on human health and psychomotor performance. Environment International, v. 121, p. 51-56, 1 dez. 2018.

11 AMOATEY, P. et al. Indoor air pollution and exposure assessment of the gulf cooperation council countries: A critical review. Environment International, v. 121, p. 491-506, 1 dez. 2018.

12 HWANG, S. H.; ROH, J.; PARK, W. M. Evaluation of PM10, CO2, airborne bacteria, TVOCs, and formaldehyde in facilities for susceptible populations in South Korea. Environmental Pollution, v. 242, p. 700-708, 1 nov. 2018.

13 ZHANG, X. et al. Effects of exposure to carbon dioxide and bioeffluents on perceived air quality, self-assessed acute health symptoms, and cognitive performance. Indoor Air, v. 27, n. 1, p. 47-64, 1 jan. 2017.

14 ZHANG, X.; WARGOCKI, P.; LIAN, Z. Physiological responses during exposure to carbon dioxide and bioeffluents at levels typically occurring indoors. Indoor Air, v. 27, n. 1, p. 65-77, 1 jan. 2017.

15 HAVERINEN-SHAUGHNESSY, U.; MOSCHANDREAS, D. J.; SHAUGHNESSY, R. J. Association between substandard classroom ventilation rates and students' academic achievement. Indoor Air, v. 21, n. 2, p. 121-131, abr. 2011.

16 RIHAM JABER, A.; DEJAN, M.; MARCELLA, U. The Effect of Indoor Temperature and $\mathrm{CO}_{2}$ Levels on Cognitive Performance of Adult Females in a University Building in Saudi Arabia. Energy Procedia, v. 122, p. 451456, set. 2017.

17 TIELE, A.; ESFAHANI, S.; COVINGTON, J. Design and development of a low-cost, portable monitoring device for indoor environment quality. Journal of Sensors, v. 2018, 2018.

18 VILCEKOVA, S. et al. Indoor environmental quality of classrooms and occupants' comfort in a special education school in Slovak Republic. Building and Environment, v. 120, p. 29-40, 1 ago. 2017.

19 KUMAR, P. et al. Real-time sensors for indoor air monitoring and challenges ahead in deploying them to urban buildings. Science of The Total Environment, v. 560-561, p. 150-159, 1 ago. 2016. 
20 PERSILY, A. Challenges in developing ventilation and indoor air quality standards: The story of ASHRAE Standard 62. Building and Environment, v. 91, p. 61-69, 1 set. 2015.

21 SALTHAMMER, T. et al. Children's well-being at schools: Impact of climatic conditions and air pollution. Environment International, v. 94, p. 196-210, 1 set. 2016.

22 INTERNATIONAL BUREAU OF WEIGHTS AND MEASURES; TAYLOR, Barry N.; THOMPSON, Ambler. The international system of units (SI). US Department of Commerce, Technology Administration, National Institute of Standards and Technology, 2001.

23 US, A. et al. International equivalence of measurements: the CIPM MRA. p. $1-2,2018$

24 CCQM. Consultative Committee for Amount of Substance: Metrology in Chemistry and Biology (CCQM). Disponível em: <https://www.bipm.org/en/committees/cc/ccqm/>. Acesso em: 29 nov. 2019.

25 BREWER, P. J. et al. Advances in reference materials and measurement techniques for greenhouse gas atmospheric observations. Metrologia, v. 56, n. 3, p. 034006, 1 jun. 2019.

26 OIML. OIML B 15 Edition 2011. [s.l: s.n.]. Disponível em: <https://www.oiml.org/en/files/pdf_b/b015-e11.pdf>.

27 WHO. WHO | About. Disponível em: <https://www.who.int/about>. Acesso em: 4 maio. 2019.

28 WHO. Air Pollution. Disponível em: <https://www.who.int/healthtopics/air-pollution\#tab=tab_3>. Acesso em: 5 maio. 2019.

29 ISO. ISO - About us. Disponível em: 〈https://www.iso.org/about-us.html>. Acesso em: 29 mar. 2019.

30 INMETRO. Inmetro Institucional. Disponível em: $<$ http://www4.inmetro.gov.br/acesso-a-informacao/institucional>. Acesso em: 9 maio. 2019.

31 InMETRO. Divisão de Metrologia Química e Térmica - Dquim. Disponível em: 
<http://www.inmetro.gov.br/metcientifica/metQuimica.asp>. Acesso em: 29 abr. 2019.

32 INMETRO. Laboratório de Análise de Gases - LABAG. Disponível em: <http://www.inmetro.gov.br/metcientifica/quimica/gases.asp>. Acesso em: 27 abr. 2019.

33 INMETRO. Inmetro - Laboratórios de Calibração Acreditados - Rede Brasileira de Calibração - RBC. Disponível em: <http://www.inmetro.gov.br/laboratorios/labrbc.asp>. Acesso em: 5 maio. 2021.

34 WESSEL, R. M. et al. International comparison CCQM-K52: Carbon dioxide in synthetic air. Metrologia, v. 45, n. 1A, p. 08011-08011, jan. 2008 .

35 ANVISA. Agência Nacional de Vigilância Sanitária - Anvisa. Disponível em: <http://portal.anvisa.gov.br/institucional>. Acesso em: 1 maio. 2019.

36 CONAMA. Conselho Nacional do Meio Ambiente - CONAMA. Disponível em: <http://www2.mma.gov.br/port/conama/>. Acesso em: 7 fev. 2019.

37 ABNT. ABNT - Conheça a ABNT. Disponível em: <http://www.abnt.org.br/abnt/conheca-a-abnt>. Acesso em: 1 abr. 2019. ABNT. ABNT - ABNT/CB-055 - Comitê Brasileiro de Refrigeração, ArCondicionado, Ventilação e Aquecimento. Disponível em: <http://www.abnt.org.br/cb-55>. Acesso em: 7 abr. 2019.

39 LIU, X. et al. A survey on gas sensing technology. Sensors (Switzerland), v. 12, n. 7, p. 9635-9665, 2012.

40 DINH, T. V. et al. A review on non-dispersive infrared gas sensors: Improvement of sensor detection limit and interference correction. Sensors and Actuators, B: Chemical, v. 231, p. 529-538, 2016.

41 JACOB Y. WONG, R. L. A. Non-Dispersive Infrared Gas Measurement. 1. ed. [s.1.] IFSA Publishing, 2012.

42 RITTERSMA, Z. M. Recent achievements in miniaturised humidity sensors - A review of transduction techniques. Sensors and Actuators, A: Physical, v. 96, n. 2-3, p. 196-210, 2002. 
43 FARAHANI, H.; WAGIRAN, R.; HAMIDON, M. Humidity Sensors Principle, Mechanism, and Fabrication Technologies: A Comprehensive Review. Sensors, v. 14, n. 5, p. 7881-7939, 30 abr. 2014.

44 ZRIBI, A. et al. Design, fabrication and characterization of thin film resistances for heat flux sensing application. Sensors and Actuators, A: Physical, v. 245, p. 26-39, 2016.

45 PROTECTION, E.-E. What are volatile organic compounds (VOCs)? | Indoor Air Quality (IAQ) | US EPA. Disponível em: $<$ https://www.epa.gov/indoor-air-quality-iaq/what-are-volatile-organiccompounds-vocs>. Acesso em: 21 maio. 2019.

46 FILIPOVIC, L.; LAHLALIA, A. Review-System-on-Chip SMO Gas Sensor Integration in Advanced CMOS Technology. Journal of The Electrochemical Society, v. 165, n. 16, p. B862-B879, 2018.

47 SPINELLE, L. et al. Review of portable and low-cost sensors for the ambient air monitoring of benzene and other volatile organic compounds. Sensors (Switzerland), v. 17, n. 7, 2017.

48 MCMURRY, P. H. Chapter 17 A review of atmospheric aerosol measurements. Developments in Environmental Science, v. 1, n. C, p. 443-517, 2002.

PROTECTION, E.-E. Particulate Matter (PM) Basics | Particulate Matter (PM) Pollution | US EPA. Disponível em: <https://www.epa.gov/pm-pollution/particulate-matter-pm-basics>. Acesso em: 11 maio. 2019.

50 LOWTHER, S. D. et al. Particulate Matter Measurement Indoors: A Review of Metrics, Sensors, Needs, and Applications. Environmental Science and Technology, v. 53, n. 20, p. 11644-11656, 2019.

51 HONEYWELL. HPM Series Particulate Matter Sensors. Disponível em: $<$ https://sensing.honeywell.com/hpma115s0-xxx-particulate-mattersensors>. Acesso em: 9 mar. 2019.

52 KUMAR, S. S.; PANT, B. D. Design principles and considerations for the "ideal" silicon piezoresistive pressure sensor: A focused review. Microsystem Technologies, v. 20, n. 7, p. 1213-1247, 2014. 
53 BARLIAN, A. A. et al. Review: Semiconductor piezoresistance for microsystems. Proceedings of the IEEE, v. 97, n. 3, p. 513-552, 2009.

54 WANG, X.; LIU, Z.; ZHANG, T. Flexible Sensing Electronics for Wearable/Attachable Health Monitoring. Small, v. 13, n. 25, p. 1-19, 2017.

55 DERI, L.; MAINARDI, S.; FUSCO, F. tsdb: A Compressed Database for Time Series. In: Lecture Notes in Computer Science (including subseries Lecture Notes in Artificial Intelligence and Lecture Notes in Bioinformatics). [s.l: s.n.]. v. 7189 LNCSp. 143-156.

56 NAIK, N. Choice of effective messaging protocols for IoT systems: MQTT, CoAP, AMQP and HTTP. 2017 IEEE International Systems Engineering Symposium (ISSE). Anais...IEEE, out. 2017.

57 SENSEAIR. K30/K33 series. Disponível em: $<$ https://senseair.com/products/flexibility-counts/k33-elg/>. Acesso em: 30 mar. 2019.

58 HONEYWELL. Honeywell HumidIcon Digital Humidity/Temperature Sensors HIH6100 Series. Disponível em: $<$ http://sensing.honeywell.com/honeywell-sensing-humidicon-hih6100series-product-sheet-009059-6-en.pdf> . Acesso em: 3 abr. 2019.

59 HONEYWELL. Humidity Sensor Theory and Behavior. Control, 2008.

60 AMS. CCS811 Ultra-Low Power Digital Gas Sensor for Monitoring Indoor Air Quality. n. December, p. 1-35, 2017.

61 BOSCH SENSORTEC. BMP180 : Digital Barometric Pressure Sensor. Disponível em: <https://aebst.resource.bosch.com/media/_tech/media/product_flyer/BST-BMP180FL000.pdf>. Acesso em: 7 ago. 2019.

62 VOTCH. Votsch VCL. Disponível em: <https://www.votechhk.com/product/vcl/>. Acesso em: 1 maio. 2019.

63 SALVADOR, S.; CHAN, P. Toward accurate dynamic time warping in linear time and space. Intelligent Data Analysis, v. 11, n. 5, p. 561-580, 10 out. 2007.

64 APTER, A. et al. Epidemiology of the sick building syndrome. Journal of Allergy and Clinical Immunology, v. 94, n. 2, p. 277-288, ago. 1994. 